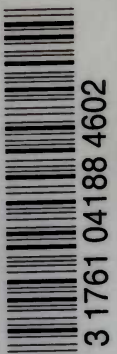




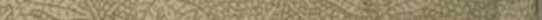
Q

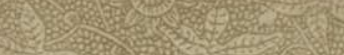

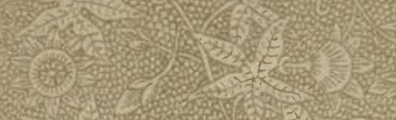

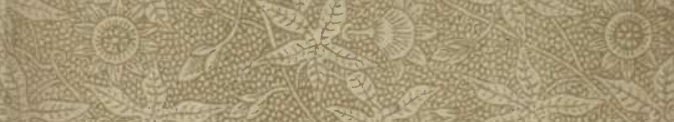

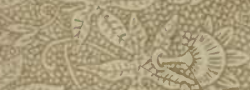
$\frac{2}{2}-20054$

cores 2.

5 1. (5).

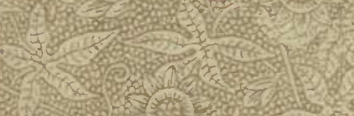

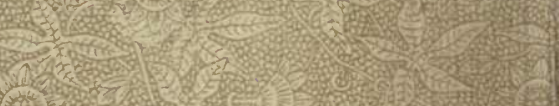

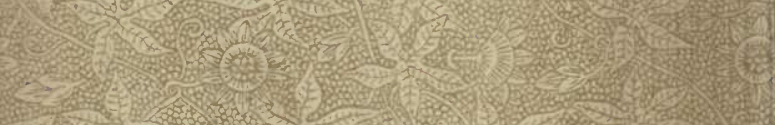
1.7. (i) 1, 2.

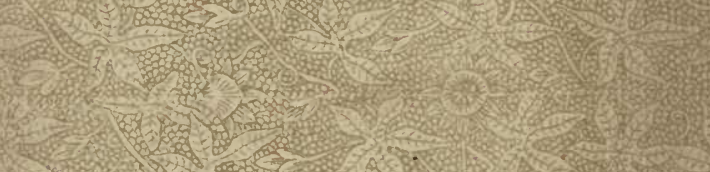

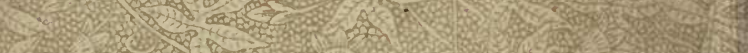

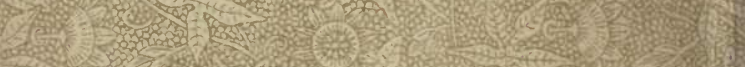

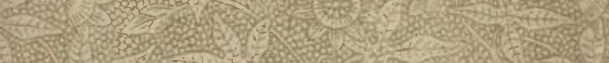
2.7. (72.

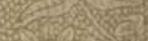



6 
To ming dear Fattier, This grain of mustard seed, goa. THE STORY OF THE PLANTS. 

$A$

\section{THE STORY OF}

\section{THE PIUANS.}

GRANT ALLEN.

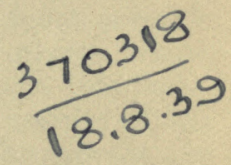

WITH ILLUSTRATIONS.

LONDON : GEORGE NEWNES, LTD. SOUTHAMPTON STREET, STRAND 1895 


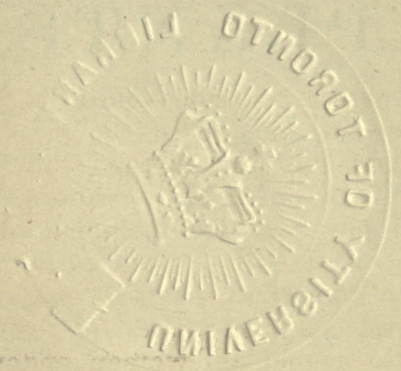

The rights of translation and of reproduction are reserved. 


\section{PREFACE.}

IN this little volume I have endeavoured to give a short and succinct account of the principal phenomena of plant life, in language suited to the comprehension of unscientific readers. As far as possible I have avoided technical terms and minute detail, while I have tried to adopt a more philosophical tone than is usually employed in elementary works. I have treated my readers, not as children, but as men and women, endowed with the average amount of intelligence and insight, and anxious to obtain some sensible information about the world of plants which exists all round them. Acting upon this basis, I have freely admitted the main results of the latest investigations, accepting throughout the evolutionary theory, and making the study of plants a first introduction to the great modern principles of heredity, variation, natural selection, and adaptation to the environment. Hence I have wasted comparatively little space on mere structural detail, and have dwelt as much as possible on those more interesting features in the interrelation of the plant and animal worlds which have vivified for us of late years the dry bones of the old technical botany.

My principle has been to unfold my subject by gradual stages, telling the reader one thing at a time, and building up by degrees his know- 
ledge of the subject. My treatment is, therefore, to some extent diagrammatic, especially in the earlier chapters ; but I endeavour as I proceed to correct the generalisations and fill in the gaps of the first crude statement. I trust that advanced students who may glance at this little book will forgive me for such concessions to the weaker brethren, especially when they see that at the same time I have ventured to lay before untechnical readers all the latest results of the most advanced botanical research, as far as could be done in so small a compass. I have even made bold to speak at times of " carbonic acid," where I ought strictly to have said "carbon dioxide," and to glide gently over the distinction between hydro-carbons and carbohydrates, which could interest none but chemical students. I have been well content to make these trivial sacrifices of formal accuracy in order to find room for fuller exposition of the delightful relations between flowers and insects, birds and fruits, soil and plant, climate and foliage. In one word, I have dwelt more on the functions and habits of plants than on their structure and classification. At the same time I have tried to lead on my reader by gradual stages to the further study of plants in the concrete; and I shall be disappointed if my little book does not induce a considerable proportion of those into whose hands it may fall to pursue the subject further in our fields and woods by the aid of a Flora.

Tue Croft, Hindhead.

G. A. April, 1895. 


\section{CONTENTS.}

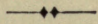

CHAP.

PAGE

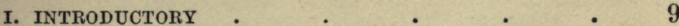

II. HOW PLANTS BEGAN TO BE • . . $\quad 14$

III. HOW PLANTS CAME TO DIFFER FROM ONE ANOTHER 26

IV. HOW PLANTS EAT • • • • • $\quad 35$

V. HOW PLANTS DRINK • . , 57

VI. HOW PLANTS MARRY. . . . $\quad 78$

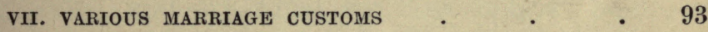

VIII. MORE MARRIAGE CUSTOMS • . . . 113

IX. THE WIND AS CARRIER . $\quad$. $\quad$. 135

X. HOW FLOWERS CLUB TOGETHER • • 147

XI. WHAT PLANTS DO FOR THEIR YOUNG • 162

XII. THE STEM AND BRANCHES • • 176

XIII. SOME PLANT BIOGRAPHIES • • • • 198

XIV. THE PAST HISTORY OF PLANTS • • 



\section{CHAPTER I.}

\section{INTRODUCTORY.}

I PROPOSE in this volume to write in brief the history of plants, their origin and their development. I shall deal with them all, both big and little, from the cedar that is in Lebanon to the hyssop that springeth out of the wall. I shall endeavour to show how they first came into existence, and by what slow degrees they have been altered and moulded into the immense variety of tree, shrub, and herb, palm, mushroom, and sea-weed we now behold before us. In short, I shall treat the history of plants much as one treats the history of a nation, beginning with their simple and unobtrusive origin, and tracing them up through varying stages to their highest point of beauty and efficiency.

Plants are living things. That is the first idea we must clearly form about them. They are living in just the same sense that you and I are. They were born from a seed, the joint product of two previous individuals, their father and mother. Plants likewise live by eating; they have mouths and stomachs, which devour, digest, and assimilate the food supplied to them. These mouths and stomachs exist in the shape of leaves, whose business it is to catch floating 
particles of carbonic acid in the air around, to suck such particles in by means of countless lips, and to extract from them the carbon which is the principal food and raw material of plant life. Plants also drink, but, unlike ourselves, they have quite different mouths to eat with and to drink with. They take in their more solid constituent, carbon, with their leaves from the air; but they take in their liquid constituent, water, with their roots and rootlets from the soil beneath them. "More solid," I say, because the greater part of the wood and harder tissues of plants is made up of carbon, in combination with other less important materials; though, when the plants eat this carbon, it is not in the solid form, but in the shape of a gas, carbonic acid, as I shall more fully explain when we come to consider this subject in detail. For the present, it will be enough to remember that Plants are living things, which eat and drink exactly as we ourselves do.

Plants also marry and rear families. They have two distinct sexes, male and femalesometimes separated on different plants, but more often united on the same stem, or even combined in the same flower. For flowers are the reproductive parts of plants; they are there for the purpose of producing the seeds, from which new plants spring, and by means of which each kind is perpetuated. The male portions of plants of the higher types are known as stamens; they shed a yellow powder which we call pollen, and this powder has a fertilising influence on the young seeds or ovules. The female portion 
of plants of the higher types is known as the pistil; it contains tiny undeveloped knobs or ovules, which can only swell out and grow into fruitful seeds provided they have been fertilised by pollen from the stamens of their own or some other flower. The ovules thus answer very closely to the eggs of animals. After they have been fertilised, the pistil begins to mature into what we call a fruit, which is sometimes a sweet and juicy berry, as in the grape or the currant, but more often a dry capsule, as in the poppy or the violet.

Plants, however, unlike animals, are usually fixed and rooted to one spot. This makes it practically impossible for them to go in search of mates, like birds or butterflies, squirrels or weasels. So they are obliged to depend upon outside agencies, not themselves, for the conveyance of pollen from one flower to another. Sometimes, in particular plants, such as the hazels and grasses, it is the wind that carries the pollen on its wings from one blossom to its neighbour; and, in this case, the stamens which shed the pollen hang out freely to the breeze, while the pistil, which is to catch it, is provided with numberless little feathery tails to receive the passing grains of fertilising powder. But oftener still, it is insects that perform this kind office for the plant, as in the dog-rose, the hollyhock, and the greater part of our beautiful garden flowers. In such cases the plant usually makes its blossom very attractive with bright-coloured petals, so as to allure the insect, while it repays him for his trouble in carrying away the pollen 
by giving him in return a drop of honey. The bee or butterfly goes there, of course, for the honey alone, unconscious that he is aiding the plant to set its seeds; but the plant puts the honey there in order to entice him against his will to transport the fertilising powder from flower to flower. There is no more fascinating chapter in the great book of life than that which deals with these marriage relations of the flowers and insects, and I shall explain at some detail in later portions of this little work some of the most curious and interesting of such devices.

Again, after the plant has had its flower fertilised, and has set its seed, it has to place its young ones out in the world to the greatest advantage. If it merely drops them under its own branches, they may not thrive at all; it may have impoverished the soil already of certain things which are necessary for that particular kind, owing to causes to be explained hereafter; and even where this is not the case, the surrounding soil may be so fully occupied by other plants that the poor little seedlings get no chance of establishing themselves. To meet such emergencies, plants have invented all sorts of clever dodges for dispersing their seeds, into the nature of which we will go in full in the sequel. Thus, some of them put feathery tops to their seeds or fruits, like the thistle and the dandelion, the willow and the cotton-bush, by means of which they float lightly on the air, and are wafted by the wind to new and favourable situations. Others, again, bribe animals to disperse them, by the allurement of sweet and pulpy 
fruits, like the strawberry or the orange; and in all these instances, though the fruit or outer coat is edible, the actual seed itself is hard and indigestible, like the orange-pip, or is covered with a solid envelope like the cherry-stone. Numerous other examples we shall see by and by in their proper place. For the present, we have only to remember that plants to some extent provide beforehand for their children, and in many cases take care to set them out in life to the best possible advantage.

Most of these points to which I am here briefly calling your attention are true only of the higher plants, and especially of land-plants. For we must not forget that plants, like animals, differ immensely from one another in dignity, rank, and relative development. There are higher and lower orders. We shall have to consider, therefore, their grades and classesto find out why some are big, some small; some annual, some perennial; why some are rooted in dry land, while some float freely about in water; why some have soft stems like spinach and celery, while others have hard trunks like the oak and the chestnut. We shall also have to ask ourselves what were the causes which made them differ at first from one another, and to what agencies they owe the various steps in their upward development. In short, we must not rest content with merely saying that the rose is like this and the cabbage like that; we must try to find out what gave to each of them its main distinctive features. We must "con"sider the lilies, how they grow," and must seek 
to account for their growth and their peculiarities.

And now let me sum up again these central ideas of our future reading on plants and their history.

Plants are living things; they eat with their leaves, and drink with their rootlets. They take up carbon from the air, and water from the soil, and build the materials so derived into their own bodies. Plants also marry and are given in marriage. They have often two sexes, male and female. Each seed is thus the product of a separate father and mother. Plants are of many kinds, and we must inquire by and by how they came to be so. Plants live on sea and land, and have varieties specially fitted for almost every situation. Plants have very varied ways of securing the fertilisation of their flowers, and look after the future of their young, like good parents thas they are, in many different manners. Plants are higher and lower, exactly like animals.

These are some of the points we must proceed to consider at greater length in the following pages.

\section{CHAPTER II.}

\section{HOW PLANTS BEGAN TO BE.}

Wнich came first-the plant or the animal?

That question is almost as absurd as if one were to ask, Which came first - the beast of prey, or the animals it preys upon? Clearly, 
the earliest animals could not possibly have been lions and tigers; for lions and tigers could not begin to exist till after there were deer and antelopes for them to hunt and devour. Now the general connection between animals and plants is somewhat the same in this respect as the general connection between beasts of prey and the creatures they feed upon. For all animals feed, directly or indirectly, upon plants and their products. Even carnivorous animals eat sheep and rabbits, let us say; but then, the sheep and the rabbits eat grass and clover. In the last resort, plants are selfsupporting; animals feed upon what the plants have laid by for their own uses. Every animal gets all its material (except water) directly or indirectly from plants. In one word, plants are the only things that linow how to manufacture living material.

Roughly speaking, plants are the producers and animals the consumers. Plants are like the pine-tree that makes the wood; animals are like the fire that burns it up and reduces it to its previous unorganised condition.

It is a little difficult really to understand the true relation of plants and animals without some small mental effort; yet the point is so important, and will help us so much in our after inquiries that I will venture upon asking you to make that effort, here at the very outset.

If you take a piece of wood or coal, you have in it a quantity of hydrogen and carbon, almost unmixed with oxygen, or at least combined with far less oxygen than they are capable of uniting 


\section{veneres, unter the

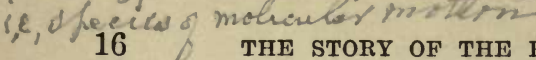 \\ 16 THE STORY OF THE PLANTS.}

with. Now put a light to the wood or coal, and what happens? They catch fire, as we say, and burn till they are consumed. And what is the meaning of this burning? Why, the carbon and hydrogen are rushing together with oxygentaking up all the oxygen they can unite with, and forming with it carbonic acid and water. The carbon joins the oxygen in a very close embrace, and becomes carbonic acid gas, which goes up the chimney and mixes with the atmosphere; the hydrogen joins the oxygen in an equally intimate union, and similarly goes off into the air in the form of steam or watery vapour. Burning, in fact, is nothing more than the union of the carbon and hydrogen in wood or coal with the oxygen of the atmosphere. But observe that, as the carbon and hydrogen burn, they give off light and heat. This light and heat they held stored up before in their separate form; it was, so to speak, dormant or latent within them. Free carbon and free hydrogen contain an amount of energy, that is to say of latent light and dormant heat, which they yield up when they unite with free oxygen. And though the carbon and hydrogen in wood and coal are not quite free, they may be regarded as free for our present purpose.

Now, where did this light and heat come from? Well, the wood, we know, is part of a tree which has grown in the open air, by the aid of sunshine. The coal is just equally part of certain very ancient plants, long pressed beneath the earth and crushed and hardened, but still possessing the plant-like property of burning 
when lighted. In both cases the light and heat as we shall see more fully hereafter, are derived from the sun, our great storehouse of energy. The sunshine fell upon the leaves of the modern oak-tree, or of the very antique club-mosses which constitute coal, and separated in them the carbon from the oxygen of carbonic acid, and the hydrogen from the oxygen of the water in the sap. In each case the oxygen was turned loose upon the air in its free form, while the carbon and the hydrogen (with a very little oxygen and a few other materials). were left in loose and almost free conditions in the leaves and wood of the oak or the club-moss. But the point to which I wish now specially to direct your attention is this-the sunlight was actually used up for the time being in effecting this separation between the oxygen on the one hand, and the carbon and hydrogen on the other. As long as the plant remained unburnt, the light and heat it received from the sun lay dormant within it, not as actual light and heat, but as separation between the oxygen and the hydrogen or carbon. Coal, indeed, has been well described as " bottled sunshine."

More than this; it took just as much light and heat from the sun to build up the plant as you can get out of the plant in the end by burning it.

Now, let us burn our piece of wood or coal, and what happens? Why, particles of oxygen rush together with particles of carbon in the fuel, and form carbonic acid. How much carbonic acid? Just as much as it took 
originally to build that part of the plant from. Simultaneously, other particles of oxygen in the air rush together with particles of hydrogen in the fuel, and form water, in the shape of steam. How much water? Just as much as it took originally to build that part of the plant from. As they unite, they give out their dormant heat and light. How much heat and light? Just as much as they absorbed in the act of building up those parts of the plant from the sunshine that fell upon them.

In other words, the same quantity of oxygen that was first separated from the carbon and hydrogen reunites with them in the act of burning, and the same amount of heat and light that were required to effect their separation is yielded up again in the act of reunion.

Let us put this point numerically, and I will simplify it exceedingly, so as to make my meaning clearer. Suppose we begin with a particle of carbonic acid and a particle of water in the interior of a green leaf-the carbonic acid swallowed from the air by the leaf, the water brought to it as sap from the roots. Now, under the influence of sunlight, these materials are separated into their component parts. The particle of carbonic acid consists of one atom of carbon, closely locked up with two $\times$ atoms of oxygen. It takes an amount of sunlight, which we will call A, to unlock this union, and separate the atoms. The oxygen goes off free into the air, and the carbon remains in the leaf as material for building the plant up. Again, the particle of water consists of two atoms of 
hydrogen, closely locked up with one atom of oxygen. It takes an monount of sunlight, which we will call $B$, to unlock this union and separate the atoms. The oxygen once more goes olf free into the air, and the hydrogen joins in a loose union with the carbon already spoken of. Now, burn the material resulting from these two acts, and what happens? Two atoms of oxygen once more unite with the one atom of carbon, to form a particle of carbonic acid; one atom of oxygen once more unites with the two atoms of hydrogen to form a particle of water, and there is given out in the act of union an amount of light and heat exactly equal to the $\mathrm{A}$ and $\mathrm{B}$ originally locked up, in the act of separating them.

I have now made it clear, I hope, what plant life really is in its final essence. In nature at large, the elements which chiefly compose itnamely, carbon and hydrogen-exist only in very close union with oxygen; the plant is a machine for separating these elements from oxygen under the influence of sunlight, and building them up into fresh forms, whose great peculiarity is that they possess energy or dormant motion.

Now the animal is the exact opposite of all this. He is essentially a destroyer, as the plant is a builder. The plant produces; the animal consumes; the plant makes living matter, the animal breaks. it down again. $\mathrm{He}$ is, in fact, a slow fire, where plant products like grasses, fruits, nuts, or grains, are consumed by degrees and reduced once more to their original condition.

The animal eats what the plant laid by. $\mathrm{He}$ 
also breathes - that is to say, takes oxygen into his lungs. Within his body that oxygen once more unites with the carbon and the hydrogen, and is given out again in union with them as carbonic acid and water. And the energy in the plant food, thus set free within his body, takes the form of animal heat and animal motionjust as the energy set free in the locomotive takes the form of heat and visible movement. Animals are thus the absolute converse of plants; all that the plants did, the animal undoes again.

Briefly to recapitulate this rather dry subject, - the plant is a mechanism for separating oxygen from carbon and hydrogen, and for storing up sun-energy. The animal is a mechanism for uniting oxygen with carbon and hydrogen, and for using, the stored-up sun-energy as heat and motion.

And now you can see why it is so absurd to ask, Which came first, the plant or the animal? You might as well ask, Which came first, the coal or the fire? All the living material in the world was first made and laid up by plants. They alone have the power to make living or energy-yielding stuff out of dead and inert water or carbontc acid. They are the origin and foundation of life. Without them there could be no living thing in the universe. It is in their green parts alone that the wonderful transformation of dead matter into living bodies takes place; they alone know how to store up and utilise the sunshine that falls upon them. 
All the animal can do is to take the living material the plant has made for him, and to consume it slowly in his own body. He destroys it (as living matter) just as truly as a fire does, and turns it loose on the air again in the dead and inert forms of water and carbonic acid.

It is clear, then, that plants must have come first, and animals afterward. The earliest living beings must needs have been plants-very simple plants; yet essentially plants in thisthat they were green, and that they separated carbon and hydrogen from oxygen under the influence of sunlight. It is that above everything that makes true plants; though some degenerate plants have now given up their ancestral habit, and behave in this respect much like animals.

How did the first plant of all come into being?

About that, at present, we know very little. We can only guess that, in the early ages of the world, when matter was fresher and more plastic than now, certain combinations were set up between atoms under the influence of sunlight, which formed the earliest living body. This would be what is called "spontaneous generation." Whether such spontaneous generation ever took place is much disputed; though some people competent to form an opinion incline to believe that it probably did take place in remote times and under special conditions. But it is certain, or almost certain, that in our 
own days at least spontaneous generation does not take place-perhaps because all the available material is otherwise employed, perhaps because the conditions are no longer favourable. At any rate, we have every reason to suppose that at the present day every living being, whether plant or animal, is the product of a previous living being, its parent, or of two previous living beings, its father and mother.

Why should this be so? Well, if you think for a moment, you will see that it results almost naturally from the other facts we have so far considered. For the plant is a machine for making living matter out of water and carbonic acid, under the influence of sunlight. As long as sunlight, direct or reflected, in sun or shade, falls upon a green plant, the plant goes on taking up carbonic acid from the air by means of its leaves, and water from the earth by means of its roots, and continues to manufacture from them fresh living material. Thus it must be always growing, as we say; in other words, the mass of living material must be constantly increasing. Now, it results from this that the plant would grow in time unwieldily large; and in simple types, when it grows very large, it splits or divides into two portions. That is the real origin of what we call REPRODUCTION. In its simplest forms, reproduction means no more than this-that a rather large body, which cannot easily hold together, divides in two, and that each part of it then continues to live and grow exactly as the whole did.

This seems odd and unfamiliar to you, because 
you are thinking of large and very advanced plants, like a sweet-pea or a potato. But you must remember that we are dealing here with very early and simple plants, and that these early and simple plants consist for the most part of tiny green mites, floating free in water. They are generally invisible to the naked eye, and are in point of fact mere specks of green jelly. Yet it is from such insignificant atoms as these that the great forest trees derive their origin, through a long line of ancestors; and if we wish to understand the larger and more developed plants, we must begin by understanding these their simple relations.

Very early plants, then, floated free in water; and there is reason to believe that for a considerable period in the beginnings of our world there was no dry land at all ; the whole surface of the globe was covered by one boundless ocean. At any rate, most of the simplest and earliest forms of life now remaining to us inhabit the water, either fresh or salt; while almost all the higher and nobler plants and animals are dwellers on land. Hence it is not unreasonable to conclude that life began in the sea, and only gradually spread itself over the islands and continents.

Floating jelly-like plants would readily reach a size at which it would be convenient for them to split in two - or rather, at which it would be difficult for them to hold together; and most

very small floating plants do to this day continue to grow, up to a certain point, and then divide into two similar and equal portions. This is the 
simplest known form of what we call reproduction. Of course, the two halves into which the plant thus divides itself are exactly like one another; and that gives us the basis for what we call HEREDITY - that is to say, the general similarity between parent and offspring. This similarity depends upon the fact that the two were once one, and when they split or divide each part continues to possess all the qualities of the original mass of which it once formed a portion.

You will observe that I here use the words, parent and offspring. I do so, partly from custom, and partly to show where this reasoning leads us. But in reality, in such very simple plants, neither part of the divided whole can claim to be either parent or child; they are equal and similar. In higher plants, however (as in higher animals), we find that the main portion of the plant continues to live and grow, and sends off smaller portions, known as spores or seeds, to reproduce its species. Here, we may fairly speak of the larger plant as the parent, and of the smaller ones which it detaches from itself as its children or offspring.

The truth is, every gradation exists in nature between these two extreme cases. The different types glide imperceptibly into one another. There is no one point at which we can definitely say, "Here reproduction by splitting or division ceases, and reproduction by eggs, or by spores or seeds begins."

Again, all the earlier and simpler plants are sexless; they simply grow till they divide, and 
then the two halves continue to exist independently. No two distinct plants or parts of plants are concerned in producing each new individual. But the higher plants, like the higher animals, are male and female. In such cases two distinct individuals combine to form a new one. They are its father and mother, so to speak, and the young one is their offspring. A little grain of pollen produced by the male plant unites with a little ovule or seedlet produced by the female; and from the union of the two springs a fresh young plant, deriving its peculiarities about equally from each of them. How and why this great change in the mode of reproduction takes place is another of the questions we must discuss hereafter; I will only anticipate now the result of this discussion by saying briefly beforehand that plants gain in this way, because greater variety is secured in the offspring, and because the weak points of one parent are likely to be reinforced and made good by the other.

Let us sum up our conclusions in this preliminary chapter :

Plants are an older type of life than animals. They are the first and most original form of living beings, and without them no life of any sort would be possible. All living matter is manufactured by plants out of material found floating in the air, under the influence of sunlight. How plants first came into existence we do not yet know; but we may suspect that they grew, in very simple and small forms, at a 
remote period, under conditions which now no longer exist. It is almost certain that the first plants were jelly-like specks, floating freely in water. They must have been green, and must also have possessed the essential plant-power of building up fresh living material when sunlight fell upon them. This power implies the other power of reproduction, that is to say of splitting up into two or more similar parts, each of which continues to live and grow like the original body. From such simple and very primordial plants all other and higher forms are most likely descended.

\section{CHAPTER III.}

HOW PLANTS CAME TO DIFFER FROM ONE ANOTHER.

ALL plants are not now alike. Some are trees, some herbs; some are roses, some buttercups. Yet we have a certain amount of reason to believe that they are all descended from one and the same original ancestor; and we shall see by and by that we can often trace the various stages in their long development. They differ immensely. Some of them are more advanced and more complex than their neighbours; some are small and low, while others are tall and strong; some, like nettles and grasses, have simple and inconspicuous flowers, while others, like lilies and orchids, have beautiful and very complicated blossoms, highly arranged in such ways as to attract and entice particular insects to visit and fertilise them. Again, some have 
tiny dry fruits, with small round seeds, which fall on the ground unheeded; while others have brilliant red or yellow berries, or winged or feathery seeds, especially fitted for special modes of dispersion. In short, there are plants which seem, as it were, very low and uncivilised, while there are others which display, so to speak, all the latest modern inventions and improvements.

The question is, How did they thus come to differ from one another? What made them vary in such diverse ways from the primitive pattern?

In order to understand the answer which modern science gives to this question, we must first glance briefly at certain early steps in the history of the process which we call creation or evolution.

The earliest plants, we saw, were in all probability mere tiny green jelly-specks, floating free in water, and taking from it small quantities of dissolved carbonic acid, which they manufactured for themselves into green living material when sunlight fell upon them. Now we shall have to consider another peculiarity of plants (and of animals as well) before we can thoroughly understand the first stage in the upward process which leads at last to the pine and the lily, the palm and the apple.

Plants are made up of separate parts or elements, known as cells, each of which consists of a thin cell-wall, usually containing living material. The very simplest and earliest plants, however, consist of a single such cell apiece; 
they are specks of green jelly, enclosed by a cell-wall, alone and isolated. In such cases, when the cell grows big and divides in two, each half floats off as a separate cell, or a separate plant, and continues to divide again and again, as long as it can get a sufficient amount of carbonic acid and sunlight. But in some instances it happens that the new cells, when budded out from the old ones, do not float off in water, but remain hanging together in long strings or threads, in single file, as you may see in certain simple forms of hair-like pond-weeds. These weeds consist of rows of cells, stuck one after another, not unlike rows of pearls in a necklace. Of course the individual cells are too small to see with one's unaided eye; but under a microscope you can see them, joined end to end, so as to form a sort of thread or long line of plant-cells. This is the beginning of the formation of the higher plants, which consist, indeed, of collections of cells, arranged either in rows or in flattened blades, or many deep together in complicated order.

However, the higher plants differ from the lower ones in something more than the number and complexity of the cells which compose them. They are very varied; and their variety adapts them to their special circumstances. For example, desert plants, like the cactuses, have thick and fleshy leaves (or, rather, jointed stems) to store up water, with a very tough skin to prevent evaporation. The flowers of each country, again, are exactly adapted to the insects of that country; and so are the fruits 
to the birds that swallow and disperse them. How did this all come about? What made the adaptation? It is a result of two great under-? lying principles known as The Struggle for Life, and Natural Selection.

Since each early plant goes on growing and dividing, again and again, as fast as it can, it must follow in time that a great number of plants will soon be produced, each fighting with the others for air and sunlight. Now, some of them must, by pure accident of situation, get better placed than others; and these will produce greater numbers of descendants. Again, unless all of them remained utterly uninfluenced by circumstances (which is not likely) it must necessarily happen that slight differences will come to exist between them. These differences of outline, or shape, or cell-wall, may happen to make it easier or harder for the plant to get access to carbonic acid and sunlight, or to disperse its young, or to fix itself favourably. Those plants, therefore, which happened to vary in the right directions would most easily go on living and produce most descendants, whild those which happened to vary in the wrong directions would soonest die out and leavel fewest descendants.

Well, the world around us, both of plants and animals, is full of creatures all struggling against one another, and all competing for food and air and sunshine. Moreover, each individual produces (as a rule) a vast number of young; sometimes, like the poppy, many thousand seeds on a single flower-stem. Now suppose only ten of 
those seeds succeed in growing each year. In the first year, that poppy will have produced ten new poppy plants; the year after, each of those ten will have produced ten more, making the total 100; in the third year, they will be 1,000; in the fourth, 10,000; and so on in the same progression till in a very few years the whole world would simply be full of poppies. And similarly with animals. If every egg in a cod's roe developed into a mature fish, the sea would soon be one solid and compact mass of cod-fish.

Why doesn't this happen? Because every other kind is producing seeds or eggs at about the same rate, and every one of them is fighting against the other for its share of light and food and soil and water. The stronger or betteradapted survive, while the weaker or lessadapted go to the wall, and are starved out of existence. At first, to be sure, it sounds odd to talk of a Struggle for Life among plants, which seem too fixed and inert to battle against one another. But they do battle for all that. Each root is striving with all its might to fix itself underground in the best position; each leaf and stem is struggling hard to overtop its neighbour, and secure its fair share of carbon and of sunshine. When a garden is abandoned, you can very soon see the result of this struggle; for the flowers, which we only keep alive by weedingthat is to say, by uprooting the sturdier competitors - are soon overgrown and killed out by the weeds - that is to say, by the stronger and better-adapted native plants of the district.

This, then, is the nature and meaning of these 
two great principles. The Struggle for Life means that more creatures are produced than there is room in the world for. Natural Selection (or Survival of the Fittest) means that among them all, those which happen to be best adapted to their particular circumstances oftenest succeed and leave most offspring.

By the action of the two great principles in question (which affect all life, animal or vegetable) the world has been gradually filled with an immense variety of wonderful and beautiful creatures, all ultimately descended (as modern thinkers hold) from the selfsame ancestors. The simple little green jelly-speck, which is the primitive plant, has given rise in time to the sea-weeds and liverworts, then to the mosses and ferns, then to the simplest flowering plants, thence to the shrubs and trees, and finally to all the immense wealth and variety of fruits, flowers, and foliage we now see around us.

The rest of this book will consist mainly of an exposition of the results brought about among plants by Variation, the Struggle for Life, and Survival of the Fittest. But before we go on to examine them in detail, I shall give just a few characteristic instances which show the mode of action of these important principles.

There is a pretty wild flower in our hedges called a red campion, or "Robin Hood." Now, a single red campion produces in a year three thousand seeds. But there are not three thousand times as many red campions this year as last, nor will there be three thousand times as 
many more again next season. Indeed, if an annual plant had only two seeds, each of which lived and produced two more, and so on continually, in twenty years its descendants would amount to no less than a million. From all this it necessarily results that a Struggle for Existence must take place among plants; they fight with one another for the soil, the rain, the carbon, the sunshine.

Again, take such a wild flower as this very red campion. Why has it light pink petals? The reason is, to attract the insects which fertilise it. Flowers, in which the pollen is carried by the wind, never have brilliant or conspicuous blossoms; but flowers which are fertilised by insects have almost always coloured petals to tell the insects where to find the honey. How did this come about? In this way, I imagine: Many plants produce a sweet juice on their leaves - for example, the common laurel. This juice, which is probably of no particular use to them, is very greedily eaten by insects. Now suppose some flower, by accident at first, happened to produce such sweet juice near its stamens, which (as we saw) are the organs for making pollen, and also near its pistil, which contains its young seeds or ovules. Then insects would naturally visit it to eat this sweet juice, which we commonly call honey. In eating it, they would dust themselves over with the floury pollen, by pure accident, and they would carry some of it away with them on their heads and legs to the next flower they visited. Chance would make them often rub off the pollen and fertilise the flower; and as such 
cross-fertilisation, as it is called, is good for the plants, producing very strong and vigorous seedlings, the young ones so set would have the best chance of flourishing and surviving in the Struggle for Existence. Thus the flowers which made most honey would be oftenest visited and crossed, so that they would soon become very numerous. Again, if they happened to have bright leaves near the honey, they would be most readily discriminated, and oftenest visited. So, in the long run, it has come about that almost all the flowers fertilised by insects produce honey to allure them, and have brilliant petals to guide their allies to the honey. That, in fact, is what beautiful flowers are for - to attract the fertilising bees and butterflies to visit and impregnate the various blossoms.

Take one more case-or, rather, the same case, extended a little further. The red campion flowers by day, and is fertilised by butterflies; therefore it is pink, because pink is an attractive colour in the daylight; and it is scentless, because its colour alone is quite enough to attract sufficient insects. But it has a close relation, the white campion, which flowers by night only, and lays itself out to be visited by moths in the twilight. Why is this kind white? Because no other colour is seen so well in the dusk; a red or pink blossom would then be almost invisible. Moreover, the white campion is heavily scented, as are almost all other night-flowering blossoms, like the jasmine, the tuberose, the stephanotis, and the gardenia. 
Observe the numerous points of similarity : all these are white; all are sweet-scented; all are moth-fertilised. Why is this? Because the scent helps to show the moth the way to the flower when there is hardly enough light for him to see the white petals. Thus every plant is adapted to its particular station in life, and its adaptation is the result of the Struggle for Existence, and Survival of the Fittest.

Briefly put, whatever variation helps the plant in any way in any particular place, or at any particular time, is likely to give it an extra chance in the fight, and is therefore reproduced in all its descendants.

So that is how plants began to vary.

To sum up. Plants grow, because they keep on continually taking in carbon and hydrogen from the world outside them, under the influence of sunlight. They multiply, because when they have attained a certain size they split up to form two or more individuals. They struggle for life with one another, because more are produced than can find means of livelihood. And the struggle results in Survival of the Fittest.

Or, looked at in another light. Plants multiply, and as they multiply by division the new ones on the whole resemble their parents ; this is the law of Heredity. But they do not exactly resemble them in every detail ; this is the law of Variation. And as some variations are to the good, and some to the bad, the better survive and produce young like themselves oftener than the worse do; this is the law of Natural Selection. 


\section{CHAPTER IV.}

HOW PLANTS EAT.

We saw in the last chapter how and why plants came to differ from one another, but not why they came to be divided into well-marked groups or kinds, such as primroses, daisies, cabbages, oaks, and willows. In the world around us we observe a great many different sorts of plants, not all mixed up together, so to speak, nor merging into one another by endless gradations, but often clearly marked off by definite lines into groups or families. Thus a primrose is quite distinct from a crocus, and an oak from a maple. For the present, however, I do not propose to go into the question of how they came to be divided into such natural groups. I will begin by telling you briefly how plants eat and drink, marry and rear families, and then will return later on to this problem of the Origin of Species, as it is called, and the pedigrees and relationships of the leading plant families.

First of all, then, we will inquire, How Plants Eat. And in this inquiry I will neglect for the most part the very early and simple plants we have already spoken about, and will chiefly deal with those more advanced and complicated types, the flowering plants, with which everybody is familiar.

Plants Eat with their Leaves. The leaves are, in fact, their mouths and stomachs. 
Now, what is a leaf? It is usually a rather thin, flat body, often with two parts, a stalk and a blade, as in the oak or the beech; though sometimes the stalk is suppressed, as in grass and the teasel. Almost always, however, the leaf is green: it is broad and flat, with a large expanded surface, and this surface is spread out horizontally, so as to catch as much as possible of the sunlight that falls upon it. Its business is to swallow carbonic acid from the air, and digest and assimilate it under the influence of sunlight. And as different situations require different treatment, various plants have leaves of very different shapes, each adapted to the habits and manners of the particular kind that produces them. The difference has been brought about by Natural Selection.

What does the leaf eat? Carbonic acid. There is a small quantity of this gas always floating about dispersed in the air, and plants fight with one another to get as much as possible of it. Most people imagine plants grow out of the soil. This is quite a mistake. The portion of its solid material which a plant gets out of the soil (though absolutely necessary to it) is hardly worth taking into consideration, numerically speaking; by far the larger part of its substance comes directly out of the air as carbon, or out of the water as hydrogen and oxygen. You can easily see that this is so if you dry a small bush thoroughly, leaves and all, and then burn it. What becomes of it in such circumstances? You will find that the greater part of it disappears, or goes off 
into the atmosphere; the carbon, uniting with oxygen, goes off in the form of carbonic acid, while the hydrogen, uniting with oxygen, goes off in the form of steam or vapour of water. What is there left? A very small quantity of solid matter, which we know as ash. Well, that ash, which returns to the soil in the solid condition, is practically almost the only part the plant got from the soil; the rest returns as gas and vapour to the air and water, from which the plant took them. You must never forget this most important fact, that plants grow mainly from air and water, and hardly at all from the soil beneath them. Unless you keep it firmly in mind, you will not understand a great deal that follows.

Why, then, do gardeners and farmers think so much about the soil and so little about the air, which is the chief source of all living material? We shall answer that question in the next chapter, when we come to consider What Plants Drink, and what food they take up dissolved in their water.

Carbonic acid, though itself a gas, is the chief source of the solid material of plants. How do plants eat it? By means of the green leaves, which suck in floating particles of the gaseous food. Their eating is thus more like breathing than ours : nevertheless, it is true feeding: it is their way of taking in fresh material for building up their bodies. If you examine a thin slice from a leaf under the microscope, you will find that its upper surface consists of a layer of cells 
with transparent walls, and no colouring matter (Fig. 1). These cells are full of water; they form a sort of water-cushion on the top of the leaf, which drinks in carbonic acid (or, to be quite correct, its floating form, carbon dioxide) from the air about it. Immediately below this cushion of water-cells you come again upon a

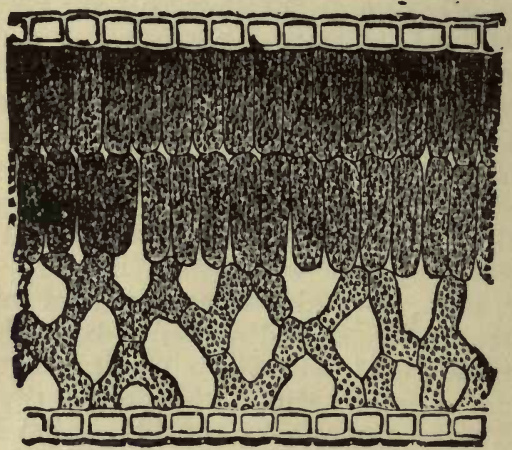

FIG. 1. - A THIN SLICE FROM A LEAF, SEEN UNDER THE Mrcroscope. On top are water-cells, which suck in carbonic acid. Beneath these are green cells, which assimilate it under the influence of sunlight. The spongy lower portion is used for evaporation.

firm layer of closely-packed green cells, filled with living green-stuff, which take the carbonic acid in turn from the water-cells, and manufacture it forthwith into sugars, starches, and other materials of living bodies. The lowest spongy part evaporates unnecessary water, and so helps to keep up cirgulation. 
The plant has often many hundred leaves, that is to say, many hundred mouths and stomachs. Why do plants need so many when we have but one? Because they cannot move, and because their food is a gas, diffused in minute quantities through all the atmosphere. They have to suck it in wherever they can find it. And what do they do with the carbonic acid when once they have got it? Well, to answer that question, I must tell you a little more about what the ordinary green leaf is made of, and especially about the green-stuff in its central cells.

Now what is this green-stuff? It is the true life-material of the plant, the origin of all the living matter in nature. You and I, as well as the plants themselves, are entirely built up of living jelly which this green-stuff has manufactured under the influence of sunlight. And the material that does this is such an important thing in the history of life that I will venture to trouble you with its scientific name, Chrorophyll. When sunlight falls upon the Chlorophyll or green-stuff in a living leaf, in the presence of carbonic acid and water, the chlorophyll at once proceeds to set free the oxygen (which it turns loose upon the air again), and to build up the carbon and hydrogen (with a little oxygen) into a material called starch. This starch, as you know, possesses energy - that is to say, latent light and dormant heat and movement, because we can eat it and burn it within our bodies. Other materials, hydro-carbons and carbo-hydrates, as they are called, are made in the same way. The main use of leaves, then, is to eat 
carbon and drink water, and, under the influence of sunlight, to take in energy and build them up into living material.

The starch and sugar and other things thus made are afterwards dissolved in the sap, and used by the plant to manufacture new cells and leaves, or to combine with other important materials of which I shall speak hereafter, in order to form fresh living chlorophyll.

Now we know what leaves are for; and you can easily see, therefore, that they are by far the most essential and important part of the entire plant. Most plants, in fact, consist of little else than colonies of leaves, together with the flowers which are their reproductive organs. We have next to see What Shapes various Leaves assume, and what are their reasons for doing so.

The leaf has, as a rule, to be broad and flat, in order to eatch as much carbon as possible; it has also usually to be expanded horizontally to the sunlight, so as to catch and fix it. For this reason, most leaves that can raise themselves freely to the sun and air are flat and horizontal. But in very crowded and overgrown spots, like thickets and hedgerows, the leaves have to fight hard with one another for air and sunlight; and in such places particular kinds of plants have been developed, with leaves of special forms adapted to the situation. The fittest have survived, and have assumed such shapes as natural selection dictated.

Where the plants are large and grow freely upward, with plenty of room, the leaves are 
usually broad and expanded, as in the tobaccoplant and the sunflower. Where the plants grow thick and close in meadows, the leaves are mostly long and narrow, like grasses. In overgrown clumps and hedgerows they are generally much subdivided into numerous little leaflets, as is the case with most ferns, and also with herb-Robert, chervil, milfoil, and vetches. In these last cases, the plant wants to get as much of the floating carbonic acid, and of the sunlight, as it can; and therefore it makes its leaves into a sort of divided network, so as to entrap the smallest passing atom of carbon, and to intercept such stray rays of broken sunlight as have not been caught by the taller plants above it. In almost all cases, too, the leaves on the same plant are so arranged round the stem and on the branches as to interfere with one another as little as possible; they are placed in an order which allows the sunshine to reach every leaf, and which secures a free passage of air between them.

An interesting example of the way some of these principles work out in practice is afforded us by a common little English pond-weed, the water-crowfoot. This curious plant grows in streams and lakes, and has two quite different types of leaves, one floating, and one submerged. The floating leaves have plenty of room to develop themselves freely on the surface of the pond; they loll on the top, well supported by the mass of water beneath; and, as there is little competition, they can get an almost unlimited supply of carbonic acid and sunshine. Therefore, they 
are large and roundish, like a very full ivy-leaf. But the submerged leaves wave up and down in the water below, and have to catch what little dissolved carbonic acid they can find in the pond around them. Therefore they are dissected into endless hair-like ends, which move freely about in the moving water in search of food-stuff. The two types may be aptly compared to lungs and gills, only in the one case it is carbonic acid and in the other case oxygen, that the highly-dissected organs are seeking in the water.

As a general rule, when a plant can spread its leaves freely about through unoccupied air, with plenty of sunlight, it makes them circular, or nearly so, and supports them by means of a stem in the middle. This is particularly the case with floating river-plants, such as the water-lily and the water-gentian. But even terrestrial plants, when they can raise their foliage easily into unoccupied space, free from competition, have similar round leaves, supported by a central leaf-stalk, as is the case with the familiar garden annual popularly (though erroneously) known as nasturtium. (Its real name is Tropæolum.) On the other hand, when a plant has to struggle hard for carbon and sunlight in overgrown thickets, or under the water, it has usually very much subdivided leaves, minutely cut, again and again, into endless segments. Submerged leaves invariably display this tendency.

But that does not conclude the whole set of circumstances which govern the forms and size of leaves. Not only do they want to eat, and to 
have access to sunshine ; they must also be supported or held in place so as to catch it. For this purpose they have need of what we may venture to describe as foliar architecture. This architecture takes the form of ribs or beams of harder material, which ramify through and raise aloft the softer and actively living cell-stuff. They are, as it were, the skeleton or framework of the leaf; and in what are commonly known as "skeleton leaves" the living cell-stuff between has been rotted away, so as to display this harder underlying skeleton or framework. It is composed of specially hardened, lengthened, and strengthened cells, and is intended, not only to do certain living work in the plant (as we shall see hereafter), but also to form a supporting scaffolding. The material of which ribs or beams are composed is called "vascular tissue" -a not very well chosen name, as this material has only a slight analogy to what is called the vascular system (or network of blood-vessels) in an animal body. It is much more like the bony skeleton. Similarly, the ribs themselves are usually called veins-a very bad name again, as they are much more like the bones of a wing or hand; they are mainly there for support, as a bony or wooden framework, though they also act for the conveyance of sap or water.

And now we are in a position to begin to understand the various shapes of leaves as we see them in nature. They depend most of all upon certain inherited types of ribs or so-called veins, and these types are usually pretty constant 
in great groups of plants closely related by descent to one another. The immense difference in their external shape (which often varies enormously even on the same stem) is mainly due to the relative extent to which the framework is filled out or not with living cell-stuff, or, as it is technically called, cellular tissue.

There are two chief ways of arranging the ribs or veins in a leaf, which may be distinguished as the finger-like and the feather-like methods (in
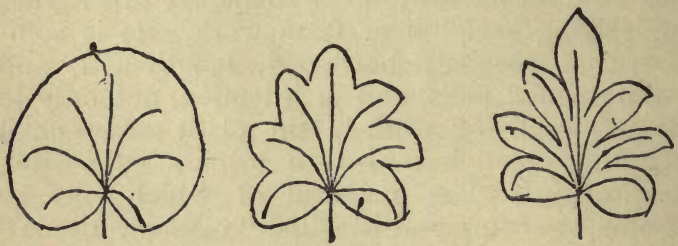

FIG. 2. FINGER-VEINEd LEAVEs. The veins are the same in the three leaves, but they differ in the amount to which they are filled in.

technical language, palmate and pinnate). In the finger-like plan the ribs all diverge from a common point, more or less radially. In the feather-like plan the ribs are arranged in opposite pairs along the sides of a common line or midrib. Yet even these two distinct plans merge into one another by imperceptible degrees, as you can see if you look at the accompanying diagram.

Now let us take first the finger-veined type (Fig. 2). Here, if all the interstices of the ribs are fully filled out with cellular tissue, we get a 
roundish leaf like that of the so-called nasturtium. But if the ribs project a little at the edge -in other words, if the cellular tissue does not quite fill out the whole space between themwe get a slightly indented leaf, like that of the scarlet geranium or the common mallow. If the unfilled spaces between the ends of the ribs are much greater, then the ribs project into marked points or lobes, and we get a leaf like that of ivy.
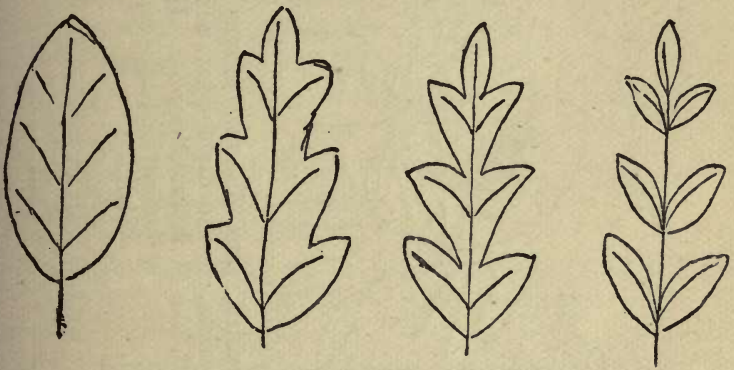

fig. 3. FEather-VEined Leaves. The four leaves have similar veins, but are differently filled in.

Carry the starving of the cellular tissue a little further still, and we have a deeply-indented leaf like that of the castor-oil plant. Finally, let the spaces unfilled go right down to the common centre from which the ribs radiate, and we get a divided or compound leaf, like that of the horsechestnut, with three, five, or seven separate leaflets. (See Fig. 5, No. 1.)

Similarly with the feather-veined type (Fig. 3); the spaces between the ribs may be more or less filled with cellular tissue in any degree you 
choose to mention. When they are very fully filled out, you get a leaf like that of bladder
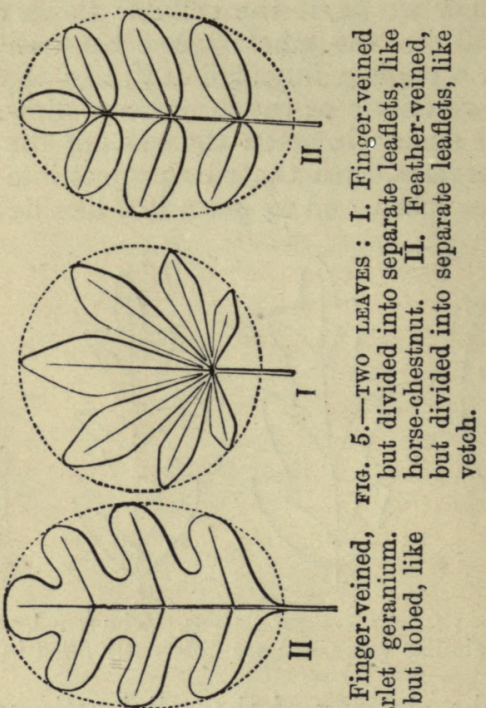

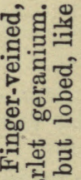

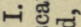

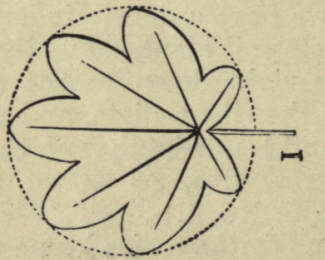

क. की

senna. A little more pointed, and less filled out at the tips, it becomes like argel. When 
the edge is not quite filled out, but irregularly indented, we get forms like the oak leaf. Finally, when the indentations go to the very bottom of each vein, so as to reach the midrib, we get a compound leaf like that of the vetch, with a number of opposite and distinct leaflets.

The reason why some leaves are thus more filled out than others is simply this: it depends upon the freedom of their access to air and sunlight. I do not mean the freedom of access of the particular leaf or the particular plant, but the average ancestral freedom of access in the kind they belong to. Each kind has adapted itself, as a rule, to certain situations for which it has special advantages, and it has learnt by the teaching of natural selection to produce such leaves as best fit its chosen site
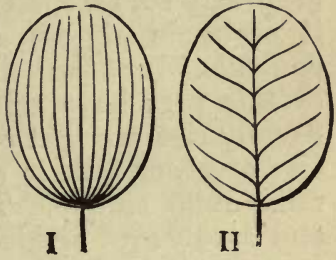

FIG. 6.-I. Parallel veins, as seen in one great group of plants, the lilies. II. Branching veins, as seen in another great group, the trees and herbs of the usual type.

and habits. Where access to carbon and sunlight is easy, plants usually produce very full round leaves, with all the interstices between the ribs filled amply in with cellular tissue; but where access is difficult, they usually produce rather starved and unfilled leaves, which consist, as it were, of scarcely covered skeletons (Figs. 4 and 5). This last condition is particularly observable in submerged leaves, and in those which grow in very crowded situations. 
The two types of rib-arrangement to which I have already called attention exist for the most part in one of the two great groups of flowering plants about which I shall have more to say to you hereafter. There is yet a third type, however, which occurs in the other great group (that of the grasses and lilies), and it is known as the parallel (Fig. 6). In this type, the ribs do not form a radiating network at all, but run straight, or nearly so, through the leaves. Examples of it occur in almost all grasses, and in tulips, daffodils, lily of the valley, and narcissus. Leaves of this sort have seldom any leaf-stalk; they usually rise straight out of the ground, more or less erect, and their architectural plan is generally quite simple. They are seldom toothed, and hardly ever divided into deeply-cut segments or separate leaflets.

A few more peculiarities in the shapes of leaves must still be noted, and a few words used in describing them must be explained very briefly. When the leaf consists all of one piece, no matter how much cut up and indented at the edge, it is said to be "simple"; but if it is divided into distinct leaflets (as in Fig. 5), it is called "compound." If the edge is unindented all round (as in Fig. 6), we say the leaf is "entire" ; if the ribs form small projections at the edge (as in Fig. 4), we call it "toothed" ; if the divisions are deeper, we say it is "lobed" ; and when the lobes are very deeply cut indeed, we call it "dissected." Thus, in order to describe accurately the shape of a leaf, we need only say which way it is veined or ribbed - whether finger- 
wise, feather-wise, or with parallel veins-and how much, if at all, it is cut or divided.

Endless varieties, however, occur, in accordance with the peculiar place the plant and its kind have been developed to inhabit. In climbing plants, for example, the leaves are usually opposite, so as to clutch more readily, and they are almost always more or less heartshaped at the base, as in convolvulus and black briony. The leaves of forest trees, on the other hand, tend to be what is known as ovate in shape, like the beech and the poplar; while those of the lime are a little one-sided, in order that each leaf may not overshadow and rob its neighbour. This one-sidedness is even more markedly seen in the hot-house begonias. Some leaves, again, are minutely subdivided into leaflets twice or three times over; such leaves are said to be doubly or trebly compound. But if you study plants as they grow (and this book is written in the hope that it may induce you to do so), you will generally be able to see that the shapes and peculiarities of leaves have some obvious reference to their place in the world, and their habits and manners.

I have spoken so far mainly of quite central and typical leaves, which are arranged with a single view to the need for feeding. But plants are exposed to many dangers in life besides the danger of starvation, and they guard in various ways against all these dangers. One very obvious one is the danger of being devoured by grazing animals; and, to protect themselves 
against it, many plants produce leaves which are prickly, or stinging, or otherwise unpleasant. The common holly is a familiar instance. In this case the ribs are prolonged into stiff and prickly points, which wound the tender noses of donkeys or cattle. We can easily see how such a protection could be acquired by the holly-bush through the action of Variation and Natural Selection. For holly grows chiefly in rough and wild spots, where all the green leaves are liable to be eaten by herbivorous animals. If, therefore, any plant showed the slightest tendency towards prickliness or thorniness, it would be more likely to survive than its unprotected neighbours. And indeed, as a matter of fact, you will soon see that almost all the bushes and shrubs which frequent commons, such as gorse, butcher's broom, hawthorn, blackthorn, and heather, are more or less spiny, though in most of these cases it is the branches, not the leaves, that form the defensive element. Holly, however, wastes no unnecessary material on defensive spikes; for though the lower leaves, within reach of the cattle and donkeys, are very prickly indeed, you will find, if you look, that the upper ones, above six or eight feet from the ground, are smooth-edged and harmless. These upper leaves stand in no practical danger of being eaten, and the holly therefore takes care to throw away no valuable material in protecting them from a wholly imaginary assailant.

Often, too, in these prickly plants we can trace some memorial of their earlier history. Gorse, for example, is a peaflower by family, a 
member of the great group of "papilionaceous," or butterfly-blossomed, plants, which includes the pea, the bean, the laburnum, the clover, and many other familiar trees, shrubs, and climbers. It is descended more immediately from a special set of trefoil-leaved peaflowers, like the clovers and lucernes; but, owing to its chosen home on open uplands, almost all its upper leaves have been transformed for purposes of defence into sharp, spine-like prickles. Indeed, the leaves and branches are both prickly together, so that it is difficult at first sight to discriminate between them. But if you take a seedling gorse plant you will find that in its early stages it still produces trefoil leaves, like its clover-like ancestors; and these leaves are almost exactly similar to those of the common genista so much cultivated in hot-houses. As the plant grows, however, the trefoil leaves gradually give place to long and narrow blades, and these in turn to prickly spines, like the adult gorse-leaves. Hence we are justified in believing that the ancestors of gorse were once genistas, bearing trefoil leaves ; and that later, through the action of natural selection, the prickliest among them survived, till they acquired their existing spiny foliage. In every case, indeed, young plants tend to resemble their earlier ancestors, and only as they grow up acquire their later and more special characteristics.

And now I must add one word about the origin of leaves in general. Very simple plants, we saw, consist of a single cell, which is not 
merely a leaf, but also at the same time a flower, a seed, a root, a branch; and everything. In other words, in very simple plants a single cell does rather badly everything which in more advanced and developed plinis is better done by distinct and highly-adapted organs. The whole evolution of plants consists, in fact, in the telling off of particular parts to do better what the primitive cell did for itself but badly. Above the very simple plants which consist of a single cell come other plants, which consist of many cells placed end on end together, as in the case of the hair-like water-weeds; and above these again come other and rather higher plants, in which the cellular tissue assumes the form of a flat and leaf-like blade, as in many broad seaweeds. None of these, however, are called leaves in the strict sense, because they consist of cells alone, without any ribs or supporting framework. The higher types, however, like ferns and flowering plants, have such ribs or frameworks, made of that stiffer and tougher material called vascular tissue. This is the most general distinction that exists between > plants ; the higher ones are known as Vascular Plants, including all those with true leaves, such as the common trees, herbs, and shrubs, and the ferns and grasses -in fact, almost all the things ever thought of as plants by most ordinary observers ; the lower ones are known as Cellular Plants, and include the kinds without true

2 leaves or vascular tissue, such as the seaweeds, fungi, and microscopic plants only recognised as a rule by botanical students. 
The higher plants, then, have for the most part special organs, the leaves, told off to do work for them as mouths and stomachs; while other organs are told off to do other special work of their own-as the roots to drink, the flowers to reproduce, the fruit and seeds to carry on the life of the species to other generations, and so forth, down to the hairs that protect the surface, or the glands that produce honey to attract the fertilising insects. To the end, however, all parts of the plant retain the power to eat carbonic acid, if necessary; so that many higher plants have no true leaves, but use portions of the stem or branches for the purpose of feeding. Any part of the plant which contains the active living green-stuff, or chlorophyll, can perform the functions of a leaf. In very dry or desert places, leaves would be useless, because their flat and exposed blades would allow the water within to evaporate. too readily. Hence most desert plants, like the cactuses, and many kinds of acacias and euphorbias, have no true leaves at all ; in their place they have thick and fleshy stems, often very leaf-like in shape, and curiously jointed. These stems are covered with a thick, transparent skin or epidermis, to resist evaporation, and are protected by numerous stinging hairs or spines, which serve to keep off the attacks of animals. Stems of this type are used as reservoirs of water, which the plant sucks up during the infrequent rains; and as they contain chlorophyll, like leaves, they serve in just the same way as swallowers and digesters of carbonic acid. 
Many other plants which live in dry or sandy places, like our common English stone-crops, do not go quite as far as the cactuses, but have thick and fleshy leaves on thick and fleshy stems, to prevent evaporation. As a general rule, indeed, the drier the situation a plant habitually frequents the fleshier are its leaves, and the greater its tendency to make the stem share in the work of feeding, or even to get rid of foliage altogether. In Australia, however, most of the forest trees, like the eucalyptuses, have got over the same difficulty in a different way; they arrange their leaves on the stem so as to stand vertically to the sun's rays, instead of horizontally, which saves evaporation, and makes the woodland almost entirely shadeless. Many of these Australian trees, however, have no true leaves, but use in their place flattened green branches.

Some plants are annuals, and some perennials. When annuals have flowered and set their seed they wither and die. But perennials go on for several seasons. Most of them, however, in cold climates at least, shed their leaves on the approach of winter. But they do not lose all the valuable material stored up in them. Trees and shrubs withdraw the starchy matter into a special layer of the bark, where it remains safe from the winter frosts, and is used up again in spring in forming the new foliage. This new foliage is usually provided for in the preceding season. If you look at a tree in late autumn, after the leaves have fallen, you will see that it is covered by little knobs which we know as 
buds. These buds are the foliage of the coming season. The outer part consists of several layers of dry brown scales, which serve as an overcoat to protect the tender young leaves within from the chilly weather. But the inner layers consist of the delicate young leaves themselves, which are destined to sprout and grow as soon as spring comes round again. Even the scales, indeed, are very small leaves, with no living material in them; they are sacrificed by the plant, as it were, in order to keep the truer leaves within snug and warm for the winter. Nor do the autumn leaves fall off by pure accident; some time before they drop the tree arranges for their fall by making a special row of empty cells where the leaf-stalk joins the stem or branch; and when frost comes on, the leaf separates quietly and naturally at that point, as soon as the valuable starchy and living material has been withdrawn and stored in the permanent layers of the bark for future service.

Smaller and more succulent plants do not thus withdraw their living material into the bark in autumn; but they attain much the same end in different manners. Thus lilies and onions store the surplus material they lay by during the summer at the base of their long leaves, and the swollen bases thus formed produce what we call a bulb, which carries on the life of the plant to the next season. Other plants, like the common English orchids, store material in underground tubers; while others, again, and by far the greater number, so store it in the root, wbich is sometimes thick and 
swollen, or in an underground stem or rootstock. In most cases, however, perennial plants take care to keep over their live material from one season to the other by some such means of permanent storage. They are, so to speak, capitalists. Natural selection has of course preserved those plants which thus laid by for the future, and has killed out the mere spendthrifts which were satisfied to live for the fleeting moment only. The soil of our meadows in winter is full of tubers, bulbs, and rootstocks; while our shrubs and trees carry over their capital from season to season in their living bark, secure from injury. In one way or another all our perennial plants manage to tide their living green-stuff, or at least its raw material, by hook or by crook, over the dangers of winter.

I have given so much space to the subject of leaves because, as you must see, the leaf is really the most important and essential part of the entire plant-the part for whose sake all the rest exists, and in which the main work of making living material out of lifeless carbonic acid and water is concentrated.

Let us sum up briefly the main facts we have learned in this long chapter.

Plants eat carbonic acid under the influence of sunlight. They store up the solar energy thus derived in starches and green-stuff in their own bodies. Very simple plants, which float freely in water, eat and drink with all portions of their surface, But higher plants eat with 
special organs. These organs are known as leaves, and are the parts where the chief business of the plant is transacted.

A leaf is an expanded mass of cells, containing living green-stuff, supported on a tougher framework, or rib-like skeleton. Leaves take in carbonic acid by means of tiny absorbing mouths, which exist on their upper surface; and they turn loose most of the oxygen, by the aid of sunlight, building up the carbon into starch, with hydrogen from the water supplied by the roots to them. Leaves are of different shapes, according to the work they have to do for the plant in different situations. Where carbon and sunlight abound they are round, or nearly so ; where carbon and sunlight are scanty, or much competed for, they are more or less divided into minute sections.

\section{CHAPTER V.}

\section{HOW PLANTS DRINK.}

We have now learnt that plants really eat for the most part with their leaves. They grow, on the whole, out of the air, not, as most people seem to fancy, out of the soil. Yet you must have noticed that farmers and gardeners think a great deal about the ground in which they plant things, and very little, apparently, about the air around them. What is the reason for this curious neglect of the real food of plants, and this curious importance attached to the mould or soil they root in? 
That is the question we shall have to consider in the present chapter; and I shall answer it in part at once by saying beforehand that, though plants do grow for the most part out of the carbonic acid supplied by the air to the leaves, they also require certain things from the soil, less important in bulk, but extremely necessary for their growth and development. What they eat through their leaves is far the greatest in amount; but what they drink through their roots is nevertheless indispensable for the production of that living green-stuff, chlorophyll, which, as we saw, is the original manufacturer and prime maker of all the material of life, either vegetable or animal.

Plants have roots. These roots perform for them two or three separate functions. They fix the plant firmly in the soil ; they suck up the water which circulates in the sap; and they also gather in solution certain other materials which are necessary parts of the plant's living matter.

The first and most obvious function of the root is to fix the plant firmly in the soil it grows in. Very early floating plants, of course, have no roots at all; they take in water and the dissolved materials it contains, with every part of their surface equally, just as they take in carbonic acid with every part of their surface equally. They are all root, all leaf, all flower, all fruit. But higher plants tend to produce different organs, which have become specially 
adapted by natural selection for special purposes. If you sow a pea or bean you will find at once that the young seedling begins from the very first to distinguish carefully between two main parts of its body. In one direction, it pushes downward, forming a tiny root, which insinuates itself with care among the stones and soil ; in the other direction, it pushes upward, forming a baby stem, which gradually clothes itself with leaves and flowers.

The tip of the root is the part of the plant which exercises the greatest discrimination and ingenuity, so much so that Darwin likened it to the brain of animals. For it goes feeling its way underground, touching here, recoiling there, insinuating little fingers among pebbles and crannies, and trying its best by endless offshoots to fix the plant with perfect security. Large trees, in particular, need very firm roots, to moor them in their places, and withstand the force of the winds to which they are often subject. After every great storm, as we know, big oaks and pines may be seen uprooted by the power of this invisible but very dangerous enemy.

The root, however, does not serve merely to anchor the plant to one spot, and secure it a place in which to grow and feed; it also drinks water. The hairs and tips of the root absorb moisture from the soil ; and this water circulates freely as sap through the entire plant, dissolving and carrying with it the starches and other materials which each part requires for its growth and nourishment (Figs. 7, 8, and 9), Without 
water, as we all know, plants will wither and die; and the roots push downward and outward in every direction in search of this necessary of life for the leaves and flowers.

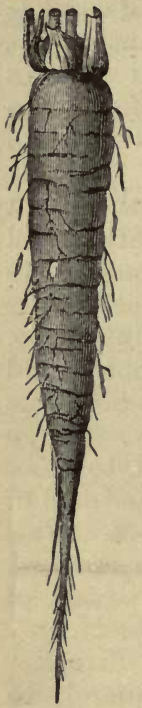

FIG. $7 . \quad$ FIG. 8.

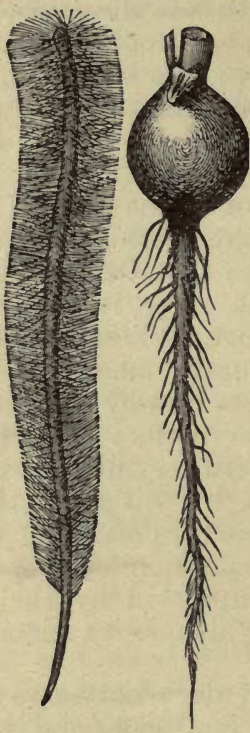

rIa. 9. raw materials that

In addition to these two functions of fixing the plant and drinking water, however, roots perform a third and almost more important one in absorbing the other needful materials of plant life from the soil about them. They drink, not water alone, but other things dissolved in it.

What are these other things? Well, the answer to that question will fairly round off our first rough idea of the $\begin{array}{ccc}\text { FIG. 7. FIG. } 8 . & \text { FIG. 9. life is made up from. } \\ \text { Fig. 7. ROOT OF THE CARRot. We saw already that } \\ \text { Fig. 8. ROOT OF THE FroGBI, We }\end{array}$ FLOATING IN WATER. Fig. 9. plants eat carbonand ROOT OF THE RADISH. The hydrogen from the small hair-like ends drink in air and water; out of water and dissolved food-salts. these they manufacture a large number of compounds, such as 
starches, oils, sugars, and so forth, all of which contain a little oxygen, but far less than the amount contained in the carbonic acid and water from which they are manufactured. These useful materials, however, though possessing energy, that is to say the power of producing light and ' heat and motion, are not exactly live-stuffs; 2 in order-to make but of them/the living green - matter of leaves, chlorophyll, or the living cell2 stuff of all bodies, animal or ve etable) protoplasm, we must have a fourth element, vitrogen; find that element is supplied by the roots in solution.

So now you see the full importance of the roots; they add to the oils and starches manufactured in the leaves) that mysterious body, nitrogen, which is necessary in order to turn these things into protoplasm and chlorophyll.

A few other things besides nitrogen are also needed by the plant from the soil ; the most important of these are sulphur and phosphorus. The plant, however, does not take in these substances in their free or simple form, as nitrogen, sulphur, and phosphorus, but in composition, as soluble nitrates, sulphates, and phosphates.

Now, I am not going to trouble you with a. long chemical account of how the plant combines. these various materials-a thing about which even chemists and botanists themselves know as. yet but very little. It will be enough to say here that the plant) builds them up at last into an extremely complex body, called protoplasm; 
and this protoplasm is the ultimate living matter, the " physical basis of life ;" the thing without which there could be no plants or animals possible.

What is protoplasm - this mysterious stuff, which builds up the bodies of plants and animals? It is a curious transparent jelly-like substance, full of tiny microscopic grains, and composed of carbon, hydrogen, axygen, nitrogen, and sulphur, Sometimes it is almost watery, sometimes halfhorny, but as a rule it is waxy or soft in texture. It is very plastic. Its peculiar characteristic is that it is restlessly alive, so to speak; seen under a microscope, it moves about uneasily, with a strange streaming motion, as if in search of something it wanted. It is, in point of fact, the building-material of life; and out of it the living parts of every creature that lives, whether animal or vegetable, are framed and compounded.

But it is plants alone that know how to make protoplasm. Animals can only take it ready-

2 made from plants, and burn it up again by feunion with oxygen in their own bodies. The plant manufactures it. The animal destroys it. Chlorophyll or the active green-stuff of leaves is a special modification or variety of protoplasm; and chlorophyll alone possesses the power to manufacture new energy yielding and living material, under the influence of sunlight, from the dead and inert bodies around it. The materials which it thus produces are afterwards worked up by the plant, together with the nitrogen, sulphur, and phosphorus supplied by the roots, into fresh protoplasm and fresh 
chlorophyll. These the animal may afterwards eat, either in the form of leaves like grass, or in the form of seeds or fruits, like corn, rice, or bananas.

The tiniest primitive one-celled plant contains protoplasm and chlorophyll though a few degenerate plants, like fungi, have none of the living green-stuff, and can make no new living material for themselves, but depend, like animals, upon the industry of others). Every living cell of every plant contains protoplasm ; a cell without any is dead and lifeless. Protoplasm, in short, is the only living material we know; and its life constitutes the larger life of the wholes compounded of it.

Well, now you are in a position to see why the farmer and the gardener attach so much importance to the soil, and so little, apparently, to the air and the sunlight. The reason is that the air is everywhere; you get it for nothing ; but the soil costs money, and, when cultivated, it requires to be supplied from time to time with fresh stores of the particular materials the plants take from it.

Let me give two simple parallel cases. A fire is made by the combination of two sorts of fuelcoal and oxygen. One is just as necessary for fire-making as the other. But we buy coal dear, and we neglect to take oxygen into consideration accordingly. The reason is that oxygen exists in abundance everywhere; so we don't have to buy it. If we paid a pound a ton for it, as we do with coal, we should very soon remember 
how necessary a part it is of every fire. Even at present we are obliged to provide for its free admission by the bars of the grate, and by checking or regulating its ingress we can slacken or quicken the burning of the fire.

Or, to take another analogy, oxygen is just as necessary to human beings and other animals as food and drink are. But, as a rule, we get oxygen everywhere in such great abundance that we never think of taking it into practical consideration. Still, in the Black Hole of Calcutta, the unhappy prisoners thoroughly realised the full value of oxygen, and would gladly have paid its weight in gold for the life-giving element.

Now, carbonic acid, on which plants mainly live, is not so common or so abundant a gas as oxygen; but still, it exists in considerable quantities in the air everywhere. So most plants are able to get almost as much as they need of it. Nevertheless, submerged plants, and plants that grow in very crowded places, seem to compete hard with one another for this aerial food; and in certain cases they appear to live, as it were, in a very Black Hole of Calcutta, so far as regards the supply of this necessary material. In farms and gardens, however, the farmer takes care that every plant shall have plenty of room and space-in other words, free access to sunlight and carbonic acid. He "gives the plants air," as he says, not knowing that he is really supplying them with their aerial food-stuff. $\mathrm{He}$ does this by keeping down weeds-by ploughing, by digging, by hoeing, or tilling. Indeed, what 
do we really mean by eultivation? Nothing more than destroying the native vegetation of a place, in order to make room for other plants that we desire to multiply. We plough out the grasses and herbs that occupy the soil; we sow or plant thinly seeds or cuttings of corn or vines or potatoes that we desire to piopagate. We give these new plants plenty of space and airin other words, free access to sunlight and carbonic acid. And that is the fundamental basis of cultivation-to keep down certain natural plants of the place, in order to give free room to others.

But as the crop-plants require to root themselves, the farmer naturally thinks most of the soil they root in-which he has to buy or rent, while the carbonic acid comes freely to him, unperceived, with the breath of heaven. Where water is scarce, as in irrigated desert lands, the farmer recognises quite equally the importance of water. But he never recognises the true importance of carbonic acid. That is why most people wrongly imagine that plants grow out of the soil, not out of the air. Still, when we burn them, the truth becomes clear. The portion of the plants derived from air and water goes off again into the air in the act of burning: so too does the nitrogen : the remaining portion derived direct from the soil is only the insignificant residue returned to the soil as ash when we burn the plant up.

Nevertheless, the farmer often needs to supply certain raw materials to the soil for the plants 
he cultivates. These raw materials are called manures; they are mostly rich in nitrates and. phosphates; and as they are usually the only things directly supplied to plants by human agency-the carbonic acid and water being supplied by wind and rain in the ordinary course of nature-they help to strengthen the popular misapprehension that plants grow directly out of the soil. Manures consist chiefly of compounds of nitrogen, phosphorus, and potash. These are the things of which the plants take most from the soil; and when the crops are cut down and carried away, it becomes necessary to restore them. This is generally done by means of farmyard manure, bones, or guano. Most manures are really the remains or droppings of animals; so that when we lay them on the soil, we are merely returning to it in another form what the animal took from it when he eat the plants up.

All plants, however, do not equally exhaust the soil of all necessary materials. Some require one sort of food, and others another. That is why farmers have recourse to what is called rotation of crops, so as to follow up one sort of plant in a field by another, whose needs are different. Thus corn is alternated with swedes or turnips. Virgin soil will produce crops for several seasons together without the need for manuring; but when many crops have been cut from it in succession, the earth gets exhausted of nitrates and phosphates, and then it becomes necessary to manure and to rotate the crops in the ordinary manner. 
But in nature crops are not, as a rule, removed from the soil; they die and wither, and return to it for the most part whatever they took from it. The dead birds and insects, and the droppings of animals, are sufficient manure for the native woodland. Still, even in nature, certain plants more or less exhaust the soil of certain valuable materials; and therefore natural selection has secured a sort of roundabout rotation of crops in a way of which I shall have more to say hereafter. Many plants, for example, which greatly exhaust the soil, have winged or feathery seeds; and these seeds are carried by the wind to fresh spots, where they alight and root themselves, in order to escape the exhausted soil in the neighbourhood of their mothers. Other plants send out runners, as they are called, on long trailing branches, which root at a distance, and so start fresh lives in unexhausted places. Yet others have tubers, which shift their place from year to year; or they push forth underground suckers, which become new plants at a distance from the parent. All these are different natural ways for obtaining what is practically rotation of crops; nature invented that plan millions and millions of years before it was discovered by European farmers.

Moreover, nature sometimes even goes in for deliberate manuring. Plants like buttercups and daisies, that live in ordinary meadow soils, to be sure, get enough nitrogen and sulphur and other such constituents from the mould in which they are rooted. But in very moist 


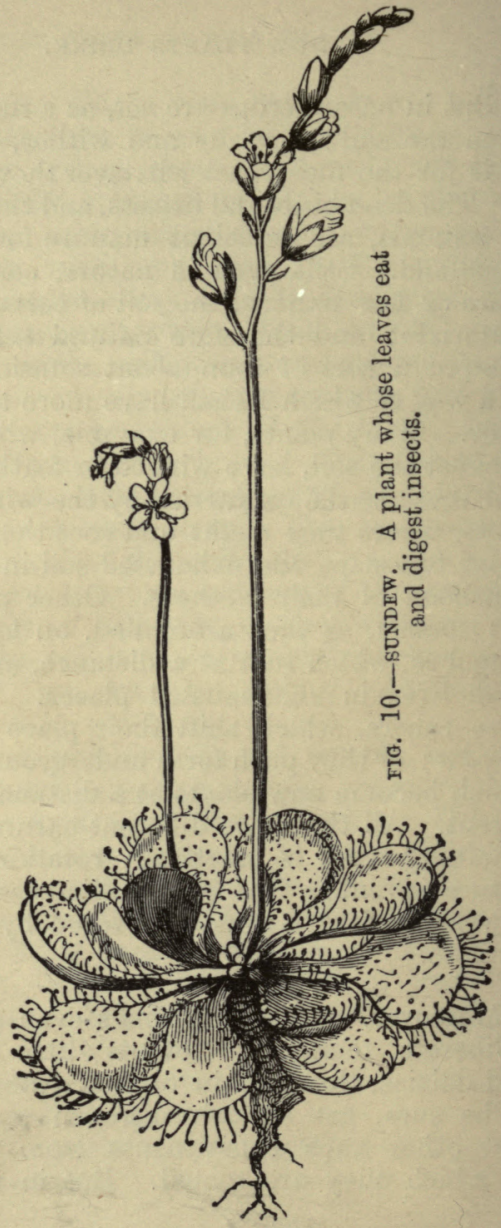


and boggy soils there is generally a lack of these necessary earth-given elements of protoplasm; and natural selection has therefore favoured any device in the plants which grow in such places for obtaining them elsewhere. This they do as a rule by catching insects, killing them, sucking their juices, and using them up as manure for manufacturing their own protoplasm and chlorophyll. Our pretty little English sundew is one of these cruel and perfidious plants (Fig. 10). Its leaves are round, and thickly covered with small red hairs, which are rather bulbous at the end, and very sticky. The bulbous expansions, in point of fact, are small red glands, which exude a viscid digestive liquid. When a small fly alights on the leaf, attracted by the smell of the sticky fluid, he is caught and held by its gummy mass; the hairs then at once bend over and clutch him, pouring out fresh slime at the same time, which very shortly envelopes and digests him. In the course of a few hours the leaf has sucked the poor victim's juices, and used them up in the manufacture of its own protoplasm.

Many other insect-eating plants exist in the marshy soils of other countries. One of the best-known is the Venus's fly-trap of tropical or subtropical North America. In this curious plant the leaf is divided into two portions, one of which forms a jointed snare for catching insects. It is hinged at the middle; and when a fly lights upon it, the two edges bend over upon him, and the bristles on the margin interlock firmly. As long as the insect struggles 
they remain tightly closed; when he eeases to move, and is quite dead, they open once more, and set their trap afresh for another insect. A great many such carnivorous and insectivorous plants are now known: and in almost every case they inhabit places where the marshy and waterlogged soil is markedly wanting in nitrogen compounds. Insect-eating leaves are thus a device to supply the plant with nitrogen by means of its foliage, in circumstances where the roots prove powerless for that purpose.

Simpler forms of the same sort of habit may be seen in many other familiar plants. Thus our English catchfies and several other of our common weeds have sticky glandular stems, which exude a viscid secretion, by whose aid they catch and digest flies. This is the beginning of the insect-eating habit, more fully evolved by natural selection in marsh-plants like sundew, and especially in larger subtropical types like the Venus's fly-trap. If you collect English wild-flowers you will soon perceive that a great many of them have sticky glands on the summit of the stem, near the flowering heads; and this is useful to them, because the flowers and seeds are particularly in want of nitrogenous matter for the pollen and ovules and the development of the seed. In short, though plants get their nitrogen mainly by means of the roots, they often lay in a supplementary store by their stems and their foliage.

Our common English teasel shows us the beginnings of another form of insect-eating, which is highly developed in certain American 
and Asiatic marsh-plants. The leaves of teasel grow opposite one another, joining the stem at the base, so as to form between them a sort of cup or basin, which will hold water. If you look close into this water you will find that it is often full of dead midges and ants; and the plant puts forth long strings of living protoplasm into the water, which suck up the decaying juices of these insects, and use them for the manufacture of more protoplasm and chlorophyll. In this case, water is used both as a trap and as a solvent; the insects are first drowned in the moat, and then allowed to decay and digest themselves in it.

Teasel, however, is but a simple example of this method of insect-catching. Several American marsh-dwellers, collectively known as pitcherplants, carry the same device a great deal further. They are far more advanced and developed water-trap setters. The Canadian side-saddle plant allures insects into its vaseshaped leaves, which are filled with sugar and water. This is just the same plan which we ourselves employ to catch flies when we trap them in a glass vessel by means of a sweetened and sticky liquid. The pitchers are formed by leaves which join at the edges; they are attractively coloured, so as to allure the flies; and they secrete on their walls a honeyed liquid, which entices the victim to venture further and further down the fatal path. But the inner sides of the vase are set with stiff downward-pointing hairs, which make it easy to go on, but impossible to crawl back again. So the flies creep 
down, eating away at the sticky sweet-stuff as they go, till they reach the bottom and the hungry water, when they fall in by hundreds,

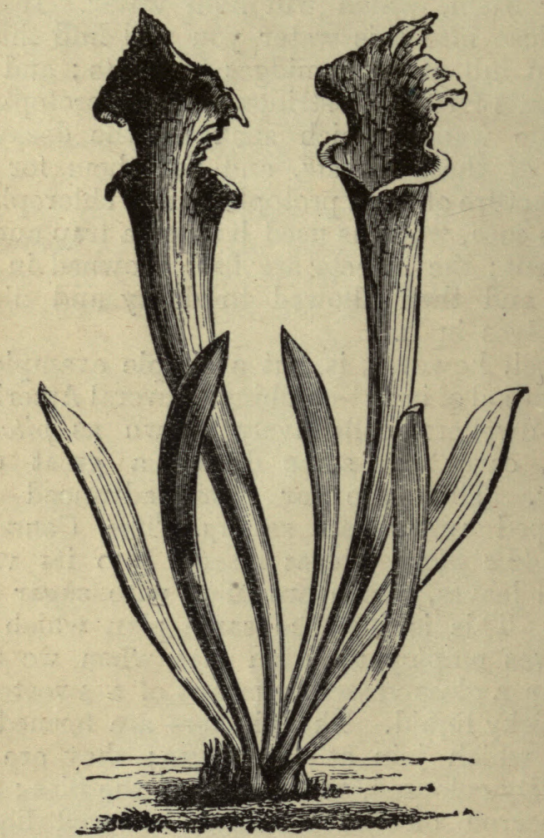

Fig. 11. - AN AUSTRALian PITCHER PLANT WHich EATS INSECTS.

and are drowned and digested. I have found these plants often by the sides of Canadian bogs, with a whole seething mass of festering and 


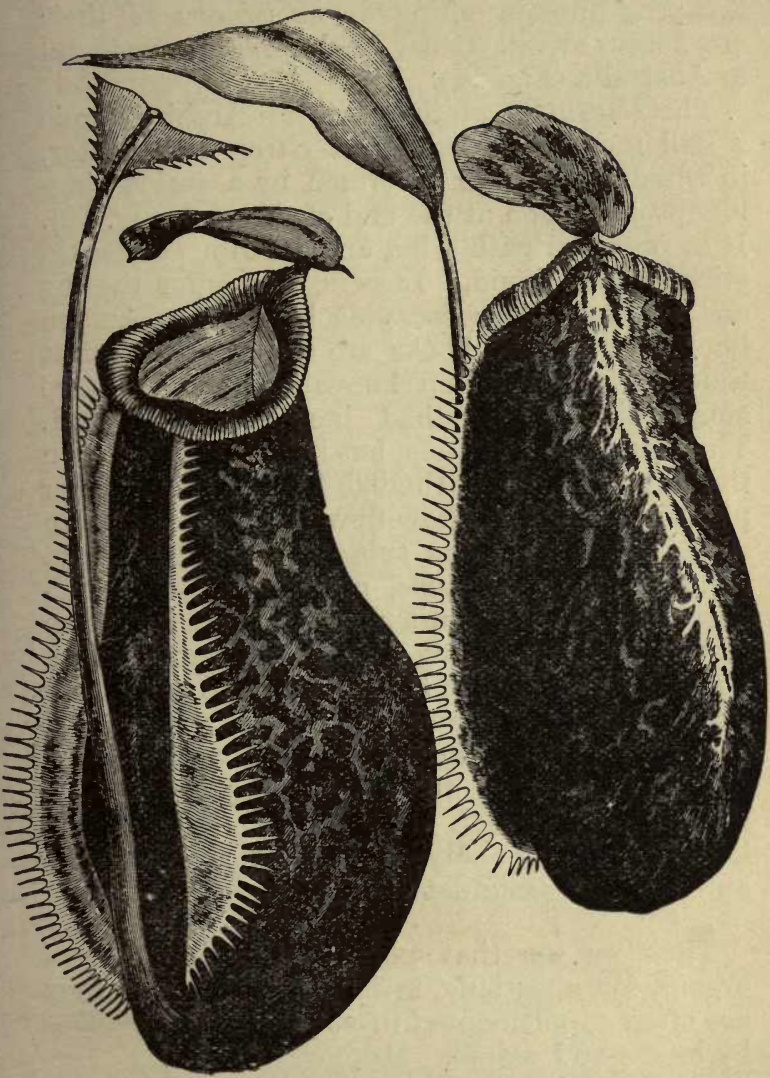

FIG. 12े.--INSECT-EATING PITCHERS OF THE MALAYAN NEPENTHES. 
decaying insects filling up every one of their murderous vases. Other pitcher-plants are found in Australia (Fig. 11).

The Nepenthes of the Malayan Archipelago is a still more remarkable water-trap insect-eater, in which the pitcher is formed by a curious juglike prolongation at the end of the leaf (Fig. 12). It is provided with a lid, and its rim secretes a sticky sweet liquid. Insects that enter the jug are prevented from escaping by strong recurved hooks; and these hooks are so powerful that at times they have been known even to capture small birds which had incautiously entered. This may seem curious, but it is not odder than the fact that our own English bladderwort, a water plant with pretty yellow flowers, which grows in sluggish streams, has submerged bladders that supply it with manure, not only from waterbeetles, larvæ, and other insects, but also from trout and other young fry of freshwater fishes. I may add that while the sundew and other liveinsect catchers have to digest their prey, the water-trap makers save themselves that additional trouble and expense by macerating and soaking it till it reaches the condition of a liquid manure, ready dissolved for absorption, and easy to assimilate.

Thus we see that while roots are the chief organs for absorbing nitrogenous matter, they are often supplemented in special circumstances by leaves and stems. Moreover, in many cases leaves also supply the plant with water. On the other hand, roots often fulfil yet another function, 
by storing up food for the plant from one season to another. It is true this is still more often done by underground stems, but the distinction between the two is very technical, and I do not think I need trouble you here with it. Large trees with solid trunks usually lay by their starch and other valuable materials over winter in a peculiar living layer of the bark; and here it is on the whole fairly free from danger. Still, even in trees the lower part of the bark is often nibbled by such animals as rabbits; and to prevent this mischance most smaller plants bury their rich food-stuffs underground during the cold season. For whatever will feed a young plant or a growing shoot will also just equally feed an animal. Hence the frequency with which plants make hoards of their collected food-stuffs underground, for use next season. The potato is a well-known instance of such underground hoards; the plant lays by in what are technically subterranean branches a supply of food-stuff for next season's growth. These branches are covered with undeveloped buds, which the farmer calls "eyes"; and from each of these eyes (if the potato is left undisturbed, as nature meant it to be) a branch or stem will start afresh next season. It will use up the starch and other foodstuffs in the potato, till it reaches the light; and there it will begin to develop green chlorophyll, and to make fresh starch for itself, and young leaves and branches.

An immense number of plants thus lay by underground stores of food for next season's use. Such are the carrot, the beet, and the 
turnip. And in every case the young shoots that spring from them use up the starches and other food-stuffs at first exactly as an animal would do. These stores are often protected against animals by hard coats or poisonous juices. Many well-known examples of subterranean stores occur among our spring garden flowers, which are for the most part either bulbous or tuberous. The material laid by in the bulb allows them to start flowering early, while annuals and other unthrifty plants have to wait till they have collected enough material in the same year to flower upon. Hyacinths, tulips, daffodils, snowdrops, crocuses, and the various kinds of squills and jonquils are familiar examples of plants which lay by in one year material for the next year's flowering season. But our wild flowers do the same thing quite as much, though less obtrusively. Our earliest spring buttercup is the bulbous buttercup, which has a swollen root-stock, full of rich material; and this enables it to flower very soon indeed, while the fibrous-rooted meadow-buttercup, which closely resembles it in most other respects, has to wait a month later, and then to raise a much taller stem, in order to overtop the summer grasses, which by that time have reached a considerable height. Still earlier, however, is another buttercup-like plant, the lesser celandine, which has material laid by in little pill-like tubers; and these have given it its curious old English name of pilewort. Other early spring wild-flowers are the wood anemone and marshmarigold, with rich and thick almost tuberous 
rootstocks; the bulbous wild hyacinth, the tuberous meadow orchid, and the common arum, or "lords and ladies," with its starchy root, very rich in food-stuffs. Indeed, in every case where a plant flowers very early in spring, you may be sure the material for its flowering was laid up by the plant in the previous year-that it is really rather a case of delayed than of very early flowering.

This is especially true of trees, like the blackthorn or the flowering almond, where the flowerbuds are usually formed over winter, and only fully developed in the succeeding spring. The same thing happens with gorse; only here, a few bushes always break into bloom in October or November, while others burst spasmodically into b occurs in January or February. The remaining bushes are covered through the winter with hairy brown buds, and burst out in early spring into golden masses of scented blossom. A like arrangement also occurs in many catkins, which are the flowers of certain trees ; the catkins of the birch and the alder, for example, are always formed in early autumn, though they only break into bloom with recurring warmth in March or April.

We have travelled away so far from our original question of How plants drink, that a summary of this chapter is even more necessary than usual.

Plants drink by means of roots. But they take up by them, not only water, which is their 
needful solvent, but also other materials urgently required for their growth and development. The most important of these materials is certainly nitrogen, which forms an indispensable component of protoplasm and chlorophyll. Where, however, the roots do not supply nitrogenous matter in sufficient quantities, plants procure it for themselves by means of their leaves or stems, and therefore become insect-eating or flesheating. Soils get exhausted at times of nitrates, phosphates, and other necessary materials of plant-life. The farmer meets this difficulty by manuring, and by rotation of erops. Nature meets it by dispersion of seeds. Roots, however, have other functions besides drinking water and sucking up with it certain dissolved materials; the chief of these other functions are fixing the plant securely in the ground, and affording a safe place of winter storage for starches and other surplus food-stuffs. Many plants die down almost entirely, above ground, in winter, and keep their raw material in underground reservoirs, most of which are stem-like rather than root-like. Animals, however, find out these subterranean reserves, and prey upon them; hence the plants often secure their hoard by nauseous tastes or other protective devices.

\section{CHAPTER VI.}

\section{HOW PLANTS MARRY.}

We next come to what is perhaps the most fascinating chapter of all in the life-history of 
plants-the chapter which tells us how they marry and are given in marriage.

In order that you may fully understand this curious and delightful subject, however, I shall have to begin by telling you a few preliminary points less interesting in themselves, and, I fear, at times not a little troublesome.

Flowers are the husbands and wives of plants. And in some plants the sexes are as fully separated as in birds or beasts; when once you know them, you can distinguish at sight a male from a female flower as readily as you can dis-

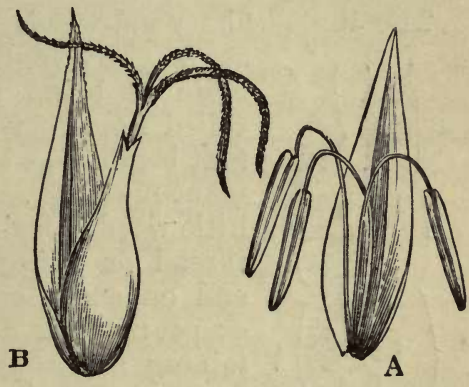
tinguish a bull from a cow, or a peacock from a peahen (Fig.

13). But in other cases the sexes are muddled up in the same blossom or on the same plant in a way that makes it rather difficult to understand their true nature without a little pains and some close attention.

So we must go back a bit for light to the lower plants. Here we find no flowers at all, and in the very lowest cases of any nothing in the least resembling a blossom. Very simple plants, in fact, have two ways of reproducing. 
The earliest way is, when a single cell divides in the middle, to form two others; a somewhat less primitive way is when a single cell breaks suddenly up, and produces from itself a whole swarm of young ones. In both these ways, however, there is no trace of sex; only one single cell is concerned in the process; the plants have a mother, perhaps, but certainly not a father.

The thread-like pond-weeds, however, which

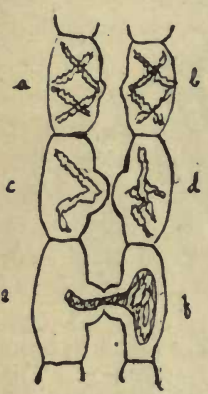
are slightly higher plants in the scale of being than the singlecelled floating types, show us the first beginnings of something like plant-marriage. These hair-like little weeds consist each of a single thread or string of cells, placed end on end together, like beads or pearls in a necklet, and containing green chlorophyll. You can find them in almost any stagnant pond in spring, where they FIG. 14.-BEGIN- cling to the side in soft greenish NINas of SEX moss-like or velvety masses. But INAPOND WEED, if you eXamine one slimy string
VERY MUCH MAGIFIED. under a microscope, you will see a curious thing often happening between the threads of two such hair-like plants. As they grow side by side, two of the strings will sometimes range themselves just parallel to one another, with their cells facing (Fig. 14). Then each opposite pair of cells begins to bulge a little at the point where they nearly touch ( $a$ and $b$ in the figure), till at last 
they join and coalesce with one another ( $c$ and $d$ in the figure). The contents of one cell pass into another (at $e$ ), and the two form a sort of egg $(f)$, which lies quiet for a while, and then buds out into a new thread or hair-like plant by division. In this strange process we have the beginning of sex-the first hint of plant and animal marriages.

What is the meaning and good of it? Why do the plants act thus? That question we don't yet quite understand, perhaps; but this seems to be in part at least its reason. Protoplasm requires to be kept, as it were, perpetually young and ever fresh; it cannot afford to lose its elasticity and its plasticity. If it does, it grows old in time and dies. To prevent this misfortune, and the death of all things, plants and animals have invented all sorts of curious expedients; for example, the protoplasm of a living cell sometimes breaks out of the cell-wall, and undergoes a process which is called "rejuvenescence," or growing young again. It lies quiet for awhile in its free condition, and then begins to build up a new wall afresh for itself. It seems by the process of breaking out to have gained for itself a new lease of life, as we ourselves often do by a trip abroad or change of scene and air and occupation. However this may be, it is certain at least that the union of two cells often produces a fresher, stronger, and more vigorous young one than can be produced by mere division of a single cell. In some way or other, when a plant or animal reaches maturity, and arrives at the limit of its own growth, it produces 
stronger and livelier young by so combining with another of its own species.

In the thread-like pond-weeds the two uniting cells are practically similar. They are not distinguished as male and female. Neither of them is larger or smaller than the other; neither of them is more active or more vigorous than its consort. But in the higher plants a marked difference invariably exists between the two cells that join to form the new individual-a difference of kind; we have sex now appearing. One of the cells is smaller, and more active; it is called a male cell or pollen cell. The other is larger, richer, and more passive; it is called a female cell, or ovule - that is to say in plain English, a little egg. Now the nature of the ovule is such that it cannot grow out into a seed or young plant till it has been united with and fertilised by the smaller but more active and lively pollencell.

Separate organs in the higher plants always produce the pollen-grain and the ovule. These organs are known as stamens and pistils (Fig. 15). They are really separate individuals, or males and females. The stamen is the father of the seed, so to speak, and the pistil its mother.

This is a hard saying, I know; and, in order that you may understand it, I must begin by telling you another point about the plant which I have hitherto to some extent studiously concealed from you. It is this-each higher plant is not so much a single individual as a community or colony.

A hive of bees will help you to understand 
this difficult paradox. I know it is difficult; but, if only you will face it, it will throw floods of light in due time on parts of our subject we must consider hereafter. So let us look at it close. A hive is a community. It consists for the most part of workers, who are practically neither male nor female. They are neuters, as we say; and their main work is to find food for the whole hive, including themselves and the grubs or larvæ which are the young of the species. But, in addition to these workers, the hive has a queen, who is the only per- FIG. 15. - $A$ FLOWER, WITH ITS PETALS fect female, or REMOVED. Outside are five stamens, mother, and who which produce pollen : in the centre lays the eggs is the pistil, which contains the from which the ovules or young seeds.

larvæ are produced; and it has also several drones, who are the males of the community, and fathers of the larvæ. Thus we have a colony or city, as it were, consisting of a few males, a single female, and a whole body of worker or feeder neuters.

Now, a higher plant, like a cherry-tree (to take a particular example), is just such a colony or joint community. The leaves, each of which is a distinct and almost self-supporting individual, are its workers and feeders. Like the 
worker bees, too, the leaves are neutersneither true males nor true females. They feed and lay by, and from them new leaves are continually produced in the buds and at the ends of branches. This is called the sexless method of reproduction, and it is essentially similar to the way in which the single-celled plant or the simple animal divides itself sexlessly into two or more little plantlets or animals. But, in addition to this sexless way, the plant also at certain times produces other sorts of leaves which are sexual individuals, and these we call, in the lump, flowers. But flowers are not all alike throughout. They consist of certain male individuals, the stamens, which answer to the drones, and of certain female individuals, the pistils or carpels, which answer to the queen or mother bee, and produce the ovules or little eggs of the family. A cherry-tree is thus a planthive or colony, consisting for the most part of workers or leaves, but also at certain times of year producing male and female members, whose business it is to found fresh swarms, as it were - to produce the seeds which are the basis and foundation of new colonies.

There is of course one great difference between a hive and a plant, and that is that in the hive the individuals are separate and distinct, while in the plant they are combined on a single stem, which serves to join them. In this respect plants are more like a branch of coral, which consists of a number of distinct animals or polypes, united by a core of stony material, and a living mass of connecting matter. Yet the 
difference between the leaves and the bees is not so great as at first sight appears; for though each leaf does not as a rule live separately, it is often capable of doing so if occasion arises. A single leaf of stonecrop, separated from the parent plant, will root itself and grow into a fresh colony; and in some plants, like begonias, a single fragment of a leaf, if placed on wet soil, is capable of growing out into a new individual. In other cases small leaves drop off from a plant as bulbils, and root and grow; while in others, again, young plants sprout out from the edges of old leaves to form new colonies. In short, though the leaf is not usually a distinct plant, it sometimes is, and it can often become one; it frequently gives rise in a sexless way to fresh plant colonies. A graver difficulty is this: the plant differs from the hive in being more closely connected and subordinated in its parts-the stem and root (which bind and unite it), bringing water and nitrogenous matter, while the leaves elaborate the starch and protoplasm and other chief food-stuffs. Even this difference, however, is less grave than it seems, if we remember that the queen bee and the larvæ are similarly dependent upon the workers for food and protection. A plant, in short, is a colony of various forms of leaves, very closely united together for mutual service, and very much specialised in various ways among themselves for particular functions.

And now we are in a position to know what work the flower has to do in the community. 
It is a collection of special and peculiar leaves, told off to act as fathers and mothers to the seeds, whence are to be born future plant swarms or future colonies.

A flower, in its simplest form, consists of a single stamen or a single carpel-that is to say, of one leaf or leaf-like organ, told off for the production of pollen; or of one leaf or leaf-like organ, told off for the production of young seeds or ovules. Flowers as simple as that do actually occur, but more often a flower is much more complex, consisting of several stamens and several carpels, as well as of other protective or attractive leaves, often highly coloured and conspicuous, which surround or envelop these essential organs.

The most familiar flowers, as we actually know them, are of this last more complex type; each comprises in itself several male and several female individuals. The male individuals are stamens, each of which generally consists of two little pollen-bags, called the anthers, and a rather slender stalk or support, known as the filament. The female individuals are carpels, each of which generally consists of a sort of sack or folded leaf, enclosing one or more tiny seeds or ovules.

But that is not at all what you mean by a flower! No; certainly not; and half the flowers you meet in a morning's walk you do not take for flowers at all, and pass by unrecognised. Such are the green or inconspicuous blossoms of the grasses, nettles, oaks, and sedges, as well as those of the pines, the dog's mercury, the spurge, and the hazel. What you mean most 
by a flower is a mass of red or yellow petals, conspicuously arranged about the true floral organs. The petals form, in point of fact, the popular notion of a flower-though from the point of view of science they are comparatively unimportant, and are commonly spoken of (with the calyx) as "the floral envelopes." It is the stamens and pistils (or carpels) that are the true flowers: they do the mass of the real work; and an enormous number of flowers possess these organs alone, without any conspicuous petals or other coloured surfaces.

However, if you take a pretty garden flower (say a scarlet geranium) as a typical example, and begin to examine it from the centre outward (which is the truest way), you

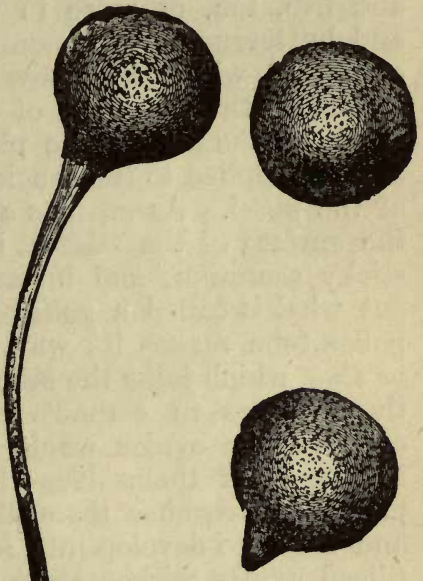
will find it consists of the following parts, in the following order :-

In the very centre of all comes the pistil, 
consisting of one or more carpels, and containing the embryo seeds or ovules (see Fig. 15). Outside this part, and next in order, come the stamens, which are most often three or six in one great group of flowering plants (the lilies), and five, ten, or more in the other (the roses and buttercups). The stamens produce grains of pollen, which somehow or other, either by means of the wind, or of insects, or of movements on the part of the plant itself, are sooner or later applied to the sensitive surface or stigma of the pistil. As soon as a pollen-grain reaches the surface of the stigma, it is held there by a sticky secretion, and instantly begins to send out what is called a pollen-tube (Fig. 16). This pollen-tube makes its way down the long stem or style which joins the stigma to the ovary, and there comes in contact with the undeveloped ovules. The ovules would not swell and grow into seeds of themselves; but the moment the pollen-tube reaches them, they quicken into life, and begin to develop into fertile seeds. Unfertilised ovules wither away or come to nothing, but fertilisation by pollen makes them develop at once into new plant colonies.

Outside these essential organs, as botanists call them, however, come, in handsome garden flowers, two other sets of organs, more leaf-like in appearance, but often brightly or conspicuously coloured. The first of these sets of organs, going still from within outward, is called the petals, or, collectively, the corolla. Sometimes, as in the dog-rose or the buttercup, the corolla consists of five separate petals; sometimes, as 
in the harebell and the gentian, it has five points, or lobes, unit it at the base into a single piece (Fig. 17). Last of all, outside the corolla again comes another row or layer, called the calyx, which sometimes consists of five separate leaves or sepals, as in the dog-rose and the buttercup, but sometimes has five points, welded at the base into one piece, as in red campion and

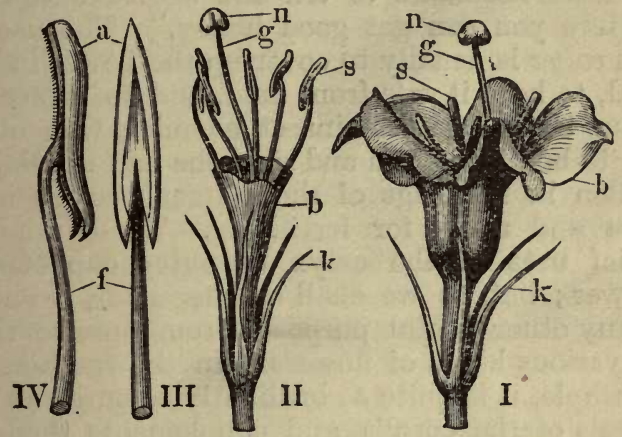

FIG. 17. - FLOWER OF A SHRUBBERY PLANT, WEIGELIA, WITH THE PETALS UNITED INTO SINGLE COROLLA. I. Entire flower. II. The same, with part of the corolla cut away. III. and IV. A stamen. $k$, calyx ; $b$, corolla ; $s$, stamen; $a$, anther of the stamen; $g$ and $n$, parts of the pistil.

convolvulus. It is these last comparatively unessential but very conspicuous parts that most people think of when they say "a flower."

What is their use? Well, they are not essential, like the pistil and stamens, because many flowers, perhaps, even most flowers, do without 
them altogether. But they are very useful for all that, as we may easily guess, because they are found in almost all the most advanced and developed flowers. The use of the corolla, with its brilliantly coloured petals, is to attract insects to the flowers and induce them to carry pollen from plant to plant. That is why they are painted red and blue and yellow; they are there as advertisements to tell the bee or butterfly, "Here you can get good honey." The use of the calyx is usually to cover up the flower in the bud, to keep it safe from cold, and to protect it from the attacks of insect enemies, who often try to break through and steal the half-developed pollen in the bags of the stamens before it is ripe and ready for fertilising. These are the chief uses of the calyx or outer cup of the flower; but, as we shall see hereafter, it serves many other useful purposes from time to time in various kinds of flowers. In the fuschia, for example, it is quite as brilliantly coloured as the petals of the corolla, and supplements them in the work of attracting insects. In the winter cherry or Cape gooseberry it forms a brilliant outer envelope or covering for the fruit, which the French call "cerise en chemise," or " cherry in its nightdress." Other uses of both calyx and corolla will come out by and by, as we proceed to examine individual instances.

"But why," you may ask, "do the plants want to get pollen carried from plant to plant? Why can't each flower fertilise itself by letting its pollen fall upon its own pistil ?" Well, the question is a natural one; and, indeed, many flowers 
do actually so fertilise themselves with their own pollen. But such flowers are almost always poor and degenerate kinds, the unsuccessful in the race, the outcasts and street arabs of plant civilisation. All the higher, nobler, and more dominant plants-the plants that have carved out for themselves great careers in the world, and that occupy the best posts in nature-have invented some mode or other of cross-fertilisation, as it is called, that is to say some plan by which the pollen of one plant or flower fertilises the pistil of another.

What does this mean? Well, regarding the plant as a colony, you will see at once that the stamens and pistil of the same blossom stand to one another somewhat in the relation of brothers and sisters, while those of different flowers on the same plant may be regarded at least in the light of first cousins. Now the very same thing that makes sex and marriage desirable, makes close intermarriage of blood relations undesirable. "Marrying in and in," as it is called, tends to produce weak and feeble offspring, while "an infusion of fresh blood" tends to make both plants and animals stronger and more vigorous. Hence, if any habit chanced to arise in plants which favoured or rendered easier such crossfertilisation, it would result in stronger and more vigorous young, and would therefore be fixed by natural selection. The actual consequence is that in the world of plants, as we see it to-day, every great dominant or successful race has invented some means of cross-fertilisation, either by the agency of wind or of insects, while only 
the miserable riff-raff and outcasts of plant-life still adhere to the old and bad method of fertilisation by means of the pollen of their own flowers.

We are now in a position to understand the main principles which govern the marriage customs of plants; we will proceed in the next chapter to consider in detail how these principles work out in particular instances. But first we must sum up what we have learnt in this chapter.

Plants marry and are given in marriage. The very lowest plants, indeed, are sexless, but in the higher there are well-marked distinctions of male and female. An intermediate stage exists in certain thread-like pond-weeds, where marriage or intermixture takes place between two adjacent cells, neither of which is male or female. The higher plants, however, are really communities or colonies, of which the leaves are the workers, and the various parts of the flower the males and females. The eentral part of the flower, known as the pistil, is the female individual; it produces ovules, or young seeds, which, however, cannot grow and swell without the quickening aid of pollen. The next row in the flower, known as the stamens, contains the male individuals; they produce pollen, which lights on the sensitive surface of the pistil, sends out tubes of very active living matter, and quickens or impregnates the ovules in the pistil. Besides these necessary organs flowers have often two other sets of parts. The corolla, 
which is made up of petals, united or distinct, is usually brightly coloured, and acts as an advertisement or allurement to the insects; it occurs chiefly in insect-fertilised flowers, and generally implies the presence of honey. The calyx or outer cup, which is made up of sepals, distinct or united, acts mainly as a protective covering. Plants can fertilise themselves if necessary, but in all the highest and most successful plants some form or other of crossfertilisation has become almost universal. Selffertilisation goes down the hill; cross-fertilisation is the road to success and vigour.

\section{CHAPTER VII.}

\section{VARIOUS MARRIAGE CUS'IOMS.}

THE simplest and earliest flowering plants had probably only three sets of organs-leaves, stamens, and pistils - workers, males, and females. Their flowers consisted at best of the necessary organs, enclosed, perhaps, in a few protective sheathing leaves, rather smaller than the rest, the forerunners of a calyx. How, then, did modern flowers come to get at last their brilliant corollas?

We must remember that anything which made flying insects visit plants would be of use to the flowers, as promoting cross-fertilisation. Now, as far as we can see at present, before flying insects were evolved in the animal world, there could have been no such things as bright-hued 
blossoms in the vegetable kingdom. But insects must very early have gone about eating pollen on plants, as they do to this day in many instances; and though in itself this would be a loss to the plant, yet plants have often found it well worth their while to pay blackmail to insects in return for some benefit incidentally conferred upon them. Again, as the insects flew from plant to plant, they would be sure to carry pollen on their heads and legs; and they would rub off this pollen on the sticky stigma of the next flower they visited, which would make them on the whole useful and profitable visitors. So the plants, finding the good cross-fertilisation did them, began in time to bribe the insects by producing honey in the neighbourhood of their pistils and stamens, and also to attract their eyes from afar by means of those alluring and brilliantly-coloured advertisements which we call petals.

I don't mean, of course, that the plants knew they were doing all this; they were unconscious agents. Whenever any variation in the right direction occurred by chance, natural selection immediately favoured it, so that in the end it comes almost to the same thing as if the plant deliberately intended to allure the insect; and for brevity's sake I shall often so word things.

How did the plant first come to develop such bright-hued petals? I think in this way. Most early types of flowers have a great many stamens apiece, and these stamens are so extremely numerous that one or two of them might readily be spared for any other purpose the plant found 
useful. Gradually, as botanists ?imagine, an outer row of these stamens got flattened out into a form like foliage leaves, only without any ribs or veins to speak of, and developed bright colours to attract the insects. Such a flattened and gaily-decked stamen, with no pollen-bearing bag, is what we call a petal. It is usually expanded, thin, and spongy, and it is admirably adapted for the display of bright colours.

We have still certain flowers among us which show us pretty clearly how this change took place. The common white water-lily is one of them. In the centre of the blossom, in that beautiful plant, we find a large pistil and numerous stamens of the ordinary sort, with round stalks or filaments, and yellow pollen-bags hanging out at their ends. Then, as we move outward, we find the filaments or stalks growing flatter and broader, and the pollen-bags gradually less and less perfect. Next we come to a few very flat and broad stamens, looking just like petals, but with two empty pollen-bags, or sometimes only one, stuck awkwardly on their edges. Last of all we arrive at true petals without a trace in any way of pollen-bags. I believe the water-lily preserves for us still some memory of the plan by which petals were first invented. Such relics of old conditions are common both in plants and animals; they help us greatly to reconstruct the history of the path by which the various kinds have reached their present perfection.

Even in our own day, in plants where stamens are numerous, they often tend to develop into petals, especially when growing in very rich 
soil, or under cultivation. This is what we call "doubling" a flower. In the double rose, for example, the extra petals are produced from the stamens of the interior, and if you examine them closely you will see that they often show every possible gradation and intermediate stage, from the perfect stamen to the perfect petal. The same thing readily happens with buttercups, poppies, and many other flowers. We may take it for granted, then, that petals are, in essence, a single outer row of stamens, flattened and coloured, and set apart by the plant to advertise its honey to insects, and so induce them to visit and fertilise it.

In the largest and most familiar group of flowering plants, to which almost all the bestknown kinds belong, the original number of petals seems to have been five; and we will take this number as regular for the present, explaining separately those cases where it is exceeded or diminished. The common ancestor of all these plants, we may conclude, had all its parts in rows of five. Thus it had five, ten, or fifteen carpels in its pistil-that is to say, one, two, or three rows of five carpels each; it had five, ten, or fifteen stamens, it had five or ten petals, and it had a calyx, outside all, of five sepals. We will now proceed to examine in detail some of the many curious marriage customs which have arisen among the group of plants that started with this ground-plan.

One great family of plants which early divided itself from this great central stock is the family 
of the buttercups. Our common English bulbous buttercup is one of its best-known members. It is yellow in colour, a point which is common to most early and simple flowers, because the stamens are generally yellow, and when they developed into petals they naturally retained at first their original colouring. Only later and for various special reasons did certain higher flowers come by degrees to be white, pink, red, blue, purple, or variegated. There is some reason to believe, indeed, that the various other colours were developed one after the other in the order here named, and to the present day all the simplest families of flowers remain chiefly yellow, as do the simpler and earlier members of more advanced families.

The common bulbous buttercup is thus prevailingly yellow, because it is an early and simple type of flower. It consists of four distinct and successive layers, or whorls of organs. Outside all comes a calyx of five sepals, which cover the flower in the bud, but are hardly noticeable in the open blossom. They also serve to keep off ants and other creeping insects, for which purpose they are turned back on the stem, and are covered with small hairs. "But I thought the plant wanted to attract insects," you will say. Yes, the right kind of insects, the flying types, which go from one flower to another of the same sort, and so promote due fertilisation. Flying insects, attracted by colour and shape of petals, keep to one brand. of honey at a time; they never mix their liquors. But ants are drawn on by the smell of honey 
only; they crawl up one stem after another indiscriminately, and steal the nectar which the plant intends for its regular winged visitors. Even if they do occasionally fertilise a flower, it will probably be with pollen of another kind, so that the result will be, not a perfect plant, but a miserable hybrid, ill adapted for any conditions. Hence plants usually possess advanced devices for keeping off ants and other climbing thieves from their precious honey. Hairs on the stalk and calyx are enough to secure this object in the meadow buttercup, which has a tall stem, and therefore is not so easily climbed; for the hairs, small as they look to us, prove to the ant a perfect forest of underwood. But in the early bulbous buttercup, which has a shorter stem, and the smell of whose honey is therefore more alluring to the groundling ant, this device is not alone sufficient; so the calyx on opening turns down its separate sepals close against the stem in such a way as to form a sort of lobsterpot, out of which the creeping insect can never extricate himself.

Inside the calyx-layer of five sepals comes next the corolla-layer of five petals. These petals, as we saw, are the attractive business advertisement of the flower; they contain at the base of each a tiny honey-gland or nectary, which is covered by a scale or small inner petal, so to speak, to protect it from the attacks of thievish insects. But when the bee or other proper fertilising agent arrives at the flower, he lights on the set of carpels in the very centre of the blossom, and proceeds to go straight for 
the little store of honey. As he does so, he turns gradually round all over the carpels, and dusts himself with pollen from the ripe stamens.

And now we must notice another curious device for ensuring cross-fertilisation in many flowers. In the bulbous buttercup the stamens and carpels do not come to maturity together; the stamens ripen first, and after them the carpels. How does this ensure cross-fertilisation? Why, if the bee comes to a flower in the first or male stage, in which the stamens are at their full, and discharging pollen, the sensitive surfaces or stigmas of the carpels will yet be immature, so that he cannot fertilise them with pollen from their own blossom. He can only collect there, without disbursing anything. But as soon as he comes to a flower in its second or female stage, with the carpels ripe, and their sensitive surfaces sticky, he will rub off some of the pollen he has thus collected, and so crossfertilise the flower he is visiting.

Each buttercup thus goes through two stages. First, its stamens ripen from without inward, till all have shed their pollen and withered. Then the carpels ripen in the same order, till all have been fertilised by the appropriate insect. Each carpel here contains a single seed, which begins to swell as soon as the ovary is impregnated.

We may take it that some such flower as that of the bulbous buttercup represents the original ancestor of all the buttercup group, from which other kinds have varied in many directions. Omitting for the present all questions as to the 
fruit and seed, which we must examine at length in a later chapter, I will now proceed briefly to describe a few of these variations in the buttercup family.

The true buttercups themselves are distinguished from all other members of the group by having a tiny scale over the nectary or honeygland at the base of the petal, or at least by having the nectary itself as a visible pit or small depression. Almost all of them are yellow, though in other respects they differ from one another, as in the shape of the leaves, or in the way in which the sepals are turned back to form a protection against insects. One of the yellow buttercups, too, commonly called the lesser celandine, has varied from the rest of the race in a peculiar fashion; for it has only three sepals, instead of five, according to the usual pattern; while, as if to make up for this loss in one part, it has eight petals instead of five in its corolla. I merely mention this fact to show how many small changes occur in different flowers, even within the limits of the same family. And though most of the true buttercups are yellow, a few are white, such as our own water-crowfoot, and the alpine buttercup called bachelors' buttons; while still fewer are red, like the turban ranunculus of our spring gardens.

But besides the true buttercups, we have also a vast group of buttercup-like plants, descendants of the same primitive five-petalled ancestor, and regarded as members of the buttercup order. In these we can trace some curious 
gradations. The little winter aconite of our gardens has this peculiarity: the petal and nectary have grown into a sort of tubular honeycup, much more attractive to greedy insects than the simple scale-bearing petal of the buttercups. But as this involves loss of expanded coloursurface, the winter aconite has made up for the deficiency by colouring its calyx a brilliant yellow, so as to resemble a corolla. Several other buttercup-like plants have even lost their petals altogether, and make coloured sepals do duty in their place. The marsh-marigold, for instance, is one of these; what look like petals in it are really very brilliant yellow sepals. Moreover, as the marsh-marigold is such a large and handsome flower, it easily attracts insects in early spring ; and this has enabled it to effect an economy in the matter of its carpels or female organs. In the buttercups, we saw, these were very numerous, and each contained only one seed; in the marsh-marigold, on the other hand, they are reduced to five or ten, but each contains a large number of seeds. This arrangement enables a few acts of fertilisation to suffice for the whole flower. You will therefore find as a rule that advanced types of flowers have very few carpels-sometimes only one-and that when they are more numerous they are often combined into a single ovary, with one sensitive surface, so that one fertilisation is enough for the whole of them.

Three familiar but highly-advanced members of the buttercup group will serve to show the immense changes effected in this respect by 
special insect fertilisation. They are the columbine, the larkspur, and the monkshood. In the simple buttercups, the honey, we saw, was easily accessible to many small insects; but in the winter aconite it was made more secure by being kept, as it were, in a sort of deep jar; and in these highest of the family it is still further hidden away, in special nooks and recesses, like vases or pitchers, so as to be only procurable by bees and butterflies. These higher insects, on the other hand, are the safest fertilisers, because they have legs and a proboscis exactly adapted to the work they are meant for; and they have also as a rule a taste for red, blue, and purple flowers, rather than for simple white or yellow ones. Hence the blossoms that specially lay themselves out for the higher insects are almost | always blue or purple.

Columbine still retains the original five sepals and five petals of its buttercup ancestor. But the sepals here are blue or purple, and are displayed between the petals in a most curious manner, so as to help in the coloured advertisement of the honey. The petals, on the other hand, are turned into long spurred horns, each with a big drop of honey in its furthest recess, securely placed where only an insect with a very long proboscis has any chance of reaching it. Within these two rows come the numerous stamens; and within them again a set of five carpels, each many-seeded. The columbine is so secure of getting its seed set by bees or butterflies that it is able to dispense with the extra carpels. 
VARIOƯS MARRIAGẼ CŨSTOMST.

Larkspur carries the same devices one step further. Here, there are five sepals, coloured blue, and prolonged into a spur at the base, which covers the nectaries. Why this outer covering? Well, in columbine, thievish insects like wasps often eat through the base of the spurred sepals and steal the honey, without benefiting the plant in any way, as they don't come near the stamens and carpels. Larkspur provides against that evil chance by covering its honey with two protective coats ; for within the spur of the sepals lies a spurred nectary made up of the petals. The petals themselves are reduced to two, because the sepals are coloured, and do all the attractive duty; and besides, even these two petals are combined into one, as a further economy. But the arrangement of the flower is so admirable for ensuring fertilisation that the plant is able still further to dispense with unnecessary parts ; so many larkspurs have only a single many-seeded carpel. Such reductions in the numbers of parts are always a sign of high development. Where the devices for effecting the work are poor, many servants lare necessary; where labour-saving improvements have been largely introduced, a very few will do the same work, and do it better.

Monkshood, again, is another example of the same tendency. Here, the one-sidedness which we saw in the larkspur reaches a still more advanced development. The upper sepal is formed into a brilliant blue hood, and it covers two curiously shaped petals, which contain an abundant store of honey. This arrangement is 
so splendid for fertilisation that the plant is able largely to reduce its number of stamens; and though it has three carpels, these are combined at the base, thus showing the first step towards a united ovary.

I have treated the single family of the buttercups at some length, because I wished to show you what sort of variations on a single plan were common in nature. We see here a family, built all on one scheme, but altering its architecture and decoration in the most singular degree in its different members. The simplest kinds are circular, symmetrical, orderly, and yellow; the highest are irregular, somewhat strangely shaped, and blue or purple. This is the general line of evolution in flowers. They begin like the buttercup; they end like the monkshood.

Familiar instances of round or radial flowers, consisting of separate petals, are the dog-rose, the poppy, the mallow, and the herb-robert or wild geranium. Most of these have five sepals and five petals; but in the poppy the petals are usually reduced to four, and the sepals to two. Again, a good instance of flowers with separate petals which have become one-sided or irregular, instead of circularly symmetrical, is afforded us by the peaflowers, which include the pea, the bean, the sweet-pea, the laburnum, the broom, the gorse, the vetch, and the lupine. This familiar family, known to botanists as the papilionaceous or butterfly-like order (I trouble you with as few long names as I can, so you must 
forgive one or two occasionally), is one of the largest in the world, and includes a vast number of the most useful and also of the most ornamental species. Tho structure of the flower, which is very similar in them all, can be easily studied in the broom or the sweet-pea, plants procurable by everybody. There are still five petals, though two of them are united to form a lower portion of the flower, known as the keel; then two others at the side are called the wings ; while a broad and often handsomely coloured advertisement-petal at the top of all is called the standard. The sepals are often combined into a single calyx-piece, though as a rule the calyx still retains five lobes or teeth, a reminiscence of the time when it consisted of five distinct and separate sepals. The stamens are welded together into a sort of long tube ; and the pistil is reduced to a single carpel or pod, containing a few big seeds, very familiar to most of us in the case of the pea, the bean, and the scarlet-runner. This shape of flower has proved so successful in the struggle for life that papilionaceous plants are now common everywhere, while hundreds of different kinds are known in various countries.

Yet closely as the peaflowers resemble one another in general aspect, they have still among themselves a curious variety of marriage customs. I will mention two only. In gorse, a flower which everybody can easily examine, the wings have two little knobs at the sides for the bee to alight upon. As he does so, the corolla springs open elastically, and dusts him all over with the 
fertilising pollen. But once it has burst, it remains permanently open, the keel hanging down in a woe-begone way, so that no bee troubles himself again to visit it. This saves time for the bees, and enables them quicker to fertilise the remaining flowers; for when they see a gorseblossom "sprung" as we call it, they recognise at once that it has already been fertilised, and they know they can get no food by going there. In the lupine, on the other hand, and in the common little English birdsfoot-trefoil, the keel is sharp at the point, and the pollen is shed into it before the flower fully opens. When a bee lights on the knobs at the side, he depresses the keel, and the pollen is pumped out against his breast in the most beautiful manner. I hope my readers will try some of these experiments in summer for themselves, and satisfy their own minds whether these things are so.

So far, we have dealt mainly with flowers in which the petals are all still distinct and separate. But in a great many plants, the petals have grown together, so as to form a single piece, a "tubular corolla," as we call it. This arrangement is very well seen in the harebell, the Canterbury bell, the heath, and the convolvulus. How did such an arrangement arise? Well, in many flowers even with distinct petals there is a slight tendency for adjacent parts to adhere at the base; and in certain blossoms this tendency to adhesion must have benefited the plant, because it would allow the proper fertilising insect to get in with ease, and to find 
his way at once to the stamens and stigma or sensitive surface. The consequence is that the majority of the higher plants have now corollas in a single piece; and most of these are also coloured red, blue, or purple. Still, even now many of them retain marks of the original five

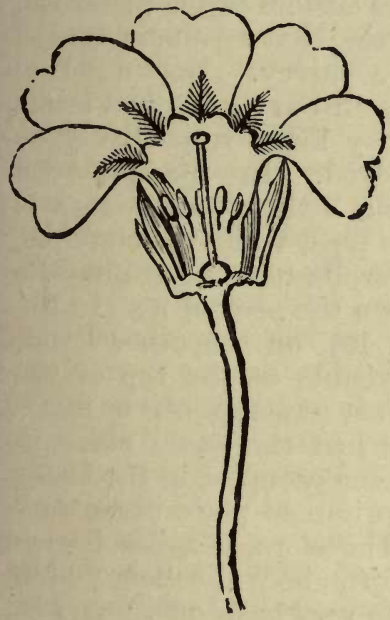

FIG. 18.-PIN-EYED PRIMROSE, CUT OPEN SO AS TO SHOW THE ARRANGEMENT OF THE STAMENS AND STIGMA.

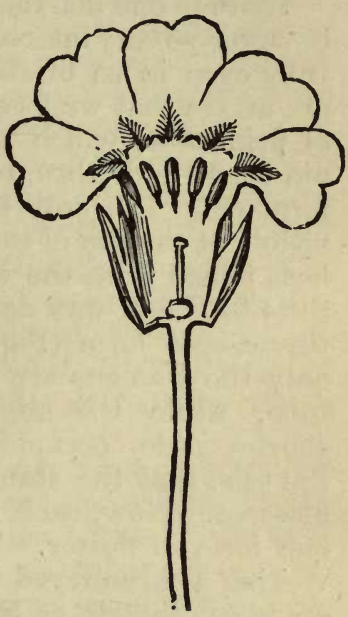

FIG. 19.-THRUM-EYED PRIMROSE, CUT OPEN SO AS TO SHOW STAMENS AND STIGMA.

petals. For instance, the harebell has the edge of the corolla vandyked into five marked lobes; while in the primrose, only the base of the corolla forms a tube or united pipe, the outer part being composed of five deeply-cut lobes, 
reminiscences of the five original petals. Indeed, some relations of the primrose, such as the pimpernel and the woodland loose-strife, have the petals only slightly united at the base, and would hardly be noticed by a casual observer as possessing a tubular corolla.

There is one marriage custom of the primrose, however, so very interesting that we must not pass it by even in so brief a survey. Most children are aware that we have in our woods two kinds of primroses, which they know respectively as pin-eyed and thrum-eyed. In the pin-eyed form (Fig. 18), only the little round stigma is visible at the top of the pipe, while the stamens, here joined with the corolla-tube, hang out like little bags half-way down the neck of it. In the thrum-eyed form (Fig. 19), on the other hand, only the stamens are visible at the top of the tube, while the stigma, erected on a much shorter style, occupies just the same place in the tube that the stamens occupied in the sister blossom. Now, each primrose plant bears only one form of flower. Therefore, ii a bee begins visiting a thrum-eyed form, he will collect pollen on his proboscis at the very base only; and as long as he goes on visiting thrum-eyed flowers, he can only collect, without getting rid of any grains on the deep-set stigmas. But when he flies away to a pin-eyed blossom, the part of his proboscis which collected pollen before will now be opposite the stigma, and will fertilise it; while at the same time he will be gathering fresh pollen below, to be rubbed off on the sensitive surface of a short-styled flower in due season. 
Thus every pin-eyed blossom must always be fertilised by a thrum-eyed, and every thrum-eyed by a pin-eyed neighbour. This is one of the most ingenious arrangements known for crossfertilisation.

Much as I should like to dwell further on these interesting cases, I must hurry on to complete our rapid survey of a great subject. Flowers like the harebell and the primrose are tubular but regular. Other flowers with a tubular corolla go yet a step further and are irregular also. This irregularity, like that of the monkshood, secures for them in the end greater certainty of fertilisation. Two wellknown groups of this sort are the sages, on the one hand, and the fox-gloves, monkey-plants, and snap-dragons on the other. I shall mention only one instance of special devices for crossfertilisation in these groups, that of the various sages, beautifully seen in the large blue salvias of our gardens. In this plant there are only two stamens, though most of the group to which it belongs have four, because the excellent arrangements for fertilisation make this single pair a great deal more effective than the thirty or forty required by the common buttercup. For the stamens are delicately poised on a sort of lever, so that the moment the bee enters the flower, they descend and embrace him, as if by magic. While the stamens alone are ripe, this continues to happen with each flower he visits; but when he goes away to an older blossom, he finds the stigma ripe, and bending over into the 
spot previously occupied by the stamens. You can try this experiment very easily for yourself by putting a straw or bent of grass down the tube of a garden salvia, when the stamens will at once bend down and embrace it in the way I have mentioned.

You must not suppose, however, that all flowers are fertilised by bees and butterflies. Many plants lay themselves out for quite different visitors. Take for example our common English figwort. This is a curious, lurid-looking, reddish-brown blossom, shaped somewhat like a helmet, and it is fertilised almost exclusively by wasps. Its shape and size exactly adapt it for a wasp's head; and it blooms at the time of year when wasps are numerous. Now wasps, as you know, are carnivorous and omnivorous creatures; so the figwort, to attract them, looks as meaty as it can, and has an odour not unlike that of decaying mutton. Certain tropical flowers again attract carrion-flies, and these have big blossoms that look like decomposing meat, and smell disgustingly. A South African flower of this sort, the Stapelia, is sometimes cultivated as a curiosity in greenhouses. I have already remarked on the white flowers which open at night, and attract the moths of twilight; while others again lay themselves out to be fertilised by midges, beetles, and other insect riff-raff. Most of these have the honey displayed on wide open discs, where it can be sipped by insects with hardly any proboscis.

In our latitudes it is only insects that so act 
as fertilisers; but in the tropics the work of fertilisation is often performed by birds, such as humming-birds, sun-birds, and brush-tongued lories. Many of the most brilliant and beautiful among the bell-shaped tropical flowers have been specially developed to suit the tastes and habits of these comparatively large and powerful fertilisers. The tongues of all, but especially of the humming-birds, are admirably adapted for sucking honey from flowers, as they are long and tubular, sometimes forked at the tip, and often hairy so as to lick up both honey and insects. The length of the beak and tongue varies to a great extent in accordance with the depth of the tube in the flowers they fertilise. Bird and flower, in other words, have each been developed to suit one another. The same sort of correspondence may often be observed between insects and flowers developed side by side for mutual convenience.

One more point I should like to touch upon before I pass away from this part of the subject; and that is the lines or spots so often found on the petals of highly developed flowers. These for the most part act as honey-guides, to lead the bee or other fertilising insect direet to the nectar. A very good case of this may be seen in an Indian plant which is found in every English cottage garden-that is to say the socalled nasturtium. This beautiful blossom can only be fertilised by humming-bird hawk-moths, no other insect in Europe at least having a proboscis long enough to reach to the bottom of 
the very deep spur which holds the honey. Now, humming-bird hawk-moths do not light on a flower, but hover lightly poised on their quivering wings in front of it. So all the arrangements of the flower are strictly set forth in accordance with the insect's habit. The calyx consists of five sepals with a very long spur, the end of which, as you can find out by biting it, is full of honey. Then come five petals, not, however, all alike, but divided into two distinct sets, an upper pair and a lower triplet. The upper pair are broad and deeply-lined with dark veins, which all converge about the mouth of the spur, and so show the inquiring insect exactly where to go in search of honey. The lower three, on the other hand, have no lines or marks, but possess a curious sort of fence running right across their face, intended to prevent other flying insects from alighting and rifling the flower without fertilising the ovary. This flower, too, has two successive stages; it opens male, with stamens only, which bend upward towards the insect; later, it becomes female, the stigma opens and becomes forked, and bends down so as to occupy the very same place previously occupied by the ripe stamens.

A great many well-known flowers have such lines as honey-guides. If I have succeeded so far in interesting you in the subject, you will find it a pleasant task to bunt them out for yourself in the violet, the scarlet geranium, the spotted orchid, and the tiger lily.

So far I have dealt only with the marriage 
arrangements of those plants which are fertilised by insects or birds, and which belong to the great group of flowering plants descended from an early common ancestor with five petals. We must next deal briefly with the marriage customs of the insect-fertilised class among the other great group whose ancestor started with but three petals; and after that we must go on to the other mode of fertilisation by means of the wind or of self-impregnation.

This chapter has consisted so much of special cases that $I$ do not think it stands in the same need of a summary as all its predecessors.

\section{CHAPTER VIII.}

MORE MARRIAGE CUSTOMS.

ALmost all the flowering plants with which most people are familiar - all, indeed, save the pines and other conifers-belong to one or other of two great groups or alliances, each remotely descended from a common ancestor. The flowers we have hitherto been considering are entirely those which belong to one out of these two groups - the group which started with rows of five, having five sepals, five petals, five or ten stamens, and five or ten carpels. In several cases, certain of these rows have been simplified or reduced in number; but almost always we can see to the end some trace of the original fivefold arrangement. This fivefold arrangement is very conspicuous in all the stonecrops, and it 
may also be well noticed in wild geraniums, and less well in the strawberry, the dog-rose, and the cinquefoil.

In the present chapter, however, I propose to go on to sundry flowers of the other great group which has its parts in rows of three, and to 2 show how they have been affected by insect visits. This will give us a clearer view of the whole subject, while it will also form a general introduction to systematic botany for those of my readers who may be induced by this book to carry their studies in this direction further.

Before proceeding, however, there is one little point I should like to note about the fivefold flowers, which we shall find much more common in the threefold, and among the wind-fertilised species. This is the separation of the sexes in different blossoms or even on separate plants. All the flowers we have so far considered have contained both male and female portions-have been made up of stamens and carpels united together in the self-same blossom. But many of them, as you will recollect, have not been actively both male and female at the same moment. The stamens ripened first, the sensitive surface of the carpels afterwards; and this, as we saw, tended to promote cross-fertilisation. But if in any species all the stamens in certain flowers were to be suppressed or undeveloped, while in other flowers the same thing happened to the carpels, self-fertilisation would become an absolute impossibility, and every blossom would necessarily be impregnated from the pollen of a neighbour. Natural selection has accordingly 
favoured such an arrangement in a considerable number of the higher plants. In such cases some of the flowers consist of stamens only, with no carpels ; while others consist of carpels alone, with no stamens. But as all are descended from ancestors which had both organs combined in the same flower, remnants of the stamens often exist in the female flowers as naked filaments or barren threads, while remnants of the carpels equally exist in the male flowers as central knobs without seeds or ovules.

The beautiful begonias, so much cultivated in conservatories, give us an excellent example of such single-sex flowers. In these plants the males and females are extremely different. The male flower has four coloured and petal-like sepals, surrounding a number of central stamens. The female flower has five coloured and petal-like sepals, surrounding a group of daintily-twisted central stigmas, while at the base of the blossom is a large triangular ovary, containing the young seeds or ovules. Usually the flowers grow in little bunches of three, each bunch consisting of two males and one female.

In the pumpkins, cucumbers, and melons, separate male and female flowers also exist on the same plant. The females here may be easily recognised by having an ovary or small undeveloped fruit at the back of the blossom, which you can cut across so as to show the young seeds or ovules within it. As the proper insects for fertilising cucumbers and melons do not live in England, gardeners usually impregnate the 
female flowers by bringing pollen from the males

I to them with a camel's hair brush. This process is commonly known as "setting" the melons. Many other garden flowers have separate male and female blossoms, which the beginner can easily recognise for himself if he takes the trouble to look for them.

In the instances we have hitherto considered, the male and female blossoms live on the same plant. But the best cross-fertilisation of all is that which is secured where the fathers and mothers belong to totally distinct plants, a plan 2 for facilitating which we have already seen in the common primrose. Well, now, if any species took to producing all male flowers on one plant, and all females on another, this great end would become absolutely certain, for every blossom would then always be fertilised by the pollen brought from a distinct plant. Many such instances have accordingly been produced in the world around us by natural selection. Only, the two kinds of plants must always grow in one another's neighbourhood. Hemp, for example, is a case of a plant where such an arrangement already exists; some plants are male only, while some are female. Mistletoe and hops are other well-known instances, which the reader should carefully examine for himself at the proper season.

All these are fivefold flowers, and I have brought them in here merely because one of the earliest and simplest threefold flowers wo are going to consider has also this peculiarity 
of separate sexes. This is the common arrowhead, a plant that grows in watery ditches, and a capital example of the threefold type in its simpler development. Each flower, whether male or female, has a green calyx of three small sepals, and a white corolla of three much larger and somewhat papery petals (Fig. 20). But the male flowers have in their centre an indefinite number of clustering stamens; while the female flowers have an equally numerous set of tiny carpels. The blossoms grow in whorls on the
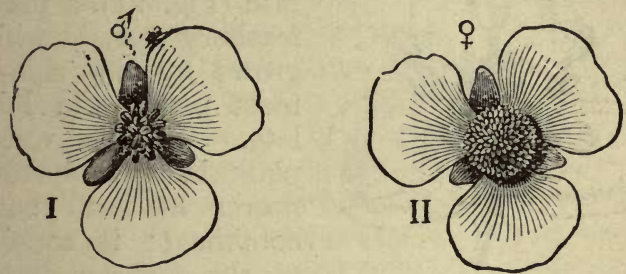

FIG. 20.-I. MALE, AND II, FEMALE FLOWERS OF ARROWHEAD.

same stem, the males above, the females beneath them. At first sight you would think this a bad arrangement, because you might fancy pollen from the males would certainly fall or blow out upon the females beneath them. But the plant prevents that catastrophe by a very simple dodge, which we shall have occasion to notice in many other parallel cases. The flowers open from below upward; thus the females mature first, and are fertilised by insects which bring to them pollen from other plants already rifled; later on the males follow suit, and their pollen 
is carried off by the visiting insect to the female flowers on the next plant it visits. Indeed, you may gather by this time how great a variety of devices natural selection has produced for securing this great desideratum of fresh blood, or cross-fertilisation, from a totally distinct plant colony.

A much commoner English wild-flower than the arrowhead shows us another form of early

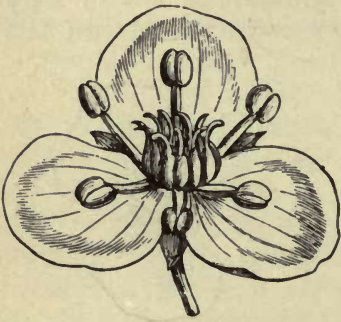

FIG. 21.-FLOWER OF WATERpLANTAIN. The male and female parts are in the same blossom. threefold blossom. I mean the water-plantain (Fig. 21), a pretty feathery weed, which grows by the side of most ponds and lakelets. In the waterplantain you have a flower of both sexes combined; it consists of three green sepals, forming a protective calyx; three delicate pinky - white petals, forming the corolla; six stamens-that is to say, two rows of three each ; and a number of small one-seeded carpels, exactly as in the buttercup, which occupies, in fact, the corresponding place among the fivefold flowers.

But it is not often in the threefold flowers that we get the calyx green and the corolla coloured, as in these simple and very early types. Most often in this great group of plants the calyx and corolla are both brightly coloured, and both alike 
employed as effective advertisements. A good case of this sort is shown in the flowering-rush, a close relation of the arrowhead and the waterplantain, but a more advanced and developed plant than either of them. Here the calyx and corolla, instead of forming two separate rows, are telescoped into one, as it were, and are both rose-coloured. In such cases we speak of the combined calyx and corolla as the perianth (another long word, with which I'm sorry to trouble you). In such perianths, however, even when all the pieces are of the same size and are similarly coloured, you can see if you look close that three of them are outside and alternate with the others; and these three are really the calyx in disguise, got up as a corolla. (An excellent example of this arrangement is afforded by the common garden tulip.) Inside its six rose-coloured perianth-pieces, the flowering-rush has nine stamens, arranged in three rows of three stamens each. Finally, in the centre, it has six carpels, equally arranged in two rows of three. Here the threefold architectural ground-plan of the flower is very apparent. You may say, in short, that the original scheme of the two great groups is something like this: five sepals, five petals, five stamens, five carpels; or else, three sepals, three petals, three stamens, three carpels. But in any instance there may be two or more such rows of any organ, especially of the stamens; in any instance certain parts may be reduced in number or entirely suppressed; and in any instance calyx and corolla may be coloured 
alike so as almost to resemble a single row or perianth.

There is one more point about the floweringrush to which I would like to allude before going on to the other threefold flowers, and that is this. In arrowhead and water-plantain the carpels are very numerous, but each one-seeded. In flowering-rush, on the other hand, which has a larger and handsomer blossom, more attractive to insects, they are reduced to six; but these six have many seeds in each, so that a single act of fertilisation suffices for each of them. You may remember that among the fivefold flowers we found a precisely similar advance on the part of the marsh-marigold above the bulbous and meadow buttercups. This sort of advance is common in nature. Where a flower learns how to produce many seeds in a carpel, it can soon dispense with several of its carpels, because a few now do well what the many did badly. Furthermore, in higher plants, there is a tendency for these carpels to unite so as to form what we call a compound ovary, with a single style, when one act of fertilisation suffices for all of them. Such combinations or laboursaving arrangements obviously benefit both the insect and the plant, and have therefore been doubly favoured by natural selection.

We see this advance beautifully illustrated in the largest and loveliest family of the threefold flowers, the lily group, which contains a great number of the handsomest insect-fertilised blossoms, and is therefore deservedly an immense favourite in flower-gardens. All the lilies 
have a perianth (or combined calyx and corolla) of six almost similar brilliantly-coloured pieces (in which, however, you can still, as a rule, detect the sepals by their habit of overlapping the petals in the bud). Then they have a set of six stamens. Inside that, again, they have a single ovary, but if you cut it across with a penknife you will see at once it contains three chambers, each as a rule with several seeds; and these three chambers are a memory of the time when the ovary consisted of three separate carpels. From their midst arises a single long style; but you may observe all the same that it is made up of three ariginal and distine styles, because it divides at the top into three stigmas or sensitive surfaces. This is the general plan of the lily group; but in certain individual lilies the stigma is undivided, and in others again the parts are increased to four or even to eight, so as to obscure the primitive threefold arrangement.

Most of the large and handsome lilies cultivated in gardens have perianths of separate pieces, such as one knows so well in the tigerlily, the Turk's-cap lily, and the beautiful Japanese lilium auratum. They have also abundant honey, stored in a deep groove of the spotted petals, and they are variegated and lined in such a way as to guide insects direct to their store of nectar. But the family has been so successful with the higher insects, and has produced such an extraordinary variety of very beautiful and brilliant flowers, that it is quite impossible to speak of them in detail. A few among them, 
like our own wild hyacinth, show a slight tendency on the part of the petals and sepals to unite into a bell-shaped tube; still, even here the pieces are really distinct and separate. But in the true garden hyacinth the pieces unite into a tubular perianth, like the tubular corolla of the common harebell, except that in the harebell the tube is formed by the union of the five petals, while in the hyacinth it is formed by the similar union of three petals and three sepals. A still higher form of the same union is shown us by the lily-of-the-valley, in which the six perianth-pieces join throughout to form a very beautiful heather - like cup or goblet. Other familiar members of this great lily group, which you ought to examine at leisure for yourself, in order to see how they are built up, are asparagus, Solomon's seal, fritillary, tulip, star-ofBethlehem, squill, garlic, onion, tuberose, and asphodel. The cultivated lilies of one sort or another to be found in our gardens may be numbered by hundreds.

A family of threefold flowers almost as beautiful as the lily group, and seldom distinguished from them save by botanists, is that which bears the pretty Greek name of amaryllids. The amaryllids are lilies which differ from the rest of their kind, in the fact that the perianth, still composed of six pieces, has grown up and around the ovary so as to seem to spring from above it, not below it. Such flowers are said to have "inferior ovaries." In other respects the amaryllids closely resemble the lilies, having six coloured perianth-pieces, six stamens, and 
an ovary of three chambers, with one style in common. Several of the amaryllids are such familiar flowers that I shall venture to describe them as illustrative examples.

The snowdrop is an amaryllid which blossoms in early spring, and which shows in a simple form the chief features of the family. It has six perianth-pieces, but these are still distinctly recognisable as calyx and corolla. The three sepals are large and pure white, and they enclose the petals; the three petals are distinctly smaller, and tipped with green in a very pretty fashion. The summer snowflake, commonly cultivated in old-fashioned gardens, is very like the snowdrop, only here the difference between sepals and petals has disappeared; all six pieces form one apparent row, white, tipped with green, in a single perianth.

In the daffodils and narcissuses we get a second group of amaryllids more advanced and aleveloped. Here the six perianth-pieces are almost alike, though they may still be distinguished as sepals and petals by a careful observer. But the perianth, which is tubular below, divides above into six lobes, beyond which it is prolonged again into what is called a crown, whose real nature can only be understood by comparison with such other flowers as the campions, where scales are inserted on the tip of the petals. This crown is comparatively little developed in the narcissus and the jonquil; but in the daffodil it has become by far the largest and most conspicuous part of the entire flower, so as completely to hide the bee who 
visits it. Of course this large crown assists fertilisation, and is a mark of advance in the daffodil and the petticoat narcissus. I hope these few remarks will induce you to examine many kinds of narcissus in detail, in order to see of what parts they are compounded.

This seems a convenient place to interpose another remark I have long wanted to make, namely, that the threefold flowers are also for the most part distinguished by having those narrow grass-like or sword-shaped leaves, with parallel ribs or veins, about which I told you when we were dealing with the question of varieties of foliage. The fivefold flowers, on the other hand, have usually net-veined leaves, either feather-ribbed or finger-ribbed. And at the risk of using two more horrid long words, I shall venture to add that botanists usually speak of the threefold group as monocotyledons, and of the fivefold group as dicotyledons. I did not invent those words, and I am sorry to have to use them here; but I will explain what they mean when I come to deal with seeds and seedlings. It is well at least to understand their use in case you come across them in your future reading.

Another family of threefold flowers, closely allied to the amaryllids, is that of the irises, many examples of which are familiar in our flower-gardens. It only differs from the amaryllids, in fact, in having the number of stamens still further reduced to three, which is always a sign of advance, because it shows that the plants are so sure of fertilisation as to be able 
to dispense with all unnecessary pollen. The ovary is also inferior, which you will learn in time to recognise as a constant sign of high development, because it means that the base of the corolla and calyx have coalesced with the carpels, and so ensured greater certainty of fertilisation. Some simple members of the iris group, like the crocuses, have mere tubular flowers, with a very long funnel-like base to the corolla, and with the ovary buried in the ground for greater safety. They are early spring blossoms, which need much protection against cold; therefore they thus bury their ovaries, and sheathe their flower-buds in a papery covering, composed of a thin and leathery leaf. Whenever a sunny day comes in winter the bees venture out; and on all such days, even though it freeze in the shade, the crocuses are open in the sunshine to welcome them.

But other irises are more complicated, like the gladiolus, and still more the garden irises, in which the difference between the calyx and corolla is carried to its furthest point in this family. The sepals in true irises are large and brilliantly coloured; they hang over gracefully; the petals are smaller and erect; the stigmas are so expanded as to look like petals; and they arch over the stamens in a most peculiar manner. If you watch a bee visiting a garden iris, you will see for yourself the use of this most peculiar arrangement; the bee lights on the bending sepal, and inserts his head between the stigma and the stamen in a way which renders fertilisation simply inevitable. But the 
most curious part of it all is that the flower, from the point of view of the bee, resembles three distinct and separate blossoms; he alights one after another on each bending sepal, and proceeds to search for honey as if in a new flower.

Highest of all the threefold flowers, and most wonderful in their marriage customs, are the

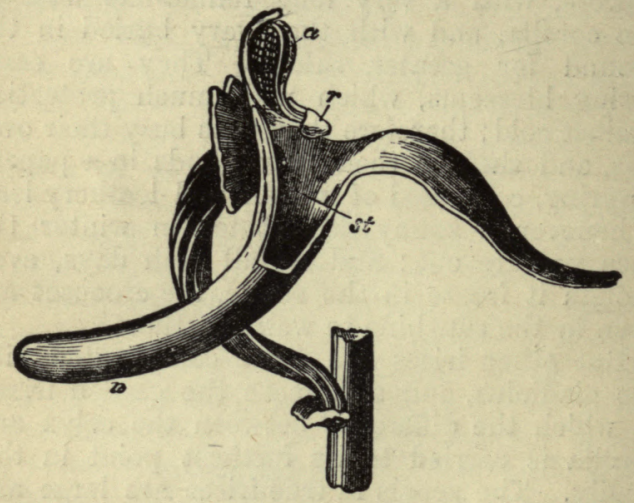

FIG. 22.-SINGLE FLOWER OF ORCHID, WITH THE PERIANTH CUT AWAY. The honey is in the spur, $n$; the pollen-masses are marked $a$; their gummy base is at $r$; the stigma at st.

great group of orchids, some of which grow wild in our English meadows, while others fix themselves by short anchoring roots on the branches of trees in the tropical forests. Many of these last produce the handsomest and most extraordinary flowers in the world, and they are 
much cultivated accordingly in hothouses and conservatories. It would be quite impossible for me to give you any account of the infinite devices invented by these plants to secure insect-fertilisation; and even the structure of the flower is so extremely complex that I can hardly undertake to describe it to you intelligibly; but I will give you such a brief statement of its chief peculiarities as will enable you to see how highly it has been specialised in adaptation to insect visits.

The ovary in orchids is inferior, and curiously twisted. It supports six perianth-pieces, three of which are sepals, often long and very handsome; while two are petals, often arching like a hood over the centre of the flower. The third petal, called the lip, is quite different in shape and appearance from the other two, and usually hangs down in a very conspicuous manner. There are no visible stamens, to be recognised as such; but the pollen is contained in a pair of tiny bags or sacks, close to the stigma. It is united into two sticky club-shaped lumps, usually called the pollen-masses (Fig. 22). In other words, the orchids have got rid of all their stamens except one, and even that one has united with the stigma.

I will only describe the mode of fertilisation of one of these plants, the common English spotted orchis; but it will suffice to show you the extreme ingenuity with which members of the family often arrange their matrimonial alliances. The spotted orchis has a long tube or spur at the base of its sepals (Fig. 22,n), and 
this spur contains abundant honey. The pollenmasses are neatly lodged in two little sacks or pockets near the stigma, and are so placed that their lower ends come against the bee's head as he sucks the honey. These lower ends $(r)$ are gummy or viscid, and if you press a straw or the point of a pencil against them, the pollenmasses gum themselves to it naturally, and come readily out of their sacks as you withdraw the pencil (Fig. 23). In the same way, when

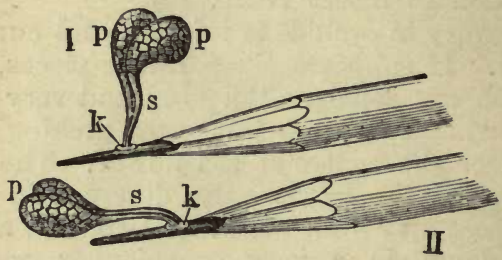

FIG. 23.-POLLEN-MASSES OF AN ORCHID, WITHDRAWN ON $\triangle$ PENCIL. In I, they have just been removed. In II, they haye dried and moved forward.

the bee presses them with his head, the pollenmasses stick to it, and he carries them away with him as he leaves the flower. Just at first, the pollen-masses stand erect on his forehead; but as he flies through the air, they dry and contract, so that they come to incline forward and outward. By the time he reaches another plant they have assumed such a position that they are brought into contact with the stigma as he sucks the honey. But the stigma is gummy too, and makes the pollen adhere to it, and in this 
way cross-fertilisation is rendered almost a dead certainty. The result of these various clever dodges is that the orchids have become one of the dominant plant-families of the world, and in the tropics usurp many of the best and most favoured positions (Fig. 24).

Darwin has written a most romantic book on the numerous devices by which orchids alone attract insects to fertilise them. I will say no more of this family, therefore - the highest and strangest among the threefold flowers - save merely to advise those who wish to know more of this curious subject to look it up in his charming volume. Instead of pursuing the matter at issue further, I will give one final example in an opposite direction.

An opposite direction, I say, because all the threefold flowers we have hitherto been considering are examples

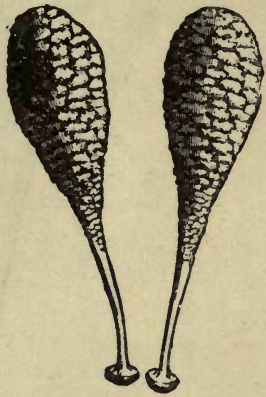

FIG. 24.-THE TWO POLLEN-MASSES, VERY MUCH ENLARGED. of a strict upward movement of evolution. Each group we have examined has been higher and more complex than the group before it. But I will now show you an instance, if not of degeneracy, at least of extreme simplification, which yet produces in the end the best possible results. This instance is that of the common English arum, known to children as cuckoo-pint or "lords and ladies" (Fig. 25). 
The structure of the cuckoo-pint is very peculiar. What looks like the flower is not really any part of the flower at all, but a large

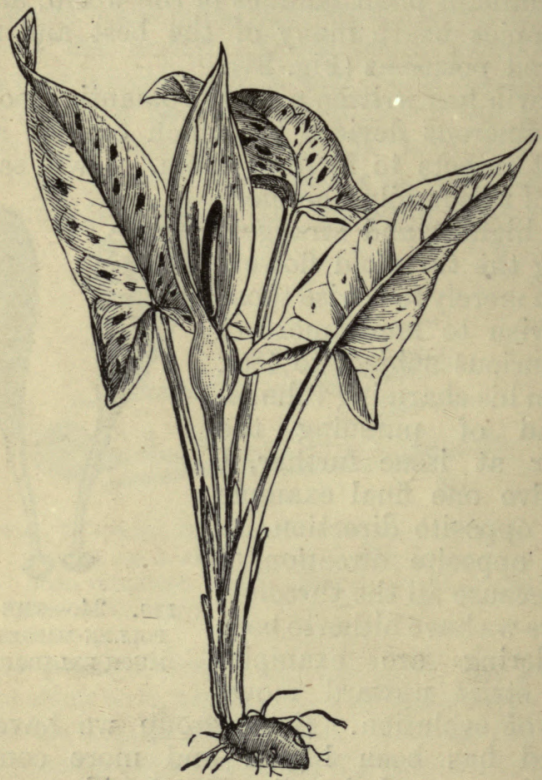

FIG. 25. - THE COMMON ARUM, OR CUCKOOPINT, SHOWING THE SPATHE WHICH SURROUNDS THE FLOWERS, AND THE SPIKE STICKING UP IN THE MIDDLE.

outer leaf or spathe surrounding a group of very tiny blossoms. You can understand this leaf better if you look at a narcissus stalk, where 
a very similar leaf is seen to enclose a whole bunch of buds and opening flowers. Only, in the narcissus the spathe is thin, whitish, and papery, while in the cuckoo-pint it is expanded, green, and purple. Though not a corolla, it serves the same purpose as a corolla generally performs : it attracts insects to the compound flower-head.

Inside the spathe we find a curious club-shaped mass, coloured bright purple, and standing straight up in the middle of the head. This is the stem or axis on which the separate little flowers are arranged. Cut open the spathe, and you will find these flowers below in the centre (Fig. 26). At first sight what you see will look like a lot of confused little knobs; but when you gaze closer you will see they separate themselves into three groups, which are the true flowers. Lowest of all on the stem come thefemaleblossoms, without calyx or corolla, each consisting of a single ovary.

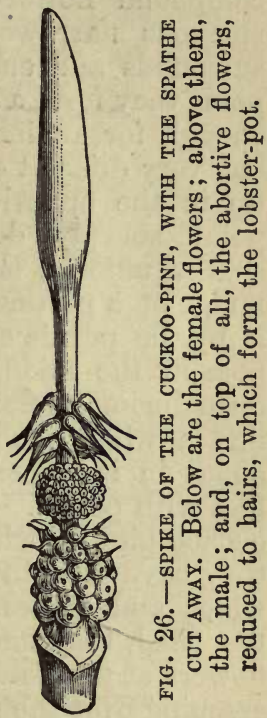
Above these in a group come the male flowers, equally devoid of calyx or corolla, and each consisting of a single stamen. Above these again come abortive or misshapen flowers, each of which has been reduced to a single downwardpointing hair. I will explain first what is the 
use of these flowers in the cuckoo-pint as it stands to-day, and then I will go back to consider by what steps the plant came to develop them.

The upper flowers, which look like hairs, and point all downwards, occupy a place in the compound flower-head just opposite the conspicuous narrowed part of the spathe which surrounds and encloses them. At this narrow point they form a sort of lobster-pot. It is easy enough for an insect to creep down past them, but very difficult or impossible for him to creep up in the opposite direction, as all the hairs point sharply downward. Now, when the spathe unfolds, large numbers of a very small midge of a particular species are attracted into it by the purple club which rises like a barber's pole in the middle. If you cut a cuckoo-pint open during its flowering period you will always find a whole mob of these wee flies, crawling about in it vaguely, and covered from head to foot with pollen. They have come from another cuckoo-pint which they previously visited, and they have brought the pollen with them on their wings and bodies. But when they first reach the head, they find no pollen there; the female flowers at the bottom ripen first, and the midges, creeping over the sensitive surface of these, fertilise them with pollen from the last plant they entered. Finding nothing to eat, if they could they would crawl out again; but they can't, for the lobster-pot hairs prevent them. So they stop on perforce, having unwittingly fertilised the female flowers, but received themselves as 
yet no reward for their trouble. By and by, however, after all the female flowers have been duly fertilised, the males above begin to ripen. When the stamens reach maturity, they shower down a whole flood of golden pollen on the expectant midges. Then the midges positively roll and revel in the flood, eating all they can, but at the same time covering themselves all over with a dust of pollen-grains. As soon as the pollen is all shed, the downward-pointing hairs wither away; the lobster-pot ceases to act; and the midges are at liberty to fly away to another plant, where they similarly begin to fertilise the female flowers. Observe that, if the stamens were the first to ripen here, the pollen would fall on the stigmas of the same plant, but that, by making the stigmas be the first to mature, the cuckoo-pint secures for itself the desired end of cross-fertilisation.

In this case it is an interesting fact that all the stages which led to the existing arrangement of the flowers still remain visible in other plants for us. These very reduced little blossoms of the cuckoo-pint, consisting each of a single carpel or a single stamen, are yet the descendants of perfect blossoms, which had once a regular calyx and corolla. Near relations of the cuckoo-pint live in Europe and Africa to this day, which recapitulate for us, as it were, the various stages in its slow evolution. Some, the oldest in type, have a calyx and corolla, green and inconspicuous, with six stamens inside them, enclosing a two or three-celled ovary. These are still essentially lilies in structure. But they have the 
flowers clustered, as in cuckoo-pint, on a thick club-stem, and they have an open spathe, which more or less protects them. Our English sweetsedge is still at this stage of evolution. The marsh-calla of Northern Europe and Canada, on the other hand, has a handsome white spathe to attract insects, while its separate flowers, still both male and female together, have each six stamens and a single ovary. But they have lost their perianth. The common white arum or "calla lily" of cottage gardens has a bright yellow spike in its midst, and if you look at it closely you will see that this spike consists entirely of a great cluster of stamens, thickly massed together. The top of the spike is entirely composed of such golden stamens, but lower down you will find ovaries embedded here and there among them, each ovary as a rule surrounded by five or six stamens. Lastly, in the cuckoo-pint the lower flowers have lost their complement of stamens altogether, while the upper ones have similarly lost their ovaries ; moreover, a few of the topmost have been converted into the curious lobster-pot hairs which assist, as I have shown you, in the work of fertilisation. We have here a singular and instructive example of what may be described as retrograde development.

And now we must go on to those modes of fertilisation which are effected by agencies other than insects. 


\section{CHAPTER IX.}

\section{THE WIND AS CARRIER.}

ALL flowers do not depend for fertilisation upon insects. In many plants it is the wind that serves the purpose of common carrier of pollen from blossom to blossom.

Clearly, flowers which lay themselves out to be fertilised by the wind will not be likely to produce the same devices as those which lay themselves out to be fertilised by insects. Natural selection here will favour different qualities. Bright-coloured petals and stores of honey will not serve to allure the unconscious breeze; such delicate adjustments of part to part as we saw in the case of bee and blossom will no longer be serviceable. What will most be needed now is quantities of pollen; and that pollen must hang out in such a way from the cup as to be easily dislodged by passing breezes. Hence wind-fertilised flowers differ from insect-fertilised in the following particulars. They have never brilliant corollas or calyxes. The stamens are usually very numerous; they hang out freely on long stalks or filaments; and they quiver in the wind with the slightest movement. On the other hand, the stigmas are feathery and protrude far from the flower, so as to catch every passing grain of pollen. More frequently than among the insect-fertilised section, the sexes are separated on different plants or isolated in distinct masses on neighbouring branches. But 
numerous devices occur to prevent self-fertilisation.

You must not suppose, again, that the windfertilised plants form a group by themselves, distinct in origin from the insect-fertilised, as the three-petalled group is distinct from the five-petalled. On the contrary, wind-fertilised kinds are found abundantly in both great groups; it is a matter of habit; so much so that sometimes a type has taken first to insect-fertilisation and then to wind-fertilisation, with comparatively slight differences in its external appearance. Closely related plants often differ immensely in their marriage customs; each has varied in the way that best suited itself, according as insects or breezes happened to serve it most readily. In my own opinion all windfertilised plants are the descendants of insectfertilised ancestors; but I do not know whether in this belief my ideas would be accepted by most moảern botanists.

As a first example of wind-fertilised flowers, I will take the common dog's mercury, a wellknown English wayside flower, frequent in copses and hedgerows, and one of the very earliest to blossom in spring. In this species the males and females grow on separate plants. They have each a calyx of three sepals (two more being suppressed, for they belong by origin to the fivefold division). The males have ten or twelve stamens apiece, which hang out freely with long stalks to the breeze. The females have a two-chambered ovary, with rudiments or relics of some two or three 
stamens by its side, showing that they are descended from earlier combined male-andfemale ancestors. The relics, however, consist of mere empty stalks or filaments, without any pollen-sacks. Of course there are no petals. Male and female plants grow in little groups not far from one another ; and the pollen, which is dry and dusty, is carried by the wind from the hanging stamens of the males to the large and salient stigma of the female flowers.

A still better example of a windfertilised blossom is afforded us by the common English salad - burnet, pretty little weed, very frequent on close-cropped chalk downs (Fig. 27). Here the individual flowers are extremely small, and they are crowded into a sort of mop-
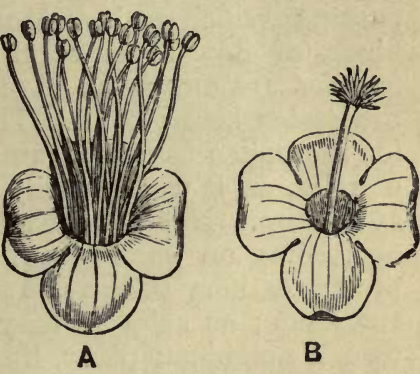

FIG. 27.-A, MaLe, AND B, FEMaLe FLOWER OF SALAD-BURNET, VERY MUCH MAGNIFIED. The flowers grow together in little tassellike heads.

like head at the top of the stem. They have lost their petals, which are now of no use to them; but they retain a calyx of four sepals, to represent the original five still found among their relations. For salad-burnet, in spite of its inconspicuousness, belongs to the family of the roses, and we can still trace in this order a regular gradation from handsome flowers like the dog-rose, through 
smaller and smaller blossoms like the strawberry and the potentilla, to green petalless types like lady's-mantle and parsley-piert, or, last of all, to wind-fertilised blossoms like those of the saladburnet. In the male flowers the very numerous stamens hang out on long thread-like stalks from the wee green cup, so that the wind may readily catch and carry the pollen: in the female blossoms the stigma is divided into plume-like brushes, which readily entrap any passing pollen-grain. Moreover, though both kinds of flower grow on the same head, the females are mostly at the top of the bunch, and the males below them. This makes it difficult for the pollen from the same head to fertilise the females, as it would easily do if the males were at the top. Nor is that all ; the female flowers open first on each head, and hang out their pretty feathery stigmas to the breeze that bends the stem; as soon as they have been fertilised from a neighbour plant, the males in turn begin to open, and shed their pollen for the use of other flowers. In salad-burnet, however, the division of the sexes into separate flowers has not become a quite fixed habit; for, though most of the blossoms are either maleor female only, as shown in the figure, we often find a cup here and there which contains both stamens and pistil together.

I have already told you that in many plants the calyx helps the corolla as an advertisement for insects; and sometimes, as in the marshmarigold and the various anemones, where there are no petals at all, it becomes so brilliant as to 
be mistaken for petals by all but botanists. One way in which such a substitution often happens is shown us by the great burnet, which is a close relation of the salad-burnet. This plant, after having acquired the habit of wind-fertilisation, has taken again at last to insect marriage. Having lost its petals, however, it can't sasily redevelopthem; so it has had instead to make its calyx purple. The plant as a whole closely resembles the saladburnet; but the flowers are rather different; the stamens no longer hang out of the calyx; the calyx cup is more tubular; and the stigma is shortened to a little sticky knob, instead of being divided into feathery fringes. These dif-

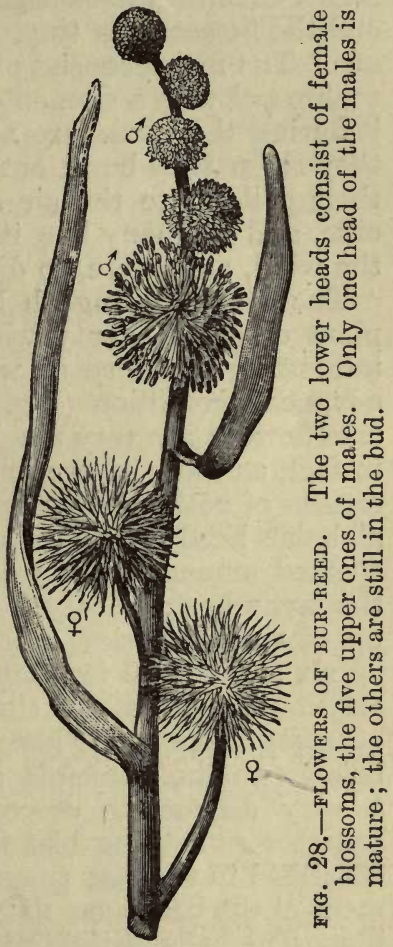
ferences are all very characteristic of the contrast between wind and insect-fertilisation.

The common nettle supplies us with an excel- 
lent example of another form of wind-fertilisation, carried to a still higher pitch of development. Here the sexes grow on different plants, and the flowers are tiny, green, and inconspicuous. The males consist of a calyx of four sepals, each sepal with a stamen curiously caught under it during the immature stage. But as soon as they ripen they burst out elastically, and shoot their pollen into the air around them. In this case, and in many like it, the plant itself helps the wind, as it were, to disseminate its pollen.

The common English bur-reed is a waterside plant of great beauty which shows us another interesting instance of wind-fertilisation in an advanced condition (Fig. 28). Here the separate flowers are very much reduced-as simple, in fact, as those of the cuckoo-pint. The males consist of nothing but stamens, gathered in close globular heads, with a few small scales interspersed among them, which seem to represent the last relics of a calyx. The females are made up of single ovaries, each surrounded by three or six scales, still forming a simple rudimentary calyx. They, too, are clustered in round heads or masses on antler-like branches. The plant belongs to the threefold group, and represents a very degenerate descendant of a primitive ancestor something like the arrowhead already described in the last chapter. But the arrangement of the heads on the stem is very interesting. The balls at the top are entirely composed of male flowers; those at the bottom are exclusively female. The female flowers ripen first, and receive pollen by aid of the wind from some 
other plant that grows close by them. As soon as they have begun to set their seeds the stigmas wither, and then the male flowers open in a bright yellow mass, the stalks of their stamens lengthening out as they do so, and allowing the wind to carry the pollen freely. Here, although the males are above, the peculiar arrangement by which the females ripen first makes it practically impossible for the flowers to be fertilised by pollen from their immediate neighbours.

The devices for wind-fertilisation, however, are on the whole less interesting than those for insect-fertilisation, so I shall devote little more space to describing them. I will only add that two great classes of plants are habitually windfertilised: one includes the majority of forest trees; the other includes the grasses, sedges, and many other common meadow plants.

The wind-fertilised forest trees belong for the most part to the fivefold group, and have their flowers, as a rule, clustered together into hanging and pendulous bunches, which we call catkins. It is obvious why trees should have adopted this mode of fertilisation, because they grow high, and it is easy for the wind to move freely through them. For this reason, most catkin-bearing trees flower in early spring, when winds are high, and when the trees are leafless; because then the foliage doesn't interfere with the proper carriage of the pollen. In summer the leaves would get in the way; the pollen would fall on them; and the stigmas would be hidden. Most catkins are long, and easily 
moved by the wind; they have numerous flowers in each, and they shake out enormous quantities of pollen. This you can see for yourself by shaking a hazel branch in the flowering season, when you will find yourself covered by a perfect shower of pollen.

In hazel (Fig. 29) the male and female flowers grow on the same tree, but are most different to look at. You would hardly take
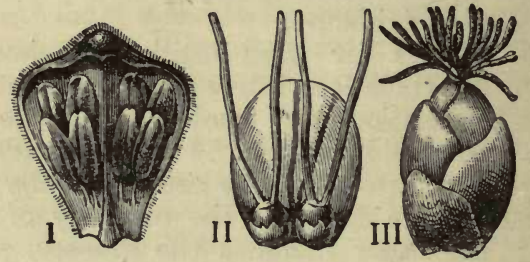

FIG. 29. -FLOWERS OF THE HAZEL. I, a single male flower, removed from a catkin. II, a pair of female flowers. III, a female catkin.

them for corresponding parts of the same species. The male flowers are grouped in long sausage-shaped catkins, each blossom covered with a tiny brown scale, and all arranged like tiles on a roof against the cold of winter. There are about eight stamens to each blossom, with little trace of a calyx or corolla. But the females are grouped in funny little buds, like crimson tufts, well protected by scales; they consist of the future hazel-nut, with a red style and feathery stigma projecting above to catch the pollen. Here the flowers are very little like 
the regular types with which we are familiar; yet intermediate cases help to bridge over the gap for us.

For example, in the alder we get a type which seems to stand half-way between the nettle and the hazel (so far, I mean, as the arrangement of the flower is concerned, for otherwise the nettle belongs to a quite different family). The male and female catkins of the alder grow on the same tree; the males consist of numerous clustered flowers, three together under a scale, which nevertheless, when we take the trouble to pick them out and examine them with a pocketlens, are seen to resemble very closely the male flowers of the nettle. Each consists of a fourlobed calyx, with four stamens opposite the sepals. The female flowers have degenerated still further, and consist of little more than a scale and an ovary.

Other well-known wind-fertilised, catkin-bearing trees are the oak, the beech, the birch, and the hornbeam. But the willows, though they bear catkins, and were once no doubt windfertilised, have now returned once more to insect-fertilisation, as you can easily convince yourself if you stand under a willow tree in early spring, when you will hear all the branches alive with the buzzing of bees, both wild and domestic. Nevertheless, the willow, having once lost its petals, has been unable to develop them again. Still, its catkins are far handsomer and more conspicuous than those of its wind-fertilised cousins, owing to the pretty white scales of the female bunches, and the 
numerous bright yellow stamens of the males. It is this that causes them to be used for "palm" in churches on Palm Sunday. The male and female catkins grow on different trees, so as to ensure cross-fertilisation, and the difference between the two forms is greater perhaps than in almost any other plant, the males consisting of two showy stamens behind a winged scale, and the females of a peculiar woolly-looking ovary.

Even more important is the great wind-fertilised group of the grasses, to which belong by far the most useful food-plants of man, such as wheat, rice, barley, Indian corn, and millet.

Grasses are for the most part plants of the open wind-swept plains, and they seem naturally to take therefore to wind-fertilisation. Their flowers are generally small, clustered into light spikes or waving panicles, and hung out freely to the breeze on slender and very movable stems, so as to yield their pollen to every breath of air that passes. Moreover, the plants as a whole are slender and waving, so that they bend before the breeze in the mass, as one often sees in a meadow or cornfield. Thus the grasses are almost the pure type of wind-fertilised plants; certainly they have carried further than any other race the devices which render windfertilisation more certain.

On this account they are so complicated and varied that I will not attempt to describe them in detail. I will only say that grasses are descendants of the threefold flowers, and in all probability degenerate lilies. Their individual 
blossoms usually consist of a very degraded calyx $(d$ and $e$ ) of two sepals (one of which represents a pair that have coalesced, Fig. 30). Inside these sepals come two very minute white petals ( $c$ and $c$ ); the third has disappeared, owing to pressure one-sidedly. The petals can
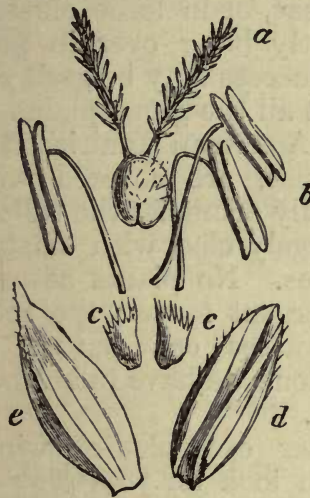

FIG. 30.-A FLOWER OF WHEAT, WITH ITS PARTS DIVIDED : $a$, the carpel and stigmas; $b$, the stamens; $c$, the petals, very minute; $d$ and $e$, the calyx.

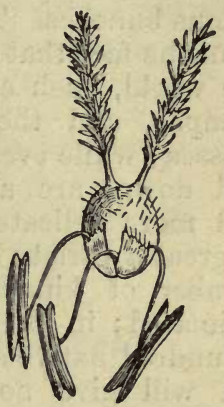

FIG. 31.-FLOWER OF W HEAT, WITH THE CALYX OF TWO CHAFFY SCALES REMOVED. This shows the arrangement of petals, stamens, and ovary.

scarcely be seen without the aid of a pocketlens. Next come three stamens $(b)$, the only part of the flower which still preserves the original threefold arrangement. Last of all we get the ovary $(a)$, of one carpel, one seeded, but with two feathery stigmas, which were once 
three. In a very few large grasses, such as the bamboos, the threefold arrangement is much more conspicuous. As a rule the stamens of grasses hang out freely to the wind, and the stigmas are feathery and most graceful in outline (Fig. 31). The flowers are usually collected in spikes like that of wheat, or in loose clusters like oats; they frequently hang over in pendulous bunches. Their success may be gathered from the fact that almost all the great plains in the world, such as the American prairies, the Pampas, and the Steppes, are covered with grasses; while even in hilly countries the valleys and downs are also largely clad with smaller and more delicate species. No plants assume so great a variety of divergent forms; the total number of kinds of grasses can hardly be estimated; in Britain alone we have more than a hundred native species.

I will give no further examples of windfertilised flowers. If you look for yourself you can find dozens on all sides in the fields around you. They may almost always be recognised by these two marked features of the hanging stamens and the feathery stigma.

Before I pass on to another subject, however, I ought to mention that by no means all flowers are regularly cross-fertilised. There are some degraded types in which self-fertilisation has become habitual. In these plants, which are usually poor and feeble weeds like groundsel and shepherd's purse, the stamens bend round so as to impregnate the pistil in the same blossom. In other less degraded cases the 
flower is occasionally cross-fertilised by insect visits; but if no insect turns up in time, the stamens, even in handsome and attractive blossoms, often bend round and impregnate the pistil. A very good example of this is seen in our smaller English mallow, which has large mauve flowers to attract insects; but should none come to visit it, the stamens and stigmas at last intertwine, and self-fertilisation takes place, for want of better. Still, as a general rule, it holds good that self-fertilisation belongs to scrubby and degraded plants; it is only adopted as a last resort when all other means fail by the superior species.

\section{CHAPTER X.}

HOW FLOWERS CLUB TOGETHER.

IN the preceding chapters I have dealt for the most part with individual flowers; I have spoken of them separately, and of the work they do in getting the seeds set. Incidentally, however, it has been necessary at times to touch slightly upon the way they often mass themselves into heads or clusters for various purposes; and we must now begin to consider more seriously the origin and nature of these co-operative societies.

Very large flowers, like the water-lily, the tulip, the magnolia, the daffodil, are usually solitary; they suffice by themselves to attract in sufficient numbers the fertilising insects. 
But smaller flowers often find it pays them better to group themselves into big spikes or masses, as one sees, for example, in the foxglove and the lilac. Such an arrangement makes the mass more conspicuous, and it also induces the insect, when he comes, to fertilise at a single visit a large number of distinct blossoms. It is a mutual convenience; for the bee or butterfly, it saves valuable time; for the plant, it ensures more prompt and certain fertilisation. In many families, therefore, we can trace a regular gradation between large and almost solitary flowers, through smaller and somewhat clustered flowers, to very small and comparatively crowded flowers. Thus the largest lilies are usually solitary or grow at best three or four together, like the lilium auratum; in the tuberose and asphodel, where the individual blossoms are smaller, they are gathered together in big upright spikes; in the hyacinth, the clustering is closer still; while in wild garlic, grape-hyacinth, and star-ofBethlehem, the arrangement assumes the form of a flat-topped bunch or a globular cluster. Of course, small flowers are sometimes solitary, and large ones sometimes clustered; but as a general rule the tendency is for the big blossoms to trust to their own individual attractions, and for the little ones to feel that union is strength, and to organise accordingly.

Botanists have invented many technical names for various groupings of flowers in particular fashions, with most of which I will not trouble you. It will be sufficient to recall 
mentally the very different way in which the flowers are arranged in the lily-of-the-valley, the foxglove, the Solomon's seal, the heath; the scabious, the cowslip, the sweet-william, the forget-me-not, in order to see what variety natural selection has produced in all these matters. Two instances must serve to illustrate their mode of action. The foxglove grows in hedgerows and thickets, and turns its one-sided spike towards the sun and the open; its flowers open regularly from below upward, and are fertilised by bees, who enter the blossoms, and whose body is beautifully adapted to come in contact, first with the stamens, and later with the stigma. (Examine this familiar flower for yourself in the proper season.) In the forgetme-not, on the other hand, the unopened flowers are coiled up like a scorpion's tail; but as each one opens, the stem below it lengthens and unrolls, so that at each moment the two or three flowers just ready for fertilisation are displayed conspicuously at the top of the apparent cluster.

There are two forms of cluster, however, so specially important that I cannot pass them over here without some words of explanation. These are the umbel and the head, both of frequent occurrence. An umbel is a cluster in which the flowers, standing on separate stalks, reach at last the same level, so as to form a flat-topped mass, like the surface of a table. An immense family of plants has very small flowers arranged in such an order; they are known as umbellates, and they include hemlock, 
fool's parsley, cow-parsnip, carrot, chervil, celery, angelica, and samphire. In other

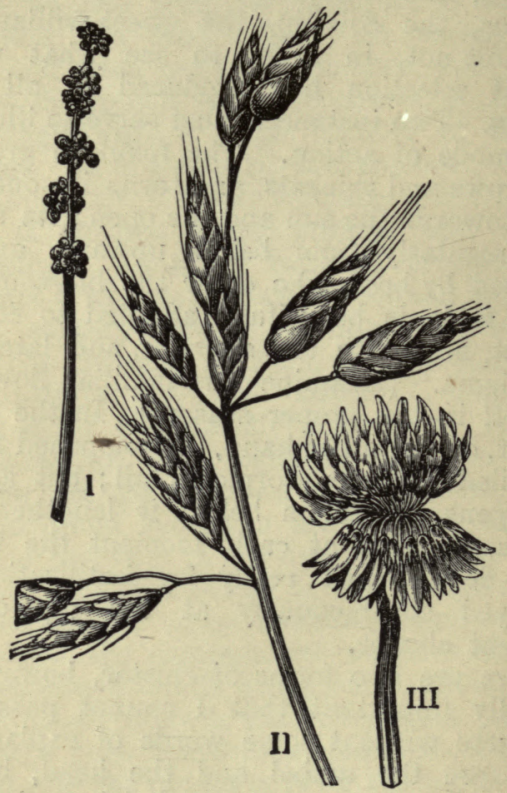

FIG. 32.-CLUSTERS OF FLOWERS. I, spike of mercury, green, wind-fertilised. II, panicle of a grass (brome), green, wind-fertilised. III, head of Dutch clover, the upper flowers unvisited as yet by insects; the lower fertilised, and turning down to make room for their neighbours.

families the same form of cluster is seen in 
ivy and garlic. A head, again, is a cluster in which the individual flowers are set close on very short stalks or none at all in a round ball or a circle. Clover and scabious are excellent examples of this sort of co-operation.

If you examine a head of common white Dutch clover (Fig. 32, iii.), you will see for yourself that it is not, as you might suppose, a single flower, but a thick mass of small white pea-like blossoms, each on a stalk of its own, and each provided with calyx, corolla, stamens, and pistil. They are fertilised by bees ; and as soon as the bee has impregnated each blossom, it turns down and closes over, so as to warn the future visitor that he has nothing to expect there. The flowers open from below and without, upward and inward; and there is always a broad line between the rifled and fertilised flowers, which hang down as if retired from business, and the fresh and upstanding virgin blossoms, which court the bees with their bright corollas. Sometimes you will find a head of clover in which all the flowers save one have already been fertilised; and this one, a solitary old maid as it were, stands up in the centre still waiting for the bees to come and fertilise it.

By far the most interesting form of head, however, is that which occurs in the daisy, the sunflower, the dandelion, and their allies, where the club or co-operative society of united blossoms so closely simulates a single flower as to be universally mistaken for one by all but botanical observers. To the world at large a daisy or a dahlia is simply a flower; in reality 
it is nothing of the sort, but a city or com. munity of distinct flowers, differing widely from one another in structure and function, but all banded together in due subordination for the purpose of effecting a common object. There is a vast and very varied family of such united flowers, known as the composites; it stands at the head of the fivefold group of flowering I plants, as the orchids stand at the head of the

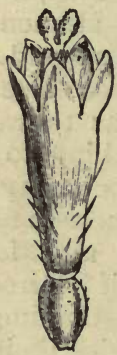

FIG. 33. - SINGLE FIORET FROM THE CENTRE OF A DAISY.

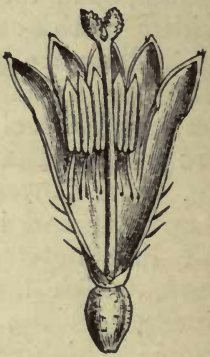

FIG. 34. - SINGLE FLORET FROM THE CENTRE OF A DAISY, WITH THE COROLLA OPENED, MUCH ENLARGED.

threefold ; and it is so widely spread, it includes so large a proportion of the best-known plants, and it fills so great a space in the vegetable world generally, that I cannot possibly pass it over even in so brief and hasty a history as this of the development of plants on the surface of our planet.

If you pick a daisy you will think at first sight it is a single flower. But if you look 
closer into it you will see it is really a great group of flowers - a compound flower-head, composed of many dozen distinct blossoms or florets, as we call them (Fig. 33). These, however, are not all alike. The florets in the centre, which you took no doubt at first sight for the stamens and pistils, are small yellow tubular blossoms, each with a combined corolla of five lobes, little or no visible calyx, five stamens united in a ring round the style, and a pistil consisting of an inferior ovary, with a style divided above into a twofold stigma (Fig. 34). Here we have clear evidence that the plant belongs by origin to the five-petalled group ; it rather resembles the harebell, in the plan of its flower, on a much smaller scale; but it has almost lost all trace of a separate calyx, it has its five petals united into a tubular corolla, it has still its original five stamens, but its carpels are now reduced to one, with a

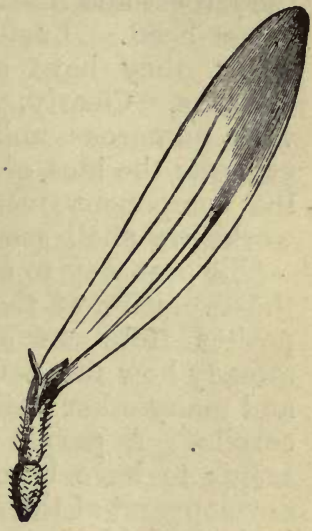

FIG. 35.-SINGLE FLORET FRONT THE RAY OF A DAISY, PINK AND WHITE, WITH AN OVARY, BUT NO STAMENS. single seed, though traces of an earlier intermediate stage, when the carpels were two, remains even yet in the divided stigma.

So much for the inner flowers or florets in the daisy. The outer ones, which you took at first 
no doubt for petals, are very different indeed from these central blossoms. They have an extremely curious long, strap-shaped corolla (Fig. 35), open down the side, but tubular at its base, as if it had been split through the greater part of its length by a sharp penknife. Instead of being yellow, too, these outer florets are white, slightly tinged with pink, and they form the largest and most attractive part of the whole flower-head. Furthermore, they are female only; they have a style and ovary, but no stamens. Clearly, we have here a flower-head with numerous unlike flowers, which at once suggests the idea of a division of labour between the component members. How this division works we shall see in the sequel.

The best way to see it is to follow up in detail the evolution of the daisy and the other composites from an earlier ancestor. We saw already how the petals combined in the harebell and many other flowers so as to form a tubular corolla. A purple flower of some such type seems to have been the starting-point for the development of the great composite family. The individual blossoms in the common ancestral form seem to have been small and numerous; and, as often happens with small flowers, they found that by grouping themselves together in a flat head they succeeded much better in attracting the attention of the fertilising insects. Many other tubular flowers that are not composites have independently hit upon the same device; such are the scabious, the devil's-bit, the sheep's-bit, and the rampion. But these 
flowers differ from the true composites in two or three particulars. In the first place, each tiny flower has a distinct green calyx, of five sepals; while the composites have none, or at least a degraded one. In the second place, the stamens are free, while in the composites they have united in a ring or cylinder. In the third place, the ovary is divided into from two to five cells, a reminiscence of the original five distinct carpels; whereas in the composites the ovary is always single and one-seeded. In all these respects, therefore, the composites are later and more advanced types than, say, the sheep's-bit, which is a flower-head composed of very tiny harebells.

The composites, then, started with florets which had little or no calyx, the sepals having been converted into tiny feathery hairs, used to float the fruit (as in thistledown and dandelion), about which we shall have more to say in a future chapter. They had a corolla of five purple petals, combined into a single tube. Inside this again came five united stamens, and in the midst of all an inferior ovary with a divided stigma. Hundreds of different kinds of composites now existing on the earth retain to this day, in the midst of the greatest external diversity, these essential features, or the greater part of them.

You may take the thistle as a good example of the composite flowers in an early and relatively simple stage of development (Fig. 36). Here the whole flower-head resembles a single large purple blossom. To increase the resemblance, 
it has below it what seems at first sight to be a big green calyx of very numerous sepals. What is this deceptive object? Well, it is called an involucre, and it really acts to the compound

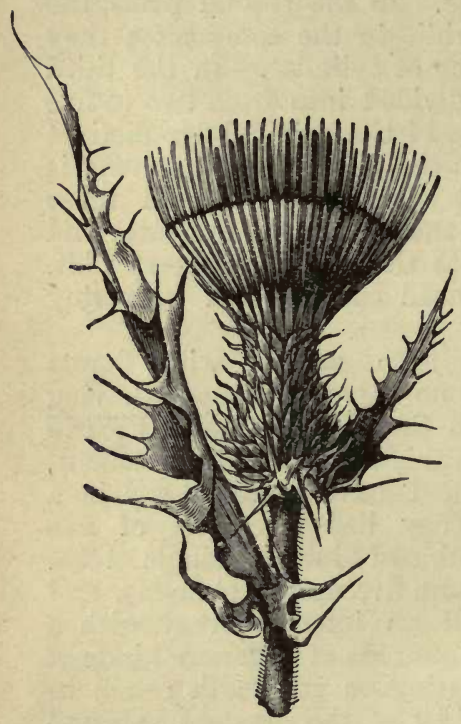

FIG. 36.-FLOWER - HEAD OF A THISTLE, CONSISTING OF VERY NUMEROUS PURPLE FLORETS, ALL EQUAL AND SIVILAR. flower-head very much as the calyx acts to the single blossom. The florets having got rid of their separate calyxes, the flower-head provides itself with a cup of leaves (technically called bracts), which protect the unopened head in its early stages, and serve to keep off ants or other creeping insects exactly as a calyx does for the single flower. Inside this involucre, again, all the florets of the thistle are equal and similar. Each has a tiny calyx, hardly recognisable as such, made up of feathery hairs which cap the inferior ovary. Within this fallacious calyx, once more, the floret has a purple corolla 
of five petals, united into a tube. Then come the five united stamens, and the pistil with its divided stigma. This is the simplest and central form of composite, from which the others are descended with various modifications.

To this central type belong a large number of well-known plants, both useful and ornamental, though more particularly deleterious. Among them may be mentioned the various thistles, such as the common thistle, the milk thistle, the Scotch thistle, and so forth, most of which have their involucres, and often their leaves as well, extremely prickly, so as to ward off the attacks of goats and cattle. The burdock, the artichoke, the saw-wort, and the globe-thistle also belong to the same central division. Among these earlier composites, however, there is one group, that of the centauries, which leads us gradually on to the next division. Our commonest centaury in Britain (known to boys as hardheads) has all the florets equal and similar, and looks in the flower very much like a thistle. But one of its forms, and most of the cultivated garden centauries, have the outer florets much larger and more broadly open than the central ones, so that they form an external petal-like row, which adds greatly to the attractiveness of the entire flowerhead. Of this type, the common blue cornflower is a familiar example. Clearly the plant has here developed the outer florets more than the inner ones in order to make them act as extra special attractions to the insect fertilisers.

The more familiar type of composites so much cultivated in gardens carries these tactics a step 
further. We saw reason to believe in a previous chapter that petals were originally sepals, flattened and brightly coloured, and told off for the special attractive function. Just in the same way the ray-florets of the daisy, the sunflower, the single dahlia, and the aster are florets which have been flattened and partially or wholly sterilised in order to act as allurements to insects. The ray-floret acts for the compound flower-head as the petal acts for the individual blossom.

In many other families of plants besides the composites we get foreshadowings, so to speak, of this mode of procedure. The outer flowers of a cluster, be it head or umbel, are often rendered larger so as to increase the effective attractiveness of the whole; and sometimes they are sacrificed to the inner ones by being made neuter or sterile, that is to say, being deprived of stamens and pistil. Thus in cow-parsnip, which is a member of the same family as the carrot and the hemlock, the outer flowers of each umbel are much larger than the central ones, while in the wild guelder-rose the central flowers alone are fertile, the outer ones being converted into mere expanded white corollas with no essential floral organs. But it is the composites that have carried this process of division of labour furthest, by making the rayflorets into mere petal-like straps, which do no work themselves, but simply serve to attract the fertilising insects to the compound flower-head.

An immense number of these composites with flattened ray-florets grow in our fields or are 
HOW FLOWERS CLUB TOGETHER.

cultivated in our gardens. In the simpler among them, such as the sunflower, the cornmarigold, the ragwort, and the golden-rod, both ray-florets and central florets are simply yellow. But in others, such as the daisy, the ox-eye daisy, the aster, and the camomile, the rayflorets differ in colour from those of the centre; the latter remain yellow, while the former become white, or are tinged with pink, or even flaunt forth in scarlet, crimson, blue, or purple. Of this class one may mention as familiar instances the dahlia, the zinnia, the Michaelmas daisies, the cinerarias, and the pretty coreopsis so common in our gardens. Gardeners, however, are not content to let us admire these flowers as nature made them. They generally "double" them-that is to say, by carefully selecting certain natural varieties, they produce a form in which all the florets have at last become neutral and strap-shaped. This is well seen in the garden chrysanthemum, where, however, if you open the very centre of the doubled flower-head, you will generally find in its midst a few remaining fertile tubular blossoms. The same process is also well seen in the various stages between the single and the double dahlia. Such "double" composites can set little or no seed, and are therefore from the point of view of the plant mere abortions. Nor are they beautiful to an eye accustomed to the ground plan of floral architecture. Remember, of course, that what we call " a double flower" in a rose, a buttercup, or any other simple blossom is one in which the stamens have been converted into 
supernumerary and useless petals; while in a composite it is a flower-head in which the central florets have been converted into barren ray-florets. In either case, however, the result is the samethe flowers are rendered abortive and sterile.

Nature's way is quite different. Here is how she manages the fertilisation of one of these ray. bearing composites-say for example the sunflower, where the individual florets are quite big enough to enable one to follow the process with the naked eye. The large yellow rays act as advertisements; the bee, attracted by them, settles on the outer edge, and fertilises the flowers from without inward. To meet this habit of "his, the florets of the sunflower pass through four regular stages. They open from without inward. In the centre are unopened buds. Next come open flowers, in which the stamens are shedding their pollen, while the stigmas are still hidden within the tube. Third in order, we get florets in which the stamens have withered, while the stigmas have now ripened and opened. Last of all, we get, next to the rays, a set of overblown florets, engaged in maturing their fertilised fruits. The bee thus comes first to the florets in the female stage, which he fertilises with pollen from the last plant be visited; he then goes on to florets in the male stage, where he collects more pollen for the next plant to which he chooses to devote his attention. The florets of the sunflower are interesting also for the fact that, unlike most composites, they still retain obvious traces of a true calyx. 
The composites which produce purple or blue ray-florets to attract insects are in some ways the highest of their class. Still, there is another group of composites which has proceeded a little further in one direction; and that is the group which includes the dandelions. In these heads all the florets alike have become strapshaped or ray-like; but they differ from the double composites of the gardeners in this, that each floret still retains its stamens and pistil. The composites of the dandelion group are chiefly weeds like the hawkbit and the sowthistle. A few are cultivated as vegetables, such as lettuce, salsify, chicory, and endive; fewer still are prized for their flowers for ornamental purposes, such as the orange hawkweed. The prevailing colour in this class is yellow, and the devices for insect-fertilisation are not nearly so high as in the ray-bearing group. I regard them as to a great extent a retrograde tribe of the composite family.

In this chapter I have dealt chiefly with the co-operative clubbing together of insect-fertilised flowers, for purposes of mutual convenience ; but you must not forget that similar clubs exist also among the wind-fertilised blossoms in quite equal profusion. Such are the catkins of forest trees, the panicles of grasses, the spikes of sedges, and the heads of the black-cap rush and many-other water-plants. Some of these, such as the burreed, we have already considered.

Lastly, I ought to add that where the flowers themselves are inconspicuous, attention is often called to them by a bright-coloured leaf or group 
of leaves in their immediate neighbourhood. We saw an instance of this in the great white spathe or folding leaf which encloses the male and female flowers of the "calla lily." In the greenhouse poinsettia the individual flowers are tiny and unnoticeable; but they are rich in honey, and round them has been developed a great bunch of brilliant scarlet leaves which renders them among the most decorative objects in nature. A lavender that grows in Southern Europe has dusky brown flowers; but the bunch is crowned by a number of mauve or lilac leaves, hung out like flags to attract the insects. A scarlet salvia much grown in windows similarly supplements its rather handsome flowers by much handsomer calyxes and bracts which make it a perfect blaze of splendid colour. It doesn't matter to the plant how it produces its effect; all it cares for is that by hook or by crook it should attract its insects and get itself fertilised.

\section{CHAPTER XI.}

WHAT PLANTS DO FOR THEIR YOUNG.

AFTER the flower is fertilised it has to set its seed. And after the seed is set the plant has to sow and disperse it.

Now, the fruit and seed form the most difficult part of technical botany, and I will not apologise for treating them here a little cavalierly. I will tell you no more about them than it is actually 
necessary you should know, leaving you to pursue the subject if you will in more formal treatises.

The pistil, after it has been fertilised and arrived at maturity, is called the fruit. In flowers like the buttercup, where there are many carpels, the fruit consists of distinct parts, each one-seeded little nuts in the meadow buttercup, but many-seeded pods in the marshmarigold and the larkspur. Where the carpels have combined into a single ovary, we get a many-chambered fruit, as in the poppy, which consists, when cut across, of ten seed-bearing chambers. Most fruits are dry capsules or pods, either single, as in the pea, the bean, the vetch, and the laburnum ; or double, as in the wallflower and shepherd's-purse; or many-chambered, as in the lily, the wild hyacinth, the poppy, the campion. As a rule the fruit consists of as many carpels or as many chambers as the unfertilised ovary.

Fruits are often dispersed entire, and this is especially true when they contain only one or two seeds. In such instances they sometimes fall on the ground direct, as is the case with most nuts; or else they have wings or parachutes which enable the wind to seize them, and carry them to a distance, where they can alight on unexhausted soil, far away from the roots of the mother plant. Such fruits are common among forest trees. The maples, for example, have a double fruit, often called a $k e y$, which the wind whirls away as soon as the seeds are ready for dispersion (Figs. 37, 38, 39, 
$40,41)$. In the lime, the common stalk of the flowers is winged by a thin leaf; and when the

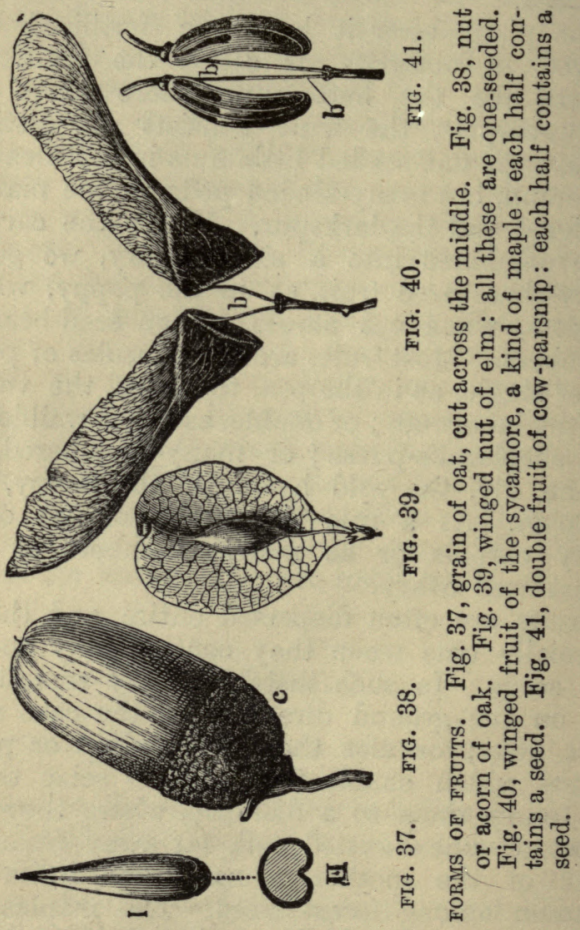

little nuts are ripe the wind detaches them and carries them away by means of this joint parachute. In the birch, elm, and ash the fruit is 
WHAT PLANTS DO FOR THEIR YOUNG. 165

a one-seeded nut, with its edge produced into a leathery or papery wing, which serves to float it.

But more often the fruit at maturity opens and scatters its seeds, as we see in the pea, the wild hyacinth, and the iris. Sometimes the seeds so released merely drop upon the ground, but most often some device exists for scattering them to a distance, so as to obtain the advantage of unexhausted soil for the young seedling. Thus most capsules open at the top, so that the seeds can only drop out when the wind is high enough to carry them to some distance. In the poppyhead the capsule opens by pores at the side, and, if you shake one as it grows, you will find it takes a considerable shaking to dislodge the seeds from the walls of their chamber. Thus only in high winds are the poppy seeds dispersed. In the mouse-ear chickweed the capsule is directed slightly upward at the end for a similar purpose. Sometimes, again, the valves of the fruit open elastically and shoot out the seeds; this device is familiarly known in the garden balsam, and it occurs also in the little English wallcress. The sandbox-tree of the West Indies has a large round woody capsule, which bursts with a report like a pistol, and scatters its seeds with such violence as to inflict a severe wound upon anybody who happens to be struck by them.

Where seeds are numerous, they are oftenest dispersed in some such manner, by the capsule opening naturally and scattering its contents; but where they are few in number, it more 
frequently happens that the fruit does not open, as in the oak or the elm; and when there is only one seed, the fruit and seed become almost

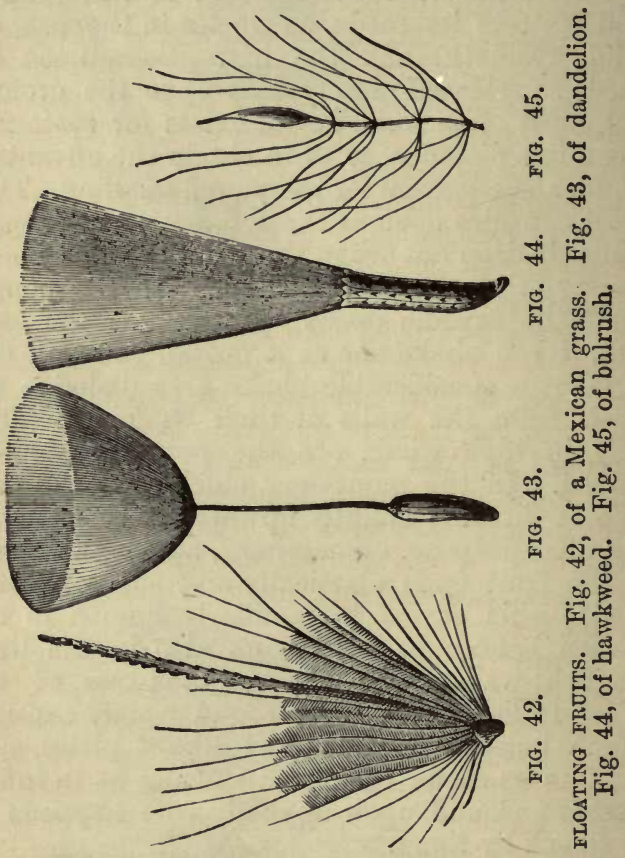

indistinguishable, and are popularly regarded as a seed only. For example, in the pea, we distinguish at once between the pod, which is a fruit containing many seeds, and the pea which 
is one such seed among the many; but in wheat or oats the fruit is small and one-seeded, and its covering is so closely united with the seed as to be practically inseparable. Fruits like these do not open, and are dispersed whole. The fruits of most composites are crowned by the featherlike hairs which represent the calyx, and float on the breeze as thistledown or dandelion-clocks (Figs. 42, 43, 44, 45). John-go-to-bed-at-noon, an English composite of the dandelion type, has a very remarkable and highly-developed parachute of this description. In the anemones and clematis the fruit consists of several distinct one-seeded carpels, each furnished with a long feathery awn for the purpose of floating; our common English clematis or traveller's joy, when in the fruiting condition, is known on this account as "old man's beard." Floating fruits like these, or those of many sedges and grasses, will often be carried by the wind for miles together. A well-known example of this type is the sedge commonly though wrongly described as cotton-grass.

In other instances it is the seed, not the fruit, that is winged or feathered. The pod of the willow opens at maturity, and allows a large number of cottony seeds to escape upon the breeze. The same thing happens in the beautiful rose-bay and the other willow-herbs. Cotton is composed of the similar floating hairs attached to the seeds of a sub-tropical mallowlike tree.

Youx will have observed, however, that not on 
of the fruits which I have hitherto mentioned is a fruit at all in the common or popular acceptation of the word. They are only at best what most people call pods or capsules. A true fruit, as most people think of it, is coloured, juicy, pulpy, sweet, and edible. How did such fruits come into existence, and what is the use of them?

Well, just as certain plants desire to attract insects to fertilise their flowers, so do other plants desire to attract birds and beasts to disseminate their fruits for them. If any fruit happened to possess a coloured and juicy outer coat, or to show any tendency towards the production of such a coat, it would sooner or later be eaten by animals. If the animal digested the actual seed, however, so much the worse for the plant, and we shall see by and by that most plants take great care to prevent their true seeds being eaten and assimilated by animals. But if the seed was very small and tough, or had a stony covering, it would either be passed through the animal's body undigested, or else thrown away by him when he had finished eating the pulpy exterior. So, many plants have acquired fruits of this description-edible fruits, intended for the attraction of birds and animals. As a rule the animals disperse the seeds in the well-manured soil near their own nests or lairs, so that the young plants produced from such fruits start in life under exceptional advantages.

Fruits that seek to attract animals use much the same baits to allure them in the way of 
colour and sweet taste as do the flowers that seek to attract insects. But just as almost any part of the flower may be brightly coloured, so almost any part of the fruit may be sweet and pulpy. Thus we get an astonishing and rather embarrassing variety of special devices in this matter.

A few instances must suffice us. In the raspberry and blackberry the fruit consists of separate carpels, in each of which the outer coat becomes soft and sweet, while the actual seed is hard and nut-like. In the one case the fruit is red, in the other black, but very conspicuous among the green leaves in autumn. These berries are eaten by birds, and their seeds are dispersed in copse or hedgerow. But in the strawberry, which is a near relation of both, with a very similar flower, the actual carpels remain to the end quite small and seed-like; they are the tiny black objects scattered about in pits like miniature nuts over the surface of the ripe berry. Here it is the common receptacle of the fruit that swells out and reddens, the part answering to the central piece which comes out whole in the middle of the raspberry; so that what we eat in the one fruit is the very same part as what we throw away in the other. In the plum, the cherry, and the peach, on the other hand, there is but one carpel, and its outer covering grows soft, sweet, and brightly coloured; while the actual seed, though soft, is contained in a hard and stony jacket, an inner layer of the fruit coat. Here the true seed is what we call the kernel, but it is amply protected by its bone- 
like coverlet. In the apple and pear the ovary is inferior; the fruit is thus crowned by the remains of the calyx; if you cut it across you will find it consists of a fleshy part, which is the swollen stem, enclosing the true fruit or core, with a number of seeds which we call the pips. All these fruits belong to the family of the roses; they serve to show the immense variety of plan and structure which occurs even in closely related species. Other succulent fruits of the same family are the rose-hip, the haw, the medlar, and the nectarine.

Among familiar woodland fruits dispersed by birds I may mention the elderberry, the dogwood, the honeysuckle, the whortleberry, the holly, the cuckoo-pint, the barberry, and the spindle-tree. The white berries of the mistletoe, which is a parasitic plant, are eaten by the missel-thrush, a bird who has a special affection for this particular food. But they are very sticky, and the seeds therefore adhere to the bird's beak and feet. To get rid of them, he rubs them off on the fork of a poplar branch, or in the bark of an apple-tree, which are the exact places where the mistletoe most desires to place itself. Many such close correspondences between bird and fruit exist in nature.

Our northern berries are chiefly designed to be eaten by small birds like robins and hawfinches. But in southern climates larger fruits exist, adapted to the tastes of larger animals such as parrots, toucans, hornbills, fruit-bats, and monkeys. Our own small kinds can generally be eaten whole, like the currant and the 
strawberry; but these large southern fruits have often a bitter or unpleasant or very thick rind, which the birds or monkeys, for whose use they are intended, know how to strip off them. Cases in point are the orange, the lemon, the shaddock, the banana, the pine-apple, the mango, the custard-apple, and the breadfruit. The melon, cucumber, pumpkin, gourd, vegetable marrow, and water-melon are other southern

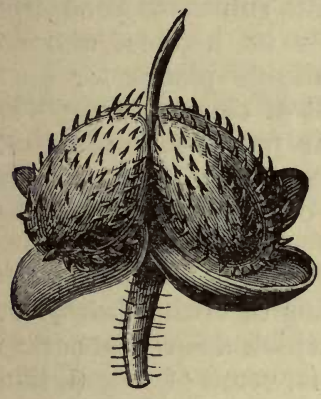

FIG. 46.

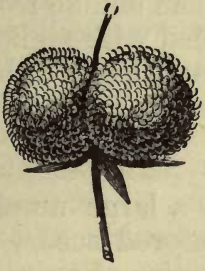

FIG. 47.

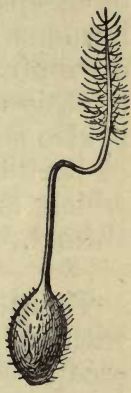

FIG. 48.

ADHESIVE FRUITS. Fig. 46, of houndstongue. Fig. 47, of cleavers. Fig. 48, of herb-bennet.

forms cultivated in the north for the sake of their fruits. In the pomegranate the fruit itself is a dry capsule, but the seeds are each enclosed in a separate juicy coat. The grape is a fruit too well known to require detailed description.

As flowers sometimes club together, so also do fruits. In the mulberry the apparent berry is really made up of the distinct carpels of several separate flowers, which grow together as they 
ripen; while the fig is a hollow stalk, in which numerous tiny fruits, commonly called seeds, are closely embedded.

In all these cases animals act as willing agents in the dispersal of fruits or seeds. But sometimes the plant compels them to carry its seeds against their will. Thus the fruits of the houndstongue (Fig. 46) consist of four small nuts, covered with hook-like prickles, which cling to the coats of sheep or cattle. The beasts rub these annoying burdens off against bushes or hedges, and so disseminate the seeds in suitable places for germination. The double fruit of cleavers (Fig. 47) is also supplied with similar prickles, while that of herb-bennet (Fig. 48) has a long curved awn which makes it catch at once on any passing animal.

There are a large number of fruits, however, with richly stored seeds, which desire rather to escape the notice of animals, some of whom, like squirrels and dormice, try to make their living out of them. These we call nuts. Their tactics are the exact opposite of those pursued by the edible fruits. For the edible fruits strive to attract animals to disperse them; the nuts, on the contrary, having the actual seed richly stored with oils and starches, desire to protect it from being eaten and destroyed. Hence they are generally green when on the tree, so as to escape notice, and brown when lying on the ground beneath it. Cases of these protectivelyarranged fruits, with hard shells and often with nauseous external coyerings (some of which are 
WHAT PLANTS DO FOR THEIR YOUNG. 173

not regarded as nuts in the strict botanical sense), are the walnut, the hazel-nut, the coconut, the chestnut, the acorn, the lime-nut, the almond, and the hickory-nut. In the Brazil nut the seeds (which are what we commonly call the nuts) are enclosed in a solid shell like that of a coco-nut, and are themselves also hard and nutlike. In the chestnut the fruit is a prickly capsule, inside which lie the seeds, which we know as chestnuts.

But why have some plants so many seeds and some so few? Well, the simpler and earlier types produce a very large number of ill-provided seeds, which they turn loose upon the world to shift for themselves almost from the outset. Many of them perish, but a few survive. On the other hand, the more advanced plants, as a rule, produce only a small number of seeds, but each of these is well provided with starches and oils for the growth of the young plant; and as most such survive, any tendency in the direction of laying by food-stuffs would of course be favoured by natural selection. Just so among animals, a codfish produces nearly a million eggs, of which only two or three on an average survive to maturity; while a bird produces half a dozen large and well-stored eggs, and a cow or a horse rarely brings forth more than one calf or foal at a birth. Decrease in the number of seeds is a fair rough test of relative progress.

In nuts, you can see at once, the seeds are very richly stored, and the young plant starts in life, able to draw for a time on these ready- 
made food-stuffs, until its green leaves are in a position to lay by starches and protoplasm in plenty for it. It draws by degrees upon the accumulated materials. Such plants are like capitalists who can start their sons well in life with a good beginning. On the other hand, the poppy has to set out on its career with a very poor equipment; it must begin picking up carbonic acid for itself almost from the outset. Such plants are like street arabs, compellea to shift as best they can from their earliest days. A coco-nut starts so well that the young palm can grow to a considerable size without working for itself; so to a less degree do walnuts, hazels, and oak-trees. Among other sets of plants there are two great groups which have especially learned to lay by food for their seedlings - the peaflower family and the grasses. In both these cases the young plants start in life with exceptional advantages. But what will feed a young plant will also feed an animal. Hence men live largely in different countries off such richly-stored seeds-among nuts, the coco-nut, the chestnut, and the walnut; among peaflower seeds, the pea, the bean, the vetch, the lentil; among grasses, wheat, rice, barley, Indian corn, rye, millet.

Recollect, however, that in all these cases the plant does not desire the seed to be eaten. It stored the tissues richly for its own sake and its offspring's alone, and we come and rob it. So, too, with the edible roots or tubers, such as potatoes, yams, turnips, beet-root, and so forth ; the plant meant to use them for its own future 
growth; man appropriates them and disappoints its natural expectations. It is quite different with the succulent fruits, like the date and the plantain, which form in many countries the staple food of great populations; nature meant those to be eaten by animals, and offered the pulp in return for the benefit of dispersion.

Finally, when the seed is put into the ground and exposed to warmth and moisture, it begins to germinate. This it does by sending up a small growing shoot towards the light, which soon develops green leaves; as well as by sending down a root towards the earth, which soon begins to suck up water, together with the dissolved nitrogenous matter. That is the beginning of a fresh plant-colony, which thus owes its existence to two separate individuals, a father and a mother. The seed consists of two first seed-leaves in the fivefold plants, as you can see very well in a sprouting bean, and of one such seed-leaf in the threefold division, as you can see very well in a sprouting grain of wheat, or, still better, a lily seed. These earliest leaves are technically known as seed-leaves or cotyledons, and that is why the fivefold plants are known to botanists by the awkward name of dicotyledons, while the threefold are called monocotyledons. These names mean merely plants with two or with one seed-leaf. 


\section{CHAPTER X̃II.}

THE STEM AND BRANCHES.

You may have observed that so far I have told you a good deal about leaves and roots, flowers and seeds, but little or nothing about the nature of the stems and branches that bear them. I have done this on purpose; for my object has been to give you as much information at a time as you could then and there understand, building up by degrees your conception of plant economy. Now, leaves and flowers are, so to speak, the units of the plant-colony, while stem and branches are the community as a whole and the mode of its organisation. You must know something about the component parts before you can get to understand the whole built up of them; you must have seen the individual citizens themselves before you can comprehend the city or nation composed by their union.

The stem, then, is the part of the plant-colony which does not consist of individual leaves, either digestive or floral, but which binds them all together, raises them visibly to the air, and supplies them with water, nitrogenous matter, and the results of previous assimilation elsewhere. The stem and branches are common property, as it were; they belong to the community: they represent the scaffolding, the framework, the canals, the roads, the streets, the sewers, of the compound plant-colony.

How did stems begin to exist at all ? The 176 
most probable answer to that question we owe, not to any professional botanist, but to our great philosopher; Mr. Herbert Spencer.

The simplest and earliest plants, we saẁ, were mere small floating cells, endowed with active chlorophyll. Next in the upward order of evolution came rows of such cells, arranged in long lines, like hairs or threads, or like pearls in a necklace, as in the green ooze of ponds and lakelets. Above these simple plants, again, come flat expanded collections of cells, as in the fronds of seaweeds. Now, all these kinds of plant are stemless. But suppose in such a plant as the last, one frond or leaf
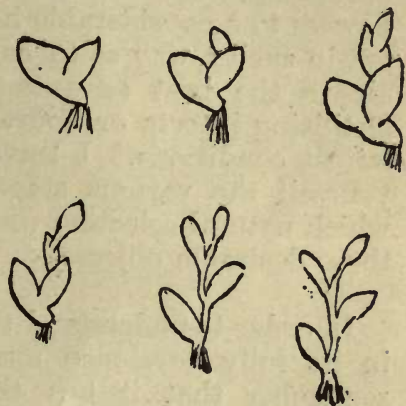

FIG. 49,-FIRST STEPS IN THE EVOLUTION OF THE STEM. took to growing out of the middle of another, as it actually does in many instances, we should get the beginning of a compound plant, many-leaved, and with a sort of early or nascent stem, formed by the part that was common to many of the leaves, like a midrib. The accompanying diagram (Fig. 49) will make this clearer than any amount of description could possibly make it. Starting from such a point, certain plants would soon find they were thus enabled to overtop others, and to obtain freer access to light and carbonic 
acid. Gradually, natural selection would ensure that the common central part of the growing plant, the developing stem, should become harder and more resisting than the rest, so as to stand up against the wind and other opposing forces. At last there would thus arise a clearlymarked trunk, simple at first, but later on branching, which would lift the leaves and flowers to a considerable height, and hang them out in such a way as to catch the sunlight and air to the best advantage, or to attract the fertilising insects or court the wind under the fairest conditions. I leave you to think out for yourself the various stages of the process by which natural selection must in the end secure these desirable objects.

In order to understand the nature of the stem, in its fully developed form, however, we must remember that it has three main functions. The first is, to raise the foliage, with the flowers and fruits as well, visibly above the surface of the ground on which they grow, so that the leaves may gain the freest possible access to rays of sunlight and to carbonic acid, while the flowers and fruit may receive the attentions of insects and birds, or other fertilising and distributing agents. The second is, to conduct from the root to the foliage and other growing parts what is commonly called the raw sapthat is to say, the body of water absorbed by the rootlets, together with the nitrogenous matter and food-salts dissolved in it, all of which are needed for the ultimate manufacture 
of protoplasm and chlorophyll. The third is, to carry away and distribute the various matured products of plant life, such as starches, sugars, oils, and protoplasm, from the places in which they are produced (such as the leaves) to the places where they are needed for building up the various parts of the compound organism (such as the flowers and fruit or the growing shoots), as well as to the places where such materials are to be stored up for safety or for future use (as, for example, the tubers and roots, or the buds, bulbs, and other dormant organs). Each of these three essential functions we must now proceed to consider separately.

In order to raise the leaves and branches visibly above the ground into the air above it, the stem is made much stronger and stouter than the ordinary leaf-tissue. If the plant does not rise very high above the ground, indeed, as in the case of small herbs, and especially of annuals, its stem need not be very hard or stiff, and is often in point of fact quite green and succulent. But just in proportion as plants grow tall and spreading, carry masses of foliage, and are exposed to heavy winds, do they need to form a stout and woody stem, which shall support the constant weight of the leaves, or even bear up under the load of snow which may cover the boughs in wintry weather. Thus, a tapering tree like the Scotch fir requires a comparatively smaller stem than an oak, because its branches do not spread far and wide, while its single leaves are thin and needle-like; whereas 
the oak, with its massive boughs extending far and wide on every side, and covered with a weight of large and expanded absorbent leaves, requires a peculiarly thick and buttressed stem to support its burden. Both in girth and in texture it must differ widely from the loose and swaying pine-tree. Every stem is thus a piece of ingenious engineering architecture, adapted on the average to the exact weight it will have to bear, and the exact strains of wind and weather to which on the average it may count upon being exposed in the course of its lifehistory. We see the result of occasional failure of adaptation in this respect after every great. storm, when the corn in the fields is beaten down by hail, or the fir-trees in the forest are. snapped off short like straw by the force of the tempest. But the survivors in the long run are those which have succeeded best in resisting even such unusual stresses; and it is they that become the parents of after generations, which of course inherit their powers of resistance.

Most stems, at least of perennial plants, and all those of bushes, shrubs, and forest trees, are strengthened for the purpose of resisting such strains by means of a material which we call wood. And what is wood? Well, it is an extremely hard and close-grained tissue, manufactured by the plant out of its ordinary cells by a deposit on their walls of thickening matter. This process of thickening goes on in each cell until the hollow of the centre is almost entirely filled up by the thickening material, leaving only a small vacant space in the very middle. The 
thickening matter, which consists for the most part of carbon and hydrogen, is built up there by the protoplasm of the cell itself : but as soon as the process is quite complete, the protoplasm emigrates from the cell entirely, and goes to some other place where it is more urgently needed. Thus wood is made up of dead cells, whose walls are immensely thickened, but whose living contents have migrated elsewhere.

In large perennial stems, like those of oaks and elms, a fresh ring of wood is added each year outside the ring of the last growing season. This new ring of wood is interposed between the bark (of which I shall speak presently) and the older wood of the core or heart, which was similarly laid down when the tree was younger. In this way, the number of rings, one inside another, enables us roughly to estimate the age of a tree when we cut it down; though, strictly speaking, we can only tell how many times growth in its trunk was renewed or retarded. Still, as a fair general test, the number of rings in a trunk give us an approximate idea of the age of the individual tree that produced it.

The principle is only true, however, of the great group of dicotyledonous trees, such as beeches or ashes, as well as of the pines and other conifers. In monocotyledonous trees, like the palms and bamboos, the stem does not increase in quite the same way from within outward, and there are therefore no rings of annual growth to judge by. Palms rise from the ground as big or nearly as big at the beginning as they will ever be in the end ; and though 
each year they rise higher and higher into the air, and produce a fresh bunch of leaves at their summit, they seldom branch, and they never produce large buttressed stems like the oak or the chestnut.

The second main function of the stem is to convey the raw sap absorbed by the roots to the leaves and branches, and especially to the growing points. This is such a very important element in plant life that we must now consider it in some little detail.

If you look for a moment at a great spreading oak-tree, with its top rising forty or fifty feet above the level of the ground, and its roots spreading as far and as deep beneath the earth, you will see at once how serious and difficult a mechanical problem it is for the plant to raise up water from so great a depth to so great a height without the aid of pump or siphon. For the plant can no more work miracles than you or I can. Yet every leaf must be constantly supplied with water, that prime necessary of life, or it will wither and die; and every growing part must obtain it in abundance, in order to give that plasticity and freedom which are needful for the earlier constructive processes. Protoplasm itself can effect nothing without the assistance of water as a solvent for all materials it employs in its operations.

How does the plant get over these difficulties? Well, the stem is well provided with a whole system of upward distributing vessels in which water may be conveyed to the various parts, 
just as it is conveyed in towns through the pipes and taps wherever it is needed. But what is the motive power for this mechanical work? How does the plant raise so much liquid to such a considerable height, without the intervention of any visible and tangible machinery?

Two main agents are employed for this pur. pose. The one is known as root-pressure; the other as evaporation.

I begin with the former. The cells of which roots are made up are most ingeniously constructed so as to exert this peculiar form of pressure. Each one of them has at its outer or free end, where it comes into contact with the moist earth, a wall of such a nature that it very readily absorbs water, and allows the water so absorbed to flow freely through it inward. But once in, the water seems almost as if imprisoned in a pump ; it cannot pass outward again, only inward and upward. You may compare the cell in this respect with those mechanical valves which yield readily to the pressure of fluids from outside, but instantly close when a fluid from inside attempts to pass through them. In this way the outer cells of the hairs on the roots, which come in contact with the moistened soil, get distended with water, and swell and swell, till at last their walls will give no longer, and their own elasticity forces the water out of them. But the water cannot flow back; so it has to flow forward. Again, each cell or vessel which the stream afterwards enters is constructed on just the same general principle as the absorbent 
root-cells ; it allows water to pass into it freely from below upward, but does not allow it to pass back again from above downward. Thus we get a constant state of what is called tuirgidity in the lower cells; they are as full as they can hold, and they keep on contracting elastically, so as to expel the water they contain into other cells next in order above them. By means of such root-pressure, as it is called, raw sap is being for ever forced up from the soil beneath into the stem and branches, to supply the leaves with water and food-salts, especially in early spring, when the processes of growth are most active and vigorous.

It is owing to this peculiar property of rootpressure that cut stems "bleed" or exude sap, especially in spring-time. The root-pressure continues of itself in spite of the fact that the stem has been divided; and the sap absorbed by the roots is thus forced out at the other end by the continuous elasticity of the cells and vessels. The fact that severed stems will thus "bleed" or exude raw sap shows in itself the reality of root-pressure.

But root-pressure alone would not fully suffice to raise so large a body of water as the plant requires to so great a height above the earth's surface. It is therefore largely supplemented and assisted by the second or subsidiary power of evaporation. This evaporation, or " transpiration" as it is generally called, is just as necessary and essential to plants as breathing is to men and animals.

We must therefore enter a little more fully 
here into the nature of so important and universal a plant function. You will remember that when we were discussing the nature of leaves, I gave you a woodcut of a thin slice through a leaf (Fig. 1) which showed the blade as naturally divided into an upper and under portion. The upper portion consisted of very close-set green cells, containing living chlorophyll, and covered by a single transparent water-layer, which absorbed carbonic acid from the air about, and passed it on to be digested. by the living chlorophyll-layer just beneath it. But the under portion was sparse-looking and spongy; it was composed of cells loosely arranged among themselves, and interspersed with great empty spaces. I told you but little at the time of the function or use of this lower portion; we must return to it now in the present connection, as a component element in the task of water-supply.

The lower portion of most leaves is the part employed in the great and necessary work of evaporation.

For this purpose the tissue at the under side of the leaf is composed of loose and spongy cells which have much of their surface exposed to the empty spaces between them : and these empty spaces are really air-cavities. The object of the cavities, indeed, is to facilitate evaporation. Liquid transpires into them from the various cells through the wall that bounds them. How fast water evaporates in the leaves of plants we all know by experience in a thousand ways. We know, for instance, that if we pick bunches 
of flowers and leave them in the sun without water, they fade and dry up in a very short time. We also know that if we forget to water plants in pots, the plants similarly dry up and die after a few hours' exposure. Leaves, in fact, are purposely arranged in most cases so as to encourage a very rapid evaporation; and evaporation is one of their chief means of waising water from the roots to the growing and living portions.

If you examine the under side of a leaf under the microscope, you will find it is covered by hundreds of little pores which look exactly like mouths, and which are guarded by two cells whose resemblance to lips is absurdly obvious. These pores are commonly known to botanists by the awkward name of stomata, which is the Greek for mouths; and mouths they really are to all external appearance. You must not suppose, however, that they are truly mouths in the sense of being the organs with which the plant eats ; the upper surface of the leaf, as we saw, with its layer of water-cells and its assimilating chlorophyll-bodies, really answers in the plant to our mouths and stomachs. The stomata or pores are much more like the openings in the skin by which we perspire; only perspiration or evaporation is an even more important part of life to the plant than it is to the animal. Each of the stomata opens into an air-cavity; and through it the liquid evaporated from the cells passes out as vapour into the open air. Many leaves have thousands of such pores on their lower surface; they may easily be recog- 
nised under the microscope by means of the curious guard-cells which look like lips, and which give the pores, in fact, their strange mouth-like aspect.

What is the use of these lips? Well, they are employed for opening and closing the evaporating pores, or stomata. In dry weather it is not desirable that the pores should be open, for then evaporation should be limited as far as possible. So, under these conditions, the lips contract, and the pore closes. Excessive evaporation at such times would, of course, damage or destroy the toliage ; the plant desires rather to store up and retain its stock of moisture. But after rain, and in damp weather, the roots suck up abundant water; and then it becomes desirable that evaporation should go on, and the leaves and growing shoots should be supplied with liquid food, as well as with the nitrogenous matter and salts dissolved in it. Hence at such times the pores open wide, and allow the water in the form of vapour to exude from them freely.

The object of this evaporation, again, is twofold. In the first place, it supplements rootpressure as a means of raising water to the leaves and growing shoots; and in the second place, by getting rid of superfluous liquid, it leaves the nitrogenous material and the foodsalts in a more concentrated form, at the very points where they are just then needed for the formation of fresh living protoplasm and other useful constructive factors of plant-life. But how does evaporation raise water from the ground ? In this way. The living contents of each cell 
on the upward path have a natural chemical affinity for water, and will suck it up greedily wherever they can get it. Thus each part, as fast as it loses water by evaporation, takes up more water in turn from its next neighbour below; and that once more withdraws it from the cell beneath it ; and so on step by step until we reach the actual absorbent root-hairs. Rootpressure by itself could not raise water as high as we often see it raised in great forest trees and tropical climbers; it has not enough mechanical motor power. But here evaporation comes in, to aid it in its task; and the real motor power in this last case is the very potent force of chemical attraction.

What I have said here about evaporation, and the way it is conducted by means of pores on the surface of the leaves, is true of the vast majority of green plants; but considerable varieties and modifications occur, of course, in accordance with the necessities of various situations. For example, the brooms and many other shrubs of the same twiggy type have few green leaves, but in their stead produce lithe green stems, filled with active chlorophyll. These stems and branches do all the work usually performed by ordinary foliage. Stems and twigs of this type are covered with mouth-like pores, or stomata, in exactly the same way as the under side of leaves in most other species. Similarly, the very flattened leaf-like branches of the butcher's broom, and of the Australian acacias and other Australasian trees, are well supplied with like pores for purposes of evapora- 
tion. Again, while the pores are usually found on the under surface of the leaf, they are situated on the upper surface of leaves which float on water, like the water-lily and the water-crowfoot; because in such plants they would be obviously useless for purposes of evaporation on the lower side, which is in contact with the water. Some leaves have the stomata on both sides alike, especially when no one side is much more exposed to sunlight than another. But wherever they are found, they always lie above masses of loose and spongy cell-tissue, in whose meshes and air-spaces evaporation can go on readily.

On the other hand, as I noted before, leaves which grow in very dry or desert situations require as much as possible to curtail evaporation. Such leaves are therefore usually thick and fleshy, and possess a very small allowance of pores. The forms of several leaves, again, are largely dependent upon the necessity for keeping the pores free from wetting, and promoting evaporation whenever it is needful for the plant's health and growth; and this is particularly the case with what are called "rolled leaves," such as one sees in the heaths and the common rock-roses. Many such additional principles have always to be taken into consideration in attempting to account for the various shapes of foliage: indeed, we can only rightly understand the form of any given leaf when we know all about its habits and its native situation.

The stem, then, besides raising the leaves and 
flowers, for which purpose it is often streng. thened by means of mechanical woody tissue, also acts as a conductor of raw sap from the tips of the roots to the leaves and growing points, for which purpose it is further provided with an elaborate system of canals and vessels, running direct from the absorbent root to all parts of the compound plant community.

The third function of the stem and branches is to convey and distribute the elaborated products of plant-chemistry and plant-manufacture from the places where they are made to the places where they are needed for practical purposes.

We saw long since that starches, sugars, protoplasms, and chlorophyll are manufactured in the leaves under the influence of sunlight; and from the materials so manufactured every part of the plant must ultimately be constructed. But we never said a word at the time about the means by which the materials in question were carried about and distributed to the various organs in need of them. Nevertheless, a moment's consideration will show you that new leaves and shoots must necessarily be built up at the expense of materials supplied by the older ones; that flowers, fruits, and seeds must. be constructed from protoplasm handed over for their use by the neighbouring foliage. Nay more; the root itself grows and spreads; and the very tips of the roots, which themselves of course can manufacture nothing, must be supplied from above with most active and discrimi- 
nating protoplasm, to guide their nîovements. Whence do they get it? From the factory in the foliage. Thus, from the summit of the tallest tree down to the lowest root that fastens it in the soil, there runs a complex system of pipes and tubes for the special conveyance of elaborated material ; and this system supplies every growing part with the food-stuff necessary for its particular growth, and every living part with the food-stuff necessary for maintaining its life and activity. An interchange of protoplasmic matter, starches, and sugars, goes on continually through the entire organism.

This downward and outward stream of living matter, carrying along with it live protoplasm and other foods or manufactured materials, must be carefully distinguished from the upward stream of crude sap which rises from the roots to the leaves and branches. The one contains only such raw materials of life as are supplied by the soil-namely, nitrogenous matter, water, and food-salts; the other contains the things eaten from the air by the plant in its leaves, and afterwards worked up by it into sugars, starches, protoplasm, and chlorophyll.

Stems are usually covered outside for purposes of protection by a more or less thick integument, which in trees and shrubs assumes the corky form we know as bark. Bark consists of dead and empty cells, thickened with a lighter thickening matter than wood, and presenting as a rule a rather spongy appearance. But beneath the bark comes a distinct layer of living. 
material, interposed between the corky dead! cells of the integument and the woody dead cells of the interior. This living layer extends over stem, twigs, and branches: it forms the binding and connecting portion of the entire plant community ; it links together in one united 2 whole the living material of the leaves and shoots It is thus the stem, above all, that gives to the complex plant colony of foliage and flowers whatever organic unity and individuality it ever possesses.

All situations, however, are not alike. Just as here this sort of leaf succeeds, and there that, so in stems and branches, here this form does best, and there again the other. The shape of the stem and branches, in fact, is the shape of the entire plant colony; and it is arranged to suit, on the average of instances, the convenience of all its component members. Much depends on the shape of the leaves; much on the conditions of wind or calm, shade or sunshine.

Some plants are annuals. These require no large and permanent stem; they spring from the seed each year, like peas, or wheat, or poppies; they make a stem and leaves; they produce their flowers; they set, and ripen, and scatter their seed; and then they wither away and are done with for ever. Hundreds of such plants occur in our fields and gardens. Even these annuals, however, differ greatly in the amount of their stem and branches. Some are quite low, humble, and succulent, like 
chickweed and sandwort; others have tall and comparatively stout stems, like wheat, oats, and barley, or still more, like the sunflower. As a rule, annuals are not very large; but a few rich seeds produce strong young plants which even within a single year attain an astounding size; this is the case with the garden poppy, the tobacco plant, and the Indian corn, and even more so with certain climbing annuals, such as the gourd, the cucumber, the melon, and the pumpkin.

Many plants, however, find it pays them better to produce a hard and woody stem, which lasts from year to year, and enables them to put forth fresh leaves and shoots in each succeeding season. Among these, again, great varieties exist. Some have merely a rather short and stout stem with many bundles of water-vessels, as in the pink and the wallflower. Their growth is herbaceous. Others, however, produce that more solid form of tissue which we know as wood, and which is made up of cells whose walls have become much thickened and hardened. Among the woody group, again, we may distinguish many intermediate varieties, from the mere shrub or bush, like the heath and the broom, through small trees like the rhododendron, the lilac, the hawthorn, and the holly, to such great spreading monsters of the forest as the oak, the ash, the pine, the chestnut, and the maple.

Once more, some plants produce an underground stem, and send up from this fresh annual branches. That is the case with hops, with 
meadow-sweet, and with buttercup, as well as with many of our garden flowers. When a plant becomes perennial, it is a mere question of its own convenience whether it chooses to produce a thick and woody stem, like trees and bushes, or to lay up material in underground roots, stocks, and branches, like the potato, the dahlia, the lilies, the bulbous buttercup, the crocus, the iris, the Jerusalem artichoke, and the meadow orchis.

Ordinary people divide most plants into three groups-herbs, shrubs, and trees. But I think you will have seen from what I have just said, that in every great family of plants different kinds have found it worth while to adopt any one of these forms at will, according to circumstances. Trees, in other words, do not form a natural group by themselves; any family of plant may happen to develop a tree-like species. Thus the herb-like clover and the tall tree-like laburnum are closely related peaflowers. Most of the composites are mere herbs or shrubs, but a very few of them in the South Sea Islands have grown into large and much-branched trees. The grasses are mainly herbs; but some of them, like the bamboos, have developed tall and treelike stems, much branched and feathery.

Take the single family of the roses, for example, so familiar to most of us; some of them are mere annual weeds, like the tiny parsley-piert that occurs as a pest in every garden. Others, again, are perennials with low tufted stems, like the strawberry; or creeping, like the cinquefoil ; or rising into a spike, like the burnet and the agri- 
mony. Yet others become scrambling bushes, like the blackberry and the raspberry. In the blackthorn and the hawthorn the bush has become more erect and tree-like. Both types of growth occur in the dog-rose and many other roses. The cherry attains the size and stature of a small tree. The mountain-ash is bigger; the apple-tree bigger still ; while the pear often grows to a considerable height and much spreading dignity. These are all members of the rose family. Here, therefore, every variety of shape and size is well represented within the limits of a single order.

One word must be given to the varieties of the stem. Sometimes, as in the oak, the trunk is much branched and intricate; sometimes, as in the date-palm, simple and unbranched, bearing only a single tuft of circularly arranged leaves. But the most interesting in this respect are the climbing and twisting stems, which do not take the trouble to support themselves, but lean for aid upon the trunk of some stronger and more upright neighbour. Stems of this sort are familiar to us all in the hop and the bindweed. In other climbers the stems do not twine to any great extent, but the plants support themselves by root-like processes, as in ivy, or by tendrils, as in the vine, or by twisted leaf-stalks, as in the canary creeper. Others cling by means of suckers, as the Ampelopsis Veitchii, or hang by opposite leaves, like clematis, or cling by hooked hairs, as is the case with cleavers. In certain instances, such creeping or climbing plants tend to become parasitic - that is to say, they fasten 
themselves by sucker-like mouths to the bark of the harder plant up which they climb, and feed upon its already elaborated juices. Our English dodder is an example of such a plant. It has no leaves of its own, but consists entirely of a mass of red stems, bearing clusters of pretty pale pink flowers.

Other plants show another form of parasitism. Misletoe is one of these. It fastens itself to a poplar or an apple-tree (very seldom an oak) and sucks its juices. But it has also green leaves of its own, which do real work of eating and assimilating as well. It is therefore not quite such a parasite as the dodder. Several plants are similarly half-parasitic on the roots of wheat and grasses. Among them I may mention, as English instances, the cow-wheat, the yellow rattle, and the pretty little eyebright.

Broomrape is a parasite of a different sort. It grows on the roots of clover, and has no true leaves ; in their place it produces short scales, which contain no chlorophyll. Several other plants are also devoid of chlorophyll, and therefore cannot eat carbonic acid for themselves. They live like animals on materials laid by for them by other plants. Such are toothwort, a pale rose-coloured leafless plant, with pretty spiked flowers, which grows by suckers on the roots of hazel-trees. The bird's nest orchid, a delicate brown plant with curious ghost-like blossoms, feeds rather on the organised matter in decaying leaves among thick beechwoods. In this book I have purposely confined your attention for the most part to the true green plants, 
which are the central and most truly plant-like type; but I ought to tell you now that a great many plants, especially among the lower kinds, behave in this respect much more like animals: instead of manufacturing fresh starches and protoplasms for themselves from carbonic acid, under the influence of sunlight, they eat up what has already been made by other and more industrious species. Such plants are retrograde. They are products of degeneracy. Among them I may specially mention all the fungi, like mushrooms, toadstools, mould, and mildew, as well as the bacilli and bacteria, microscopic and degenerate plants which cause decomposition. Their life is more like that of animals than of true vegetables.

In tropical forests, where the soil is almost monopolised by huge spreading trees, the smaller plants have been forced to secure their fair share of light and air by somewhat different means from those which are common in cooler climates. Many of them, without being parasitic, have learnt to attach themselves by their roots to the outer bark of the trees, and so to get at the light, no ray of which ever struggles through the living canopy of green in the dense jungle. These plants have green leaves, and eat for themselves; but they use the boughs of their host instead of soil to root themselves in. Such plants are technically known as epiphytes. This is the mode of life of most of the handsome orchids cultivated in our conservatories.

Now let us recapitulate. The stem unites the 
various parts of the plant-the root, the leaves, the flowers, the fruit. It conducts water and nitrogenous matter from the soil to the foliage. It also carries the manufactured materials from the points where they are made to the points where they are wanted for the growth of fresh organs. It supports and raises the whole plant colony. Finally, it stores up material in drought or winter, which it uses for new branches, leaves, or flowers, when rain or spring or favourable conditions in due time come round again.

\section{CHAPTER XIII.}

SOME PLANT BIOGRAPHIES.

WE have considered so far the various elements which go to make up the life of plants-how they eat and drink, how they digest and assimilate, how they marry and get fertilised, how they produce their fruit and set their seeds, finally how they are linked together in all their parts by stem and vessels into a single community. But up to the present moment we have considered these elements in isolation only, as so many processes the union of which makes up what we call the life of an oak, or a lily, or a strawberry plant. In order really to understand how all these principles work together in practical action, we ought to take a few specimen lives of real concrete plants, and trace them through direct, from the cradle to the grave, 
with all their vicissitudes. I propose, therefore, in this chapter to give you brief sketches of one or two such life-histories; and I hope these few hints may encourage you to find out many more for yourself, by personal study of plants in their native surroundings.

"In their native surroundings," I say, since all life is really, in Mr. Herbert Spencer's famous phrase, "sdaptation to the environment;" and therefore we can only understand and discover the use and meaning of each part or organ by watching the plant in its own home, and among the general conditions by which it and its ancestors have always been limited. It would be impossible, for example, to see the use of the thick outer covering of the coconut (from which coconut matting is manufactured) if we did not know that the coconut palm grows naturally by the sea shore in tropical islands, and frequently drops its fruits into the water beneath it. The nuts are thus carried by the waves and currents from islet to islet; and the coconut palm, which is a denizen of seasand, owes to this curious method of watercarriage its wide dispersion among the coral-reefs of the Pacific. But a plant that is so dispersed must needs make provision against wetting, bruising, and sinking in the sea; and since only those coconuts would get dispersed over wide spaces of water which happened to possess a good coating of fibre, the existing plant has come to produce the existing nut as we know it -richly stored with food for the young palm while it makes its first steps among the barren rocks and 
sand-banks, and well provided by its shaggy outer coat against the dangers of the sea, the reefs, and the breakers. Similarly, we could never understand the cactus except as a native of the dry plains of Mexico. Or again, there is an orchid in Madagascar with a spur containing honey at a depth of eighteen inches. Now, no European insect could possibly reach so deep a deposit; but a Madagascar moth has a gigantic proboscis, exactly fitted for sucking the nectary and fertilising the flowers. Thus no plant can properly be understood apart from its native place; and I have therefore confined myself for the most part in these few brief life-histories to native British plants, whose circumstances and surroundings are known to everybody.

As an example of a very simple and easy lifehistory, I will take first a little wayside weed, commonly known as whitlow-grass, but called by botanists, in their scientific Latin, Draba verna. This curious little herb is not a grass at all (as its name might make you think), but a member of the great family of the crucifers, succulent plants with four petals and six stamens in each flower, to which the cabbage, the turnip, the sea-kale, and many other well-known garden species belong. But whitlow-grass is not a large and conspicuous plant like any of these ; it is one of the smallest and shortest-lived of our British weeds. It has managed to carve itself out a place in nature on the dry banks and in clefts of rock during the few weeks in spring while such spots are as yet unoccupied by more permanent denizens. The herb starts from a very minute 
seed, dropped on the soil by the parent plant many months before, and patiently waiting its time to develop till winter frosts are over, and warmer weather and moisture begin to quicken its tiny seed-leaves. As soon as these have opened and used up their very small stock of internal nutriment, the young plant begins to produce on its own account a rosette of little oblong green leaves, pressed close to the ground for warmth and shelter. They eat as they go, and make fresh leaves again out of the absorbed and assimilated material. Direct sunshine falls upon them full front; and as no other foliage overshadows them or competes in their neighbourhood for carbonic acid, they grow apace into a little tuft of spreading leaves, about half an inch long or less, and forming in the mass a rough circle. For about a week or ten days the little mouths go on drinking in carbonic acid as fast as they can, and manufacturing it under the influence of sunlight into starches and protoplasm. At the end of that time they have collected enough material to send up a slender blossoming stem, about an inch high or more, bearing no leaves, but developing at the top a few tiny flower-buds. These shortly open and display their flowers, very small and inconspicuous, with four wee white petals, each so deeply cleft that they resemble eight to a casual observer. Inside the petals are six little active stamens; and inside the stamens again a twocelled ovary. The blossoms are visited and fertilised on warm March mornings by small spring midges, attracted by the petals. They 
immediately set their seeds in the flat green capsule, ripen them rapidly in the eye of the sun, and shed them at once, the whole life of the plant thus seldom exceeding three or four weeks in a favourable season. At the same time, the leaves and roots wither, as the material they contained is rapidly withdrawn from them, and used up in the process of maturing the seeds; so that as soon as the fruiting is quite complete, the plant dies down, having exhausted itself utterly in the two short acts of flowering and seed-bearing. During the remaining ten months of the year or thereabouts, there are no more whitlow-grasses at all in existence; the species remains dormant, as it were, for a whole long period in the form of seeds lying buried in the soil, and only springs to life again when the return of March gives it warning that its day has once more come round to it.

Contrast with this brief and very spasmodic life of some thirty days the comparatively long though otherwise extremely similar biography of the Mexican agave, commonly cultivated in hothouses in England, and largely grown in the open air in the South of Europe under the (incorrect) name of "American aloes." The agave is a large and strikingly handsome lily of the amaryllis family, about which I have already told you something in a previous chapter. It begins life as a small plant, like a London pride, springing from a comparatively large and richly-stored seed on its own dry prairies. Its leaves, which spread in a rosette, are not unlike those of the house-leek in shape; they are very 
large, thick, and fleshy. But as they grow in the hot and dry climate of Mexico, an almost desert country, with a very small rainfall, they have a particularly hard outer skin, so as to prevent undue evaporation; and they are protected against the attacks of herbivorous animals by being spiny at the edges, and ending in a stout and dagger-like point of the most formidable description. The centre of the plant is occupied by a sort of sheath of leaves, concealing the growing point. For several years the round bunch of outer leaves grows bigger and bigger, till it attains a diameter of ten or fifteen feet at the base, seeming still like a huge rosette, with hardly any visible stem to speak of. Meanwhile these huge leaves are busy all the time, eating and assimilating, and storing up manufactured food-stuffs as hard as they can in their thick and swollen bases. After six or seven years in their native climate, the plant feels itself in a position to send up a flowering stalk, which is formed from the materials already laid by in these immensely thick and richly-stored leaf bases. The stalk springs from the middle of the central leaf-sheath. In a very few weeks the agave has sent up from this point a huge flowering scape, twenty or thirty feet high, and a foot or fifteen inches thick at the bottom. On this scape it produces with extraordinary rapidity a vast number of large and showy yellow flowers, which look not unlike an enormous candelabrum, with many divided branches. The plant is enabled to produce this immense flowering stem and these numerous flowers in so short a period, 
because it draws upon its large store of elaborated material for the purpose. But as the flowering stem rises, and the flowers unfold, and the big fruits and seeds develop and ripen, the leaves below grow gradually flaccid and empty; and their bases shrink, being depleted of their store of valuable food-stuffs; so that by the time the seeds are ripe, the whole plant is used up, having exhausted itself, like the tiny whitlowgrass, in the act of fruiting. It then dies down altogether, and never recovers, though new plants or offsets usually develop at its base from side buds, after the original agave has begun to wither. In English hothouses it takes thirty or forty years before the agave has collected enough material to send up a stem and flower; hence the common exaggeration that it needs a hundred years for " the blossoming of an aloe."

As a familiar example of a very different kind of perennial plant, we may take our English beech-tree. The beech sets out in life as a tender young seedling, which grows from a goodsized triangular nut, whose cotyledons are wellstored with food-stuffs for its early development. As the nut germinates, the cotyledons open out, become flat and green, like thick fleshy leaves, and begin to absorb carbonic acid from the air, which they work up at once with the material supplied by the tiny root into protoplasm and chlorophyll. In the angle between them a young shoot develops, which soon puts forth delicate blades of true foliage leaves; and these in turn grow and assimilate material under the influence of sunlight. In the first year the little beech-tree 
is but a tiny sapling, with a short stem, already woody; but year after year, this stem grows higher, branches out and divides, and slowly clothes itself in the smooth grey bark characteristic of the species. The particular way in which it branches is this: each autumn there is formed at the base of every leaf a winter bud, long and brown, and covered with close scales, which enable it to survive the cold of winter. When spring comes round again, each one of these buds develops in turn into a leafy branch, so that (accidents excepted) there are as many new branches or twigs every year as there were leaves on the tree in the preceding season. The young leaves and branches emerge slowly and cautiously from the buds in spring, for fear of frost; they are protected at first by certain scaly brown coverings known as stipules. Gradually, however, as the weather grows warmer, the stipules fall off, and display the tender green leaves, exposed to the air, but still folded together. As soon as they can trust the season, however, the leaves unfold, though they are still thickly covered at the edges by protective hairs, which afterwards fall off, but which guard the fresh green chlorophyll in the cells just at first both from chilly winds and from the injurious effect of excessive sunlight. Year after year the beech-tree grows by so subdividing and adding branch to branch; while its stem increases by yearly rings of growth, till it attains at length considerable dimensions.

During many such seasons of growth the beech-tree does not flower; all the material it 
manufactures through the summer in its large flat leaves it lays by in its stem to supply the young shoots and branches at the beginning of the subsequent season. But at last, when it has reached the height and girth of a small tree, it / begins to store up protoplasm and starches for blossom also. Some of its buds are now leafbuds, but some are flower-buds, produced in autumn, and held over till April. In the spring these flower-buds lengthen and produce bunches of blossoms, which we call catkins, some of them males, and some females, but both sexes growing on the same tree together. They bloom, like most other catkins, in the early spring, while the leaves are still very little developed, so as to prevent the foliage from interfering with the carriage of the pollen. The

- males are produced in hanging clusters an inch 2 or so long; while the females stand up in small globular bunches, on erect flower-stems. They are wind-fertilised; and shortly after flowering, 3 the male catkins drop off entire, having done their life-work, while the females swell out into the familiar husks or four-valved cups, containing each some two or three triangular nuts, richly stored with food-stuffs.

The agave only flowers once, and then dies down, exhausted. But the beech goes on flowering for many years together, and grows meanwhile larger and larger in bulk, its trunk increasing in girth, and becoming buttressed at the base, so as to support the large head of branches and the dense mass of foliage. For the boughs are so arranged that a great crown 
of leaves is exposed in summer to the sun and air at the outer circumference of the domeshaped mass ; and in this way every leaf gets its fair share of light and carbon, and interferes as little as possible with the work of its neighbours. Old beeches will grow to more than 100 feet in height, and live for probably three or four centuries. At last, however, their protoplasm grows old and seems to get enfeebled; the trunk decays, and the entire tree falls first into dotage, then dies by slow degrees of pure senility.

The common vetch is another familiar plant whose life-history introduces to us some totally different yet interesting features. It belongs to the wide-spread family of the peaflowers, to which I have already more than once alluded, and it takes its origin from a comparatively large and rich round seed, not unlike a pea, whose cotyledons are well stored with supplies of starch and other food-stuffs. It sends up at first a short spreading stem, which twines or trails over surrounding plants, developing as it goes very curious leaves of a compound character. Each leaf consists of five or six pairs of leaflets, placed opposite one another on the common stalk in the feather-veined fashion. But the four or five leaflets at the end of each leafstalk do not develop any flat blade at all, and are quite unleaflike in appearance: they are transformed, indeed, into long thin tendrils, which catch hold of neighbouring branches or stems of grasses, twine spirally round them, and so enable the vetch to climb up bodily in spite 
of its weak stem, and raise its leaves and flowers to the air and the sunlight.

At the base of every leaf, again, you will find, if you look, two arrow-shaped appendages, which block the way up the stem towards the developing flowers for useless creeping insects such as steal the honey without assisting fertilisation. On each appendage is a curious black spot, the use or function of which is not apparent while the blossoms are in the bud. But after a few weeks' growth, the vetch begins to produce solitary flowers in the angle of each upper leaf; flowers of the usual pea-blossom type, but pink or reddish purple, and handsome or attractive. These flowers contain abundant honey to allure the proper fertilising insects. Just as they open, however, the black spot on the arrow-headed appendages of the lower leaves, in whose angles there are no flowers, begins also to secrete a little drop of honey.

What is the use of this device? Well, if you watch the vetch carefully, you will soon see that ants, enticed by the smell of honey in the opening flowers, crawl up the stem in hopes of stealing it. But ants, as we know, are thieves, not fertilisers. As soon as they reach the first black spot, they stop and lick up the honey secreted by the gland, and then try to pass on to the next appendage above it. But the arrow-shaped barbs, turned back against the stem, block their further progress; and even if they manage to squeeze themselves through with an effort, they are met just above by another honey-gland and another barrier in the shape of 
a second arrow-shaped appendage. No ant ever gets beyond the third or fourth barricade; the device is efficient: the vetch thus offers blackmail to creeping thieves in the shape of stemhoney, in order to guard from their depredations the far more valuable and useful honey in the flowers, which is intended to attract the fertilising insects.

When the purple flowers have in due time been fertilised, they produce long narrow pods, each containing about a dozen round pea-like seeds. As the pods ripen, the plant shrivels up, and usually dies away, leaving only the ripe seeds to represent its kind through the winter. But sometimes, in damp and luxuriant autumns, the stem struggles through the winter to a second season, and flowers again in the succeeding summer. We express this fact as a rule by saying that the vetch is usually an annual, but occasionally a biennial.

With most annuals, such as wheat or sunflower, the whole strength of the plant is used up in the production of seed; and as soon as the seed is set, the plant dies immediately. Where annuals have the sexes on separate plants, however, the male plants die as soon । as they have shed their pollen, their task being thus complete; while the females live on 2 till their seed has ripened.

Common coltsfoot is another well-known plant whose life-history shows some points of great interest. It grows in the first instance from a feathery fruit, one-seeded and seed-like, which is carried by the wind, often from a great 
distance. These flying fruits alight at last upon some patch of bare or newly-turned soil, such as the bank of a stream where there has been lately a landslip, or the side of a railway cutting. These bare situations alone suit the habits of the baby coltsfoot; if the fruit happens to settle on a light soil, already thickly covered with luxuriant vegetation, it cannot compete against the established possessors. But the winged fruits, being dispersed on every side, enable many young plants to start well in life on the poor stiff clays which best suit the constitution of this riverside weed. The seedling grows fast in such circumstances, and soon produces large angular leaves, very broad and thick, which in the adult plant have often a diameter of five or six inches. They are green above, where they catch the sunlight and devour carbonic acid; but underneath they are covered with a thick white wool, which is there for a curious and interesting purpose. The damp clay valleys and river glens where coltsfoot lives by choice are filled till noon every day with mist and vapour; and heavy dew is deposited there every night through the summer season. Now, if this dew were allowed to clog the evaporation pores or stomata on the leaves of coltsfoot, the plant would not be able to raise water or proceed with its work except for perhaps a few hours daily. To prevent this misifortune, the under side of the leaves is thickly covered with a white coat of wool, on which no. dew forms, and off which water rolls in little: round drops, as you have seen it roll off a serge: 
table-cloth. By this ingenious device the coltsfoot manages to keep its evaporation pores dry and open, in spite of its damp and moistureladen situation. One may say, indeed, that every point in the structure of every plant has thus some special purpose; indeed, one large object of the study of plants is to enable us to understand and explain such hidden purposes in the economy of nature.

During its early life, once more, the young plant of coltsfoot is constantly engaged, like the whitlow-grass and the agave, in laying by material for its future flowering season. But it does not lay by, as they do, in its expanded leaves or other portions of its body visible above $\mathrm{g}$ round; instead of that, it puts forth a creeping underground stem or root-stock, which pushes its way sideways through the tough clay soil, often for several feet, and sends up at intervals groups of large roundish leaves, such as I have already described, to work above ground for it. You might easily take each such group for a separate plant, unless you dug up the root-stock and saw that they were really the scattered foliage of one subterranean stem, which grows horizontally instead of upward. During the summer the coltsfoot lays by in this buried root-stock quantities of rich material for next year's leaves and for its future flowers. In winter the leaves die down, and you see not a trace of the plant above ground. But in very early spring, as soon as the soil thaws, certain special buds begin to sprout on the underground stem, and send up tall naked scapes or flower- 
stems, usually growing in tufts together, and each crowned by a single large fluffy yellow flower-head. These stems are covered below by short purplish scales; and their purple colouring matter enables them to catch and utilise to the utmost the scanty sunshine that falls upon the plant in chilly March weather: For this particular colouring matter has the special property of converting the energy in rays of light into heat for warming the plant. The scape is also wrapped up in a sort of cottony wool, which helps to keep it warm ; and the unopened flower-head turns downward at first for still further safety against chill or injury. These various devices enable the coltsfoot to blossom earlier in the season than almost any other insect-fertilised flower, and so to monopolise the time and attention of the first flower-haunting March insects.

Coltsfoot is a composite by family; so its flowers are collected together into a head, after the ancestral fashion, and enclosed by an involucre which closely resembles a calyx. But the type of flower-head differs somewhat from that in any of the composite plants I have hitherto described for you, because its outer florets are not flat and ray-shaped, but strap-like or needle-shaped. The inner florets, however, are bell-shaped, and much like those of the common daisy. The naked scapes, each resembling to the eye a shoot of asparagus, and each crowned by a single fluffy yellow flower-head, are familiar objects on banks or railway cuttings in the first days of spring; I have known them 
open as early as the 12th of January, in sunny weather. But they grow entirely without leaves, and are produced at the expense of the material laid up in the underground stem by last season's foliage. They blossom, are fertilised, set their seeds, turn into heads of white feathery down, and produce ripe fruits which blow away and get dispersed, all before the leaves begin to appear at all above the solr. Thus you never can see the foliage and flowers together; it is only by close observation that you can discover for yourself the connection between the heads of yellow flowers which come up in early spring, and the groups of large angular woolly leaves which follow them in the same spots much later in the season.

The life-history of the coltsfoot introduces us also to another conception which we must clearly understand if we wish to know anything about many plant biographies. I have said already that parts of one and the same coltsfoot plant might easily be mistaken for separate individuals; and, indeed, if the stem gets severed, particular groups of leaves may live on as such, in two or more distinct portions. This leads us on to the consideration of a great group of plants like the common wild strawberry, in which a regular system of subdivision exists, and in which new plants are habitually produced by offsets or runners, as well as by seedlings. Such a method of increase is to some extent a survival into higher types of the primitive mode of reproduction by subdivision.

A strawberry plant grows in the first mstance 
from a seed, which was embedded in a carpel or seed-like fruitlet on the ripe red swollen receptacle which we commonly call a strawberry. This seed germinates, and produces a seedling, which puts forth small green leaves, divided into three leaflets each at the end of a long and slender leaf-stalk. As it grows older, however, besides its own tufted perennial stem or stock, it sends out on every side long branches or runners, which are in fact horizontal or creeping stems in search of new rooting places. These stems run along the ground for sorne inches, and then root afresh. At each such rootingpoint, the plant sends up a fresh bunch of leares, which gradually grows into a distinct colony, by the decay of the intermediate portion or runner. Again, this new plant itself in turn sends forth runners in every direction all round it; so that often the ground is covered for yards by a network of strawberry plants, all ultimately derived from a single seedling. Theoretically, we must regard them all as severed parts of one and the same plant, accidentally divided from the main stem, since only the union of two different parents can give us a totally distinct individual. But practically they are separate and independent plants, competing with one another thenceforth for food, soil, and sunshine.

A great many plants are habitually propagated in such indirect ways, as well as by the normal method of flowering and seeding. Indeed, it is difficult to separate the two processes of mere growth, as shown in budding or branching, and reproduction by subdivision, as shown in the 
springing of saplings from the roots or stem, the production of runners, the division of bulbs, and the rooting of suckers. I will therefore give here a few select instances of these frequent incidents in the life-history of various species.

The tiger-lilies of our gardens produce little dark buds, often called bulbils, in the angles of their foliage leaves. These buds at last fall off and root themselves in the soil, forming to all appearance independent plants. Much the same thing happens with many English wildflowers. For example, in the plant known as coral-root (allied to the cuckoo-flower) little budbulbs are formed in the angles of the leaves, which drop on the damp soil of the woods where the plant grows, and there develop into new individuals. In this last-named case the plant seldom sets its fruit at all, the reproduction being almost entirely carried on by means of the bulbils. Such instances suggest to us the pregnant idea that a seed is nothing more than a bud or young shoot, to whose making two separate parents have contributed. There is, in short, no essential difference between the two processes of growth and reproduction.

Again, in the common lesser celandine the root-stock emits a large number of tiny pill-like tubers, which grow and lay by rich material underground (derived from the leaves) during the summer season. In the succeeding spring, however, each of these tubers develops again into a separate plant, in a way with which the familiar instance of the potato has made us familiar. In the crocus, once more, and many 
other bulbous plants, several small bulbs are produced each year by the side of the large one, and these smaller bulbs are of course, strictly speaking, mere branches of the original crocus-stem. But they grow separate at last, by the decay or death of the central bulb, and themselves in turn produce at their side yet other bulbs, which become the centres of still newer families. We may parallel these cases with those of trees whose boughs bend down and root in the ground so as to become in time independent individuals; or with runners like those of the strawberry and the creeping buttercup, which root and grow afresh into separate plantlets.

Sometimes still more curious things happen to plants in the way of reproduction by subdivision. There is an English pondweed, for example, which grows in shallow pools liable to be frozen over in severe winters. As cold weather approaches, the top of the growing shoots in this particular pondweed break off of themselves, much as leaves do at falling time. But they break off with all their living material still preserved within them undisturbed; and they then sink and retire to the unfrozen depths of the pond, where they remain unhurt till spring comes round again. This is just what the frogs and newts and other animal inhabitants of the pond do at the same time, to prevent getting frozen. Next year the severed tops send out roots in the soft mud of the bottom, and grow up afresh into new green pondweeds.

It is therefore impossible to make any broad line of distinction in this way between what may 
beconsidered as modes of individual persistence in the self-same plants, and what may be regarded as modes of reproduction by subdivision. Some plants, like couch-grass and elm, are almost always surrounded by young shoots which may ultimately become to all intents and purposes independent individuals; while others, like corn-poppy or Scotch fir, never produce any offsets or suckers. In the meadow orchids each plant produces every summer a second tuber by the side of the old one; and from the top of this tuber the next year's stem arises in due time with its spike of flowers. Here we may fairly regard the tuber as a simple means of persistence in the plant itself; there is nothing we could possibly call reproduction. But in many lilies the older bulbs produce numerous small branch bulbs at their sides; and these younger bulbs may become practically independent, each of them sending up in the course of time its own stem and its own spike of flowers.

Even when the main trunk of a tree is dead, through sheer old age, it often happens, as in the elm and birch, that the roots send up fresh young shoots, which may grow again, and prolong the life of the plant indefinitely. In stone-crops and other succulent herbs, which grow in very dry and desert situations, the merest fragment of a stem, dropped on moist soil, will send out roots and grow afresh into a new individual. Cactuses and other desert plants have often to resist immense drought, and therefore possess extraordinary 
vitality in this way. They will grow again from the merest cut end under favourable conditions.

These few short hints as to the life-history of various plants in different circumstances will serve to show you how vast is their variety. Every plant, indeed, has endless ways and tricks of its own; and every point in its structure, however unobtrusive, has some purpose to serve in its domestic economy. Thus the ivy-leaved toad-flax, which grows on dry walls, has straight flower-stalks, which become bent or curved when the flowering is over. Why is this? Well, the plant has acquired the habit of bending round its flower-stalk after the blossoming season, because it cannot sow its seeds on the bare stone, so it hunts about diligently for a crevice among the mortar into which it proceeds to insert its capsule, so that the seedlings may start fair in a fit and proper place for their due germination. So, too, the subterranean clover, growing on close-cropped hillocks much nibbled over by sheep, where its pods of rich seeds would be certainly devoured if exposed on a long stalk like that of other clovers, has developed a few abortive corkscrewlike blossoms in the centre of its flower-head, by whose aid the whole group of pods burrows its wayd spirally into the soil beneath; so that the plant thus at once escapes its herbivorous enemies, and sows its own seed for itself automatically. It would be impossible in our space to do more than thus briefly indicate by two or three examples the immense number and variety of these special adaptations. Every plant has 
hundreds of them. There is not a tiny hair on the surface of a flower, not a spot or a streak in the blade of a leaf, not a pit or depression on the skin of a seed, that has not its function. And close study of nature rewards us most of all for our trouble in this, that it reveals to us every day some delightful surprise, forces on our attention some hitherto unsuspected but romantic relation of structure and purpose.

I will mention but one more case as a typical example. There exists as a rule a definite relation between the shape and arrangement of the leaves in plants, and the shape and arrangement of the roots and rootlets, with regard to water-supply. Each plant, in point of fact, is like the roof of a house as respects the amount of rain which it catches and drains away; and it is important for each that it should utilise to the utmost its own particular supply of drainage or rain water. Hence you will find that some plants, like the dock, have large channeled leaves, with a leaf-stalk traversed by a depression like a drainage runnel: plants of this type carry off all the water that falls upon them towards the centre, inwards. But such plants have always also a descending tap-root, which instantly catches and drinks up the water poured by the drainage system of the leaves towards the middle of the plant. In other plants, again, however, with round leaf-stalks and outward pointed leaves, the water that falls upon the foliage drains outward towards the circumference; and in all such plants the roots, instead of descending straight down, are spread- 
ing and diffused, so as to go outward towards the point where the water drips on them. Moreover, in this latter case it is found, on digging up the plant carefully, that the absorbent tips of the rootlets are clustered thickest about the exact spots where the leaves habitually drop the water down upon them. Every plant is thus to some extent a catchmentbasin which utilises its own rainfall : it collects rain for itself, and conducts it by a definite system of pipes and channels to the precise spots in the soil where it can best be sucked up for the plant's own purposes.

On the other hand, while every part of every plant is thus minutely arranged for the common advantage, every species of plant and animal fights only for its own hand against all comers. Nature is therefore one vast theatre of plot and counterplot. The parasites prey on the vegetative kinds ; the vegetative kinds respond in turn by developing checks to counteract the parasites. The squirrels produce sharper and ever sharper teeth to gnaw through the nutshells; the nut. trees retaliate by producing for their part thicker and ever thicker shells to baffle the squirrels. And this play and by-play goes on unceasingly from generation to generation ; because only the cleverest squirrels can ever get enough nuts to live upon; and only the hardest-shelled and bitterest-rinded nuts can escape the continual assaults of the squirrels. In order, therefore, really to understand the structure and life of any one species, we should have to know in the minutest detail all about its native conditions, 
its soil, its surroundings, its allies, its hired friends, its blackmailing foes, its exterminating enemies. Such exhaustive knowledge of the tiniest weed is clearly impossible; but, even the little episodes we can pick out piecemeal are full of romance, of charm, and of novelty.

\section{CHAPTER XIV.}

THE PAST HISTORY OF PLANTS.

I PROMISED some time since to return in due season to the question why plants, as a rule, exhibit distinct kinds or species, instead of merging gradually one into another by imperceptible degrees. This problem is generally known as the problem of the origin of species. You might perhaps expect (since plants have grown and developed, as we have seen, one out of the other) that they would consist at present of an unbroken series, each melting into each, from the highest to the lowest. This, however, is not really the case; they form on the contrary groups of distinct kinds : and the reason is, that natural selection acts on the whole in the opposite direction. It tends to make plants group themselves into definite bodies or species, all alike within the body, and well marked off from all others outside it.

Here is the way this arrangement comes about. As situations and circumstances vary, a form is at last arrived at in each situation which approximately fits the particular circum- 
stances. This form may perhaps vary again in other situations, and give rise to individuals better adapted to the second set of circumstances. But just in proportion as such individuals surpass in adaptation one another will they live down the less adapted. Hence, the intermediate forms will tend to perish, and the world to be filled in the end with groups of plants, each distinct from others, and each relatively fixed and similar within its own limits.

At all times, and in all places, this process of variation and adaptation is continually going on; new kinds are being formed, and intermediates are dying out between them. For the intermediates are necessarily less adapted than the older form to the old conditions, and than the newer form to the new ones.

Moreover, when any great point of advantage is once gained by a kind, it tends to go on and be preserved, while variations in other parts continue uninterrupted. Thus, the first composite plant (to take a concrete example) gained by the massing of its flowers into a compact head: and it then became a starting-point for fresh developments, each of which maintained the massed flower-head, with its ring of united stamens, while adding to the type some fresh point of its own, which specially adapted it to a particular situation. So, too, the first peaflower gained by the peculiar form of its oddly-shaped corolla, and therefore became the ancestor of many separate kinds, each of which retains the general pea-like type of blossom, while differing 
in other respects as widely from its neighbours as gorse and clover, peas and laburnum, broom and vetches, scarlet-runners and lupines. A group of kinds, so derived from a common progenitor, but preserving throughout one or more of that progenitor's peculiarities while differing much in other respects among themselves, is called a family. Thus we speak of the family of the peaflowers, the family of the roses, the family of the lilies, the family of the orchids. Each family may include several minor groups, known as genera (in the singular, a genus); and each such genus may further include several distinct kinds or species.

For example, all the peaflower family are distinguished by their possession of a peculiar blossom whose corolla consists of a standard, a keel, and two wings, like sweet-pea or broom. This family contains several genera, one of which is that of the clovers, including certain peaflowers which have learned to mass their blossoms into a roundish head, and have trefoil leaves, and very few seeds in the short seed-pod. The clovers, again, are subdivided into species or kinds, such as purple clover, Dutch clover, hop clover, and hare's foot clover ; in Britain alone, we have twenty-one such distinct species or kinds of clover. You will see at once that this method of grouping by ancestral forms enables us largely to reconstruct the history of each particular plant or animal.

Why don't these kinds cross freely with one another, and so produce an endless set of puzzling hybrids? Well, they do occasionally; 
and such mongrel forms often show us every possible variation between the two parents. But this can only happen when the parent stocks are very close to one another; and even then, the hybrids tend to die out rapidly. Why? Because each of the parents is better adapted to a particular situation; the hybrid usually falls between two stools, and gets killed down accordingly. It cannot stand the competition of the true species. New kinds, however, may sometimes take their rise from chance hybrids, which happen to possess some combination of advantages.

Thus plants in the mass, as we see them around us at the present day, are divisible into several well-marked groups, some of which are now dominant or leading orders, while others are hardly more than mere belated stragglers or loitering representatives of types once common, but now outstripped in the race by younger competitors. I cannot close without briefly describing to you the main divisions of such orders or groups, as now accepted by modern botanists.

The widest distinction of all between plants is that which marks off the simpler and earlier forms, which are wholly composed of cells, from the higher and stem-forming types, which are also provided with systems of vessels and woody tissue. The first class is known as Celuular Plants; the second class as Vascular Plants. These are the greatest and most general divisions. 
The Cellular Plants comprise many sorts, from the simple one-celled types which float freely in water, up to the relatively high and complex seaweeds, which produce large fleshy fronds, and often display a considerable division of labour between their various parts and organs. Still, as most of them live in water, either fresh or salt, and wave freely about in the liquid that surrounds them, they have no need of an elaborate system of conducting vessels, because every. part can drink in water and dissolved food-salts from the neighbouring pond, sea, or river. Still less have they any necessity for a woody stem, which would only be a disadvantage to them in stormy weather. Hence most of the cellular plants (with certain exceptions to be noted hereafter) are water-weeds; while most of the vascular plants (with other exceptions to be similarly treated) are land plants. In particular trees and shrubs, the highest forms of plant life, are invariably terrestrial.

Various successive stages of these cellular plants may be briefly described in rough outline. First of all we get the simple one-celled plant, the lowest type of all, consisting of a single mass of protoplasm, generally with chlorophyll, surrounded by a cell-wall. Next above these come the hair-like water-weeds, which consist of rows of such simple cells, placed end to end in single file, one in front of another, like pearls in a necklace. These kinds are many-celled, but each cell is here in contact with two others only, one below, and one above it. Thirdly, we get the flat leaf-like water- 
weeds, which have thin green fronds, composed of a single broad sheet of cells, not a hair-like row; each cell has here many cells around it, but all lie in one plane; the sheet is only one cell thick; it does not spread abroad in more than two directions. Lastly, we get the ordinary thick-fronded seaweed, in which sheets of cells, many layers deep, grow in divided masses on rope-like bases, and closely resemble to the eye true vascular plants with stems, leaves, and branches.

Most of these cellular plants, when they possess green chlorophyll, are known as alga.

There are several low forms of plants, however, which do not possess chlorophyll, but live at the expense of other plants, exactly as animals do. These are generally known in the lump as fungi. Many of them are terrestrial. The distinction, however, is not a genealogical one. Cellular plants of various grades have often taken, time after time, to this lower parasitic or carrion-eating habit; and though they therefore resemble one another externally in their absence of green colour, in their usual whiteness and fleshiness, and in their mushroom-like substance, they do not really form a natural class; their resemblance is due to their habits only. In short, we call any cellular plant a fungus, if instead of supporting itself by green cells, it has adopted the trick of living on organised material already laid up by other plants or animals.

Among these fungus-like plants, again, some of the simplest and lowest are the celebrated 
bacteria, which are one-celled organisms, living in stagnant or putrid fluids, and also in the bodies and blood of diseased animals. They answer among fungi to the one-celled alga. Many of them cause infectious diseases; such are the bacilli of diphtheria, typhus, cholera, consumption, small-pox, and influenza. Surrounded by a suitable nutritious fluid, these tiny parasitic plants increase with extraordinary and fatal rapidity. Though they are really onecelled, and reproduce by cell-division, they often hang together in rude lumps or clusters which simulate to some extent the many-celled bodies. In this book, however, where we have concentrated our attention mainly on the true or green plants, I have not thought it well to dwell at any length on the habits or structure of these animal-like organisms.

Another well-known group of small funguslike plants is that which contains the yeastfungus, a one-celled plant, which reproduces by budding.

The higher fungi are many-celled, and often possess well-marked organs for different purposes. They answer rather to the seaweeds and higher alga. Familiar examples are the common moulds, which form on jam, dead fruit, and other decaying material. Some of them, like the smut of wheat and oats, are parasitic on growing plants, and most dangerous enemies to green vegetation. The highest fungi are the groups which include the mushroom, the puff-ball, and all those other large and curiously-shaped forms commonly lumped to- 
gether in popular language under the name of toadstools. Their anatomy and physiology is extremely complex.

To recapitulate; Cellular Plants belong to two main types; those which contain chlorophyll, and live like plants by eating and assimilating carbon under the influence of sunshine; these are generally grouped together in a rough class as ALGA : and those which contain no chlorophyll, but live, like animals, by using up or destroying the carbon-compounds already stored up by green plants; these are generally grouped together in a rough class as FUNGI.

The lichens form a curious mixed group, whose strange habits cannot here be described at any adequate length; they are not so much separate plants as united colonies of algæ and fungi, in which the green alga does the main work of collecting food, while the parasitic fungus, increasing with it at the same rate, eats it up in part, while contributing in turn in various ways to the general good of the compound community. This is therefore hardly a case of pure destructive parasitism, but rather one of a co-operative society banded together on purpose for mutual advantage.

The mosses and liverworts, once more, show us an intermediate stage between the true cellular and the true vascular plants. They have a rudimentary stem, and beginnings of vessels. $\subset$ They have also leaves, or " organs equivalent to them; and they display the first approach to something like flowers. 
The Vascular Plants, again, which are characterised by the possession of special vessels for the conveyance of sap and organised material, and by the presence of more or less woody fibres, are divisible in to two main groups - the flowerless, and the flowering.

The flowerless group of Vascular Plants are mainly represented by the ferns and horsetails. These were at one time the leading vegetation of the entire world, far outnumbering in kinds all the rest put together. But they have now been lived down by the flowering plants, which at present compose the main mass of the plant aristocracy.

The flowering plants, once more, fall into two main groups; the small but widespread group of naked-seeded plants, including the cycads, pines, firs, cypresses, and yews; and the very large group of fruit-bearing plants, including almost all the kinds of herb, shrub, bush, or tree familiarly known to you, as well as almost all those various plants with which we have busied ourselves in this little volume. You will thus see that the vast majority of species in the vegetable kingdom belong to small and relatively inconspicuous orders. Indeed, for the most part, we habitually disregard the cellular plants, thinking only of the vascular; while among the vascular themselves, again, we disregard the flowerless, thinking only of the flowering; and among the flowering kinds, we concentrate our attention as a rule on the fruit-producing group (in the botanical sense of the word) and neglect the naked-seeded. In short, we usually confine 
our attention to the highest division of the highest group of the highest half of the vegetable kingdom. The rest are for us mere inconspicuous mosses, moulds, or seaweeds.

The fruit-producing group of flowering plants are finally divided into the dicotyledons and the monocotyledons, whose chief differences I have already pointed out to you. And to complete our picture of this infinite hierarchy, the dicotyledons, once more, are divided into various families, such as the buttercups, the roses, the crucifers, the composites, the labiates, the umbellates, the saxifrages, and the catkinbearers. The buttercup family, in particular (to select a single group), is further divisible into genera, such as buttercup, marsh marigold, larkspur, anemone, clematis, and aconite; while the buttercup genus (to take one only among these) comprises in turn a vast number of species, such as the water-crowfoot, the ivyleaved crowfoot, the meadow buttercup, the bulbous buttercup, the lesser celandine, the goldilocks, and so on for pages. Similarly, the monocotyledons are divided into various families, such as the orchids, lilies, grasses, and sedges: the families are divided into many genera; and each genus into several species. The infinite variety of circumstances is such that each type goes on varying and varying for ever in order to fit itself for the endless situations it is called upon to fill, and the endless diversity in the accidents of climate or soil or position that it may chance to come across. Thus we have in England-more than a hundred different kinds of 
grasses, each specially adapted for some one particular situation.

Only the closest individual study can give any adequate idea of this immense diversity of plants in nature.

The geological history of the world shows us that the development of plants has been slow and progressive. In the earliest rocks (of which an account is given in another volume of this series), we get few traces of any plants but the lowest: so that at that time it is probable none but seaweeds and their like existed-cellular plants which contain hardly any parts solid enough for preservation. By the age when the coal was laid down, however, ferns, horsetails, and many gigantic extinct plants with solid stems had begun to exist ; but few or no flowering plants, except conifers, had yet been developed. Later still came the true flowering plants, with covered seeds, at first in simple and antiquated forms, but becoming more complex as birds, mammals, and flying insects of the flower-haunting types were developed side by side with them to visit and fertilise them or to disperse their seeds. Succulent fruits, of course, could only arise when tribes of fruit-eaters had been evolved to assist them; while such special bee-fertilised types as the sage group, and such complex forms as the orchids and composites, requiring the aid of highly-developed insects, are of extremely recent evolution. Plant and animal life have continually reacted upon one 1 another. 
Whoever has been interested in the study of plants by this little book may be glad to know what is the best way of continuing his acquaintance with the subject in future. Nothing gives one such a grasp of the facts of botany and of life in general as careful study of the plants which grow in one's own country. Students in the British Isles should therefore buy a copy of Bentham and Hooker's British Flora, and seek by the aid of the key at its beginning to identify for themselves every flowering plant they come across in our woods and meadows. American students should get in like manner Asa Gray's Manual of Botany. In the course of identifying all the plants you find, you will begin to understand the nature of plant life and the course of plant evolution in a way that is quite impossible through any mere book-reading. Buy also a simple platyscopic lens, and a sharp penknife to assist you in dissection. Armed with these simple but useful tools, you will soon malke rapid and solid progress in the knowledge of nature.

For further and more detailed information on the laws of plant life, you cannot do better than consult Kerner and Oliver's Natural History of Plants, which sets forth in full an immense number of interesting and curious facts, in language comprehensible to any attentive and careful student. 

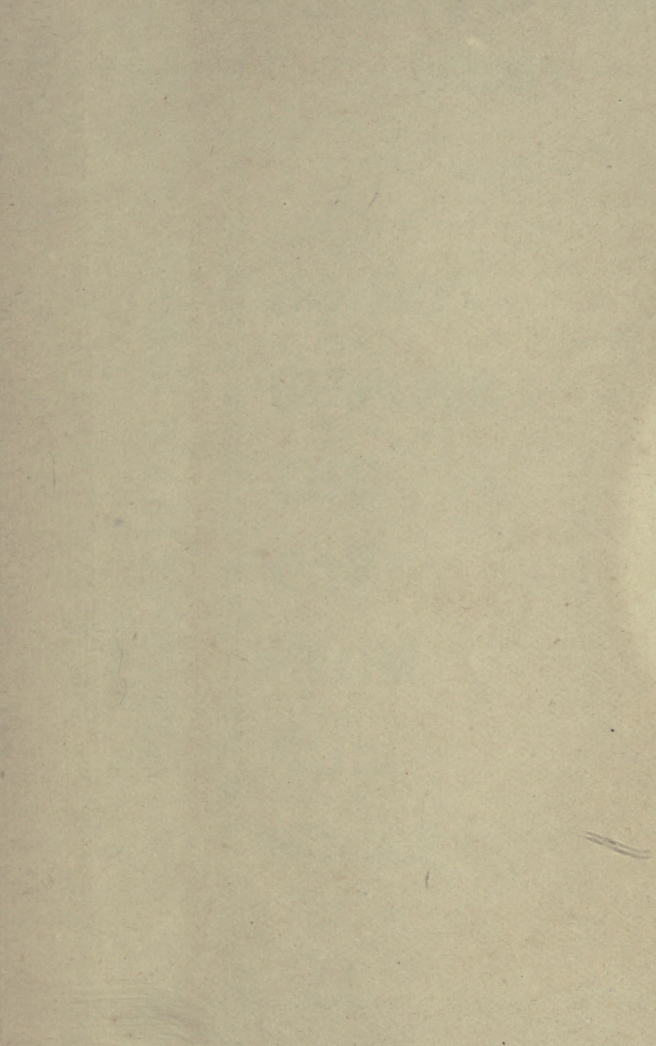



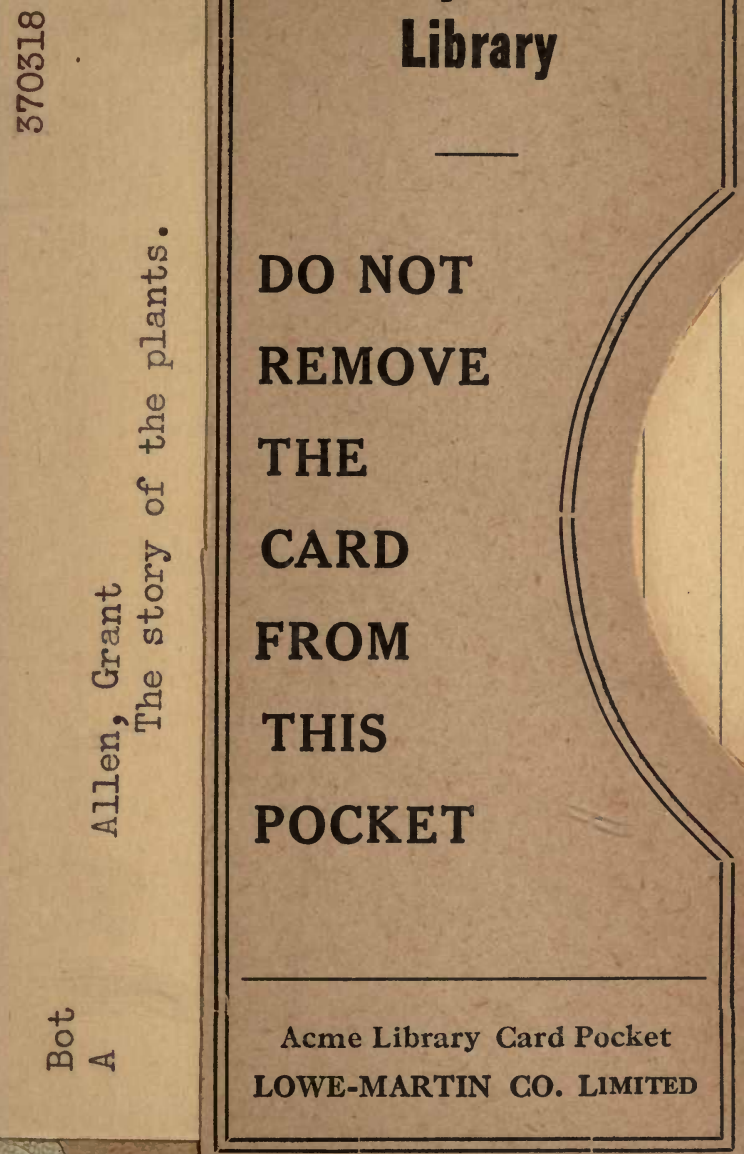




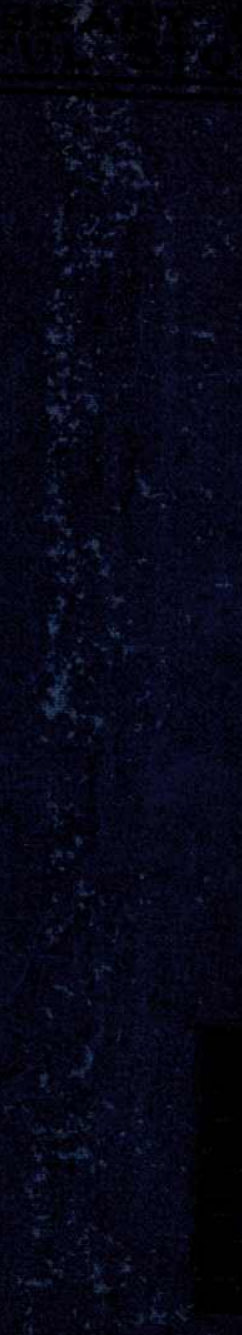

